UNIVERSIDADE DE SÃO PAULO

ESCOLA DE ENFERMAGEM

KARINA FERNANDES TREVISAN

FORÇA MUSCULAR PERINEAL E INCONTINÊNCIA

URINÁRIA E ANAL NA GESTAÇÃO:

ESTUDO DE COORTE

SÃO PAULO

2015 



\section{FORÇA MUSCULAR PERINEAL E INCONTINÊNCIA URINÁRIA E ANAL NA GESTAÇÃO: ESTUDO DE COORTE}

Tese apresentada ao Programa de PósGraduação em Enfermagem da Escola de Enfermagem da Universidade de São Paulo para obtenção de título de Doutora em Ciências

Área de Concentração: Cuidado em Saúde

\section{Orientadora:}

Prof $^{a}$. Dr ${ }^{\mathrm{a}}$. Maria Luiza Gonzalez Riesco

\section{São Paulo}


AUTORIZO A REPRODUÇÃO E DIVULGAÇÃO TOTAL OU PARCIAL DESTE TRABALHO, POR QUALQUER MEIO CONVENCIONAL OU ELETRÔNICO, PARA FINS DE ESTUDO E PESQUISA, DESDE QUE CITADA A FONTE.

VERSÃO CORRIGIDA, SENDO QUE A VERSÃO ORIGINAL SE ENCONTRA DISPONÍVEL NA BIBLIOTECA "WANDA AGUIAR HORTA" DA ESCOLA DE ENFERNAGEM DA UNIVERSIDADE DE SÃO PAULO - EEUSP

Assinatura:

Data:

\section{Catalogação na Publicação (CIP)}

\section{Biblioteca "Wanda de Aguiar Horta"}

Escola de Enfermagem da Universidade de São Paulo

Trevisan, Karina Fernandes

Força muscular perineal e incontinência urinária e anal na gestação: estudo de coorte / Karina Fernandes Trevisan. São Paulo, 2015.

$126 \mathrm{p}$.

Tese (Doutorado) - Escola de Enfermagem da Universidade de São Paulo.

Orientadora: Prof.a Dr.a Maria Luiza Gonzalez Riesco

Área de concentração: Cuidado em Saúde

1.Gravidez. 2.Força muscular. 3. Incontinência urinária. 4. Períneo. 5. Enfermagem obstétrica. I. Título. 
Nome: Karina Fernandes Trevisan

Título: Força muscular perineal e incontinência urinária e anal na gestação: estudo de coorte

Tese apresentada ao Programa de Pós-Graduação da Escola de Enfermagem da Universidade de São Paulo para obtenção do título de Doutora em Ciências.

Aprovado em:

Banca Examinadora

Prof. Dr. Instituição:

Julgamento: Assinatura:

Prof. Dr. Instituição:

Julgamento: Assinatura:

Prof. Dr. Instituição:

Julgamento: Assinatura:

Prof. Dr. Instituição:

Julgamento: Assinatura:

Prof. Dr. Instituição:

Julgamento: Assinatura: 
A Deus,

Agradeço pela minha vida.

Agradeço a oportunidade de estar neste mundo, aprendendo e buscando aperfeiçoamento.

Obrigada pelas portas que se abrem em meus caminhos, pela força para conseguir atravessa-las e pelas pessoas que encontro e auxiliam-me nesta caminhada. 


\section{Agradecimesntos Especiais}

A meu companheiro amado Fábio Trevisan, pela paciência, amor e carinho, por me ajudar a concluir mais esta etapa de minha vida profissional.

A meu filho querido e amado Gabriel, em seus 5 anos de idade, conseguiu entender minhas ausências para a realização deste estudo.

A meu pai Ídio, pelo apoio e dedicação incondicional em me auxiliar em tudo que preciso e minha mãe Mônica que sempre com carinho e dedicação apoia-me, escuta e aconselha... com paciência e amor...

A meus irmãos Fábiola e Rodrigo, que fazem parte de minha vida e de minha sustentação. E a toda família que é a base de equilíbrio da vida.

A toda equipe espiritual, que sustenta e fortalece minha vida e meus caminhos.

À querida amiga e parceira Nathalie Leister, com quem dividi esta pesquisa e com quem criei muita afinidade e carinho. Agradecimento profundo pelo auxilio em todas as etapas da pesquisa e também por dividir comigo a ComMadre.

À querida Professora Doutora Maria Luíza que, com carinho, dedicação, paciência e entendimento, foi responsável pela construção desta pesquisa, realizada com prazer e satisfação. 


\section{Agradecimentos}

$\mathcal{A}$ todas as gestantes que aceitaram fazer parte desta pesquisa;

A todos profissionais do Serviço de Pré Natal da Next Seisa;

A diretora executiva da Next Seisa Lídia S. S. A. Bueno de Miranda;

A gerente de enfermagem da Sext Seisa Ângela Simeone Godoy Levatte que concordou e facilitou a realização deste estudo;

A Dra Miriam Raquel Diniz Zanetti por todo apoio e dedicação na estruturação da pesquisa,

À enfermeira Aldrin Veiga Zilet que colaborou com a coleta de dados da pesquisa,

As auxiliares de pesquisa Camila da Silva Cruz, Carina Pinheiro Barreto, Cristiane Pereira de Barros, Gisele de Sousa Santana, Karina Cristina da Silva, Leonor Ramos Pinheiro, Fernanda da Silva Santos, Priscila Tavares de Oliveira;

Ao Bernardo dos Santos, responsável pela análise estatística;

$\mathcal{A}$ todas as professoras do Departamento de Enfermagem Obstétrica e Psiquiatrica da Escola de Enfermagem da Vniversidade de São Paulo;

À professora Ivone Boreli que foi responsável pela cuidadosa revisão de português.

A Fundação de Amparo a Pesquisa do Estado de São Paulo (FAPESP) e ao Conselho Nacional de desenvolvimento Científico e Tecnológico (CNNPq), pelo financiamento desta pesquisa; $e$

$\mathcal{A}$ todas as pessoas que, de uma forma ou outra, contribuíram para a concretização deste estudo, agradeço de coração. 
Trevisan KF. Força muscular perineal e incontinência urinária e anal na gestação: estudo de coorte [tese]. São Paulo: Escola de Enfermagem, Universidade de São Paulo; 2015.

\section{RESUMO}

Introdução: A gestação é considerada um fator que favorece o aparecimento de incontinência urinária (IU) e anal (IA), pois pode levar ao enfraquecimento da musculatura do assoalho pélvico. Objetivos: 1. Analisar a força dos músculos do assoalho pélvico (FMAP) de mulheres durante a gestação; 2. Analisar a IU e IA em mulheres durante a gestação; 3. Identificar a interferência da IU na vida da gestante. Método: Coorte prospectiva, realizada com gestantes em um serviço do setor suplementar de saúde, em Guarulhos, SP. Foram incluídas as 500 mulheres que iniciaram o acompanhamento pré-natal e atenderam aos critérios de inclusão, no período ininterrupto entre 21 de novembro de 2012 e 17 de setembro de 2013. A idade gestacional (IG) foi considerada como exposição; a FMAP, IU, IA e interferência da IU na vida da gestante foram consideradas como desfechos. As gestantes foram seguidas em três etapas: Etapa 1, com IG abaixo de 13 semanas; Etapa 2, com IG de 20 a 27 semanas; Etapa 3 , com IG de 31 a 38 semanas. A FMAP foi avaliada por meio da perineometria (Peritron ${ }^{\mathrm{TM}}$ ) e a IU e IA foram avaliadas por meio de entrevista. Utilizou-se, também, o International Consultation on Incontinence Questionnaire-Short Form (ICIQ-SF). Foi realizada análise descritiva, inferencial e multivariada. O projeto foi aprovado pelo Comitê de Ética em Pesquisa da Escola de Enfermagem da USP. Resultados: Foram avaliadas 500, 226 e 187 gestantes, nas etapas 1, 2 e 3 da coorte, respectivamente. As perdas de seguimento foram analisadas, indicando que estas foram aleatórias e não influenciaram os desfechos. A FMAP não variou significativamente ao longo da gestação, com média de 30,5 (d.p.=17,3), 29,2 (d.p.=14,9) e 28,7 (d.p.=15,5) $\mathrm{cmH}_{2} \mathrm{O}$, nas etapas 1, 2 e 3, respectivamente. Considerando o ponto de corte de $30 \mathrm{cmH}_{2} \mathrm{O}$, a maioria das gestantes apresentou FMAP $<30 \mathrm{cmH}_{2} \mathrm{O}$, em todas as etapas $(\mathrm{p}=0,055)$. A incidência de IU na gestação foi $18,6 \%$ e a prevalência foi $19,0 \%, 42,5 \%$ e $35,3 \%$, no primeiro, segundo e terceiro trimestres, respectivamente $(\mathrm{p}<0,001)$. A incidência de IA foi 5,4\% e a prevalência variou de $7,5 \%$ a $11,5 \%$. Ao longo da gestação, média do escore do ICIQ-SF variou de 7,8 (d.p.=4,8) a 8,3 (d.p.=4,0). Na análise multivariada, as variáveis que, em conjunto, explicam a variação da FMAP na gestação foram: IG (por semana: $r=-0,09$; 95\% IC -0,16 a -0,02), gestação anterior (por gestação: $r=-1,73$; 95\% IC $-3,20$ a -0,25), IU prévia $(\mathrm{r}=-3,03$; 95\% IC $-5,96$ a $-0,11)$ e realização de exercícios perineais $(r=2,37$; 95\% IC 0,48-4,26). Para IU, as variáveis foram: IG (segundo trimestre: OR=5,26; 95\%IC $3,44-8,02$; terceiro trimestre: $\mathrm{OR}=3,34 ; 95 \% \mathrm{IC} 2,09-5,31)$, IU prévia $(\mathrm{OR}=5,62 ; 95 \% \mathrm{IC}$ 3,93-8,04), FMAP $\left(\geq 30 \mathrm{cmH}_{2} \mathrm{O} ; \mathrm{OR}=0,58 ; 95 \% \mathrm{IC} 0,41-0,82\right)$, realização de exercícios perineais $(\mathrm{OR}=0,53 ; 95 \% \mathrm{IC} 0,31-0,89)$ e idade materna (por ano: $\mathrm{OR}=1,05$; $95 \% \mathrm{IC} 1,02-$ 1,08). Apenas IA prévia (OR=11,13; 95\% IC 6,70-18,50) manteve associação com IA na gestação. Conclusão: A realização de exercícios perineais pelo menos duas vezes por semana aumenta a FMAP e reduz a ocorrência de IU na gestação. A FMAP $\geq 30 \mathrm{cmH}_{2} \mathrm{O}$ também é um fator protetor contra a IU na gestação. A chance de IU é maior no segundo trimestre da gestação e em mulheres com antecedentes de IU. O impacto da IU na vida da gestante pode ser considerado moderado.

PALAVRAS-CHAVE: Gravidez. Força Muscular. Incontinência Urinária. Períneo. Enfermagem Obstétrica. 
Trevisan KF. Pelvic floor muscle strength and urinary and anal incontinence during pregnancy: a cohort study [thesis]. São Paulo: Escola de Enfermagem, Universidade de São Paulo; 2015.

\begin{abstract}
Introduction: Pregnancy is considered a factor that favors the onset of urinary (UI) and anal incontinence (AI) as it can weaken the pelvic floor muscles. Objectives: 1. To analyse the pelvic floor muscles strength (PFMS) of women during pregnancy; 2. To analyse the UI and AI of women during pregnancy; 3. To identify the interference of UI in women's life. Methods: Prospective cohort study conducted with pregnant women in an insurance health care facility, in Guarulhos, SP. The 500 women who began prenatal care and met the inclusion criteria were included in a continuous period of time, from November 21, 2012 to September 17, 2013. Gestational age was considered the exposure; PFMS, urinary and faecal continence and UI interference in woman's life were considered the outcomes. The pregnant women were followed in three steps: Step 1, gestational age below 13 weeks; $\underline{\text { Step 2 }}$, from 20 to 27 weeks; $\underline{\text { Step 3 }}$, from 31 to 38 weeks. The PFMS was evaluated by perineometry (Peritron ${ }^{\mathrm{TM}}$ ) and UI and AI by interview. There was adooted the International Consultation on Incontinence Questionnaire-Short Form (ICIQSF). Descriptive, inferential and multivariate analysis was performed. The Research Ethics Committee of USP School of Nursing approved the project. Results: A total of 500, 226 and 187 pregnant women were respectively evaluated in the steps 1, 2 and 3 of the cohort. The losses to follow-up analysis indicate these were random and did not influence the outcomes. The PFMS did not vary significantly during pregnancy, with a mean of $30.5(\mathrm{SD}=17.3), 29.2(\mathrm{SD}=14.9)$ and $28.7(\mathrm{SD}=15.5) \mathrm{cmH}_{2} \mathrm{O}$ in steps 1,2 and 3 , respectively. Considering the $30 \mathrm{cmH}_{2} \mathrm{O}$ as cut off, most of the women had the PFMS under this in all steps $(\mathrm{p}=0.055)$. The incidence of UI during pregnancy was $18.6 \%$ and the prevalence was $19.0 \%, 42.5 \%$ and $35.3 \%$ in the first, second and third trimesters, respectively $(\mathrm{p}<0.001)$. The incidence of AI was $5.4 \%$ and the prevalence ranged from $7.5 \%$ to $11.5 \%$. Throughout pregnancy, ICIQ-SF score averages ranged from 7.8 $(\mathrm{SD}=4.8)$ to $8.3(\mathrm{SD}=4.0)$. In the multivariate analysis, the variables that together explain the variation in the PFMS during pregnancy were gestational age (per week: $r=-0.09$; 95\%CI -0.16 to -0.02 ), previous pregnancy (each pregnancy: $r=-1.73 ; 95 \%$ CI -3.20 to $0.25)$, previous UI ( $\mathrm{r}=-3.03 ; 95 \% \mathrm{CI}-5.96$ to -0.11$)$ and perineal exercises $(\mathrm{r}=2.37 ; 95 \%$ CI 0.48 to 4.26$)$. To explain the variation in the UI, the variables were: gestational age (second trimester: $\mathrm{OR}=5.26$; 95\% CI 3.44 to 8.02; third trimester: $\mathrm{OR}=3.34$; 95\% CI 2.09 to 5.31), previous UI (OR $=5.62 ; 95 \%$ CI 3.93 to 8.04), $\mathrm{PFMS}>30 \mathrm{cmH}_{2} \mathrm{O}(\mathrm{OR}=0.58 ; 95 \%$ CI 0.41 to 0.82 ), perineal exercises ( $\mathrm{OR}=0.53$; $95 \% \mathrm{CI} 0.31$ to 0.89$)$ and maternal age (per year: $\mathrm{OR}=1.05 ; 95 \%$ CI 1.02 to 1.08$)$. Just prior AI (OR=11.13; 95\% CI 6.70 to 18.50) is associated with AI during pregnancy. Conclusion: Perform perineal exercises at least twice a week increases the PFMS and reduce the occurrence of UI during pregnancy. The PFMS $>30 \mathrm{cmH}_{2} \mathrm{O}$ is also a protective factor against UI during pregnancy. The chance to have UI is higher in the second trimester of pregnancy and in women with previous UI. The impact of UI on the women's life can be considered moderate.
\end{abstract}

KEYWORDS: Pregnancy. Muscle Strength. Urinary Incontinence. Perineum. Midwifery. 


\section{LISTA DE QUADROS E FIGURAS}

Quadro 1 - Estudos sobre FMAP, IU e IA na gestação.................................. 21

Quadro 2 - Cronograma das etapas de coleta de dados, Guarulhos - 2012-

Figura 1 - Peritron ${ }^{\mathrm{TM}}$ com sensor vaginal................................................... 51

Figura 2 - Fluxograma das participantes do estudo, Guarulhos, SP - 2012 2014 60

Figura 3 - Gráfico de floresta do modelo final da análise multivariada da FMAP, Guarulhos, SP - 2012-2014

Figura 4 - Gráfico de floresta do modelo final da análise multivariada da IU, Guarulhos, SP - 2012-2014. 


\section{LISTA DE TABELAS}

Tabela 1 - Distribuição das gestantes da coorte conforme os grupos A, B, C, e D, Guarulhos, SP- 2012-2014

Tabela 2 - Distribuição das gestantes dos grupos A, B, C e D, conforme as variáveis quantitativas e valor-p, Guarulhos, SP - 2012-2014

Tabela 3 - Distribuição das gestantes dos grupos A, B, C e D, conforme as variáveis qualitativas e valor-p, Guarulhos, SP - 2012-2014

Tabela 4 - Distribuição das gestantes na etapa 1 da coorte, conforme a idade materna, número de gestações, abortos, partos vaginais e cesarianas anteriores e maior peso do $\mathrm{RN}$ em parto anterior, Guarulhos, SP - 2012-2014

Tabela 5 - Distribuição das gestantes na etapa 1 da coorte conforme a faixa etária, cor da pele, escolaridade, ocupação, gestação, aborto, parto vaginal e cesariana anteriores, trauma perineal em parto anterior, IU e IA prévias à gestação e momento da IU e IA, Guarulhos, SP - 2012-2014

Tabela 6 - Distribuição das gestantes nas etapas 1, 2 e 3 da coorte, conforme a idade gestacional, Guarulhos, SP - 2012-2014

Tabela 7 - Distribuição das gestantes nas etapas 1, 2 e 3 da coorte conforme a situação conjugal, estado nutricional e exercícios perineais, Guarulhos, SP - 2012-2014

Tabela 8 - Valores da média, desvio-padrão (d.p.), intervalo de confiança de 95\% (95\% IC), mediana, mínimo, máximo e valor-p da FMPA e do escore do ICIQ-SF das gestantes nas etapas 1, 2 e 3 da coorte, Guarulhos, SP - 2012-2014

Tabela 9 - Distribuição das gestantes nas etapas 1, 2 e 3 da coorte, conforme a FMAP, IU e IA e valor-p, Guarulhos, SP - 2012-2014

Tabela 10 - Distribuição das situações em que ocorre IU nas etapas 1, 2 e 3 conforme respostas das gestantes à questão 6 do ICIQ-SF (Quando você perde urina?), Guarulhos, SP - 2012-2014

Tabela 11 - Correlação de Pearson entre a FMAP e a idade materna, número de gestações, abortos, partos vaginais e cesarianas anteriores e maior peso do RN em parto anterior e valor-p, Guarulhos, SP 2012-2014 
Tabela 12 - Distribuição das gestantes nas etapas 1, 2 e 3 da coorte, conforme a FMAP e a faixa etária, cor da pele, escolaridade, ocupação, situação conjugal, gestação, aborto, parto vaginal e cesariana anteriores, trauma perineal em parto anterior, IU e IA prévia e atual, estado nutricional, exercícios perineais e maior peso do RN em parto anterior e valor-p, Guarulhos, SP - 2012-2014

Tabela 13 - Valores da média, desvio-padrão (d.p.), intervalo de confiança de 95\% (95\% IC), mediana, mínimo, máximo e valor-p da IU nas etapas 1, 2 e 3 da coorte conforme a idade materna, número de gestações, abortos, partos vaginais e cesarianas anteriores e maior peso do RN em parto anterior, Guarulhos, SP - 2012-2014

Tabela 14 - Distribuição das gestantes nas etapas 1, 2 e 3 da coorte, conforme a IU e a faixa etária, cor da pele, escolaridade, ocupação, situação conjugal, gestação, aborto e parto vaginal e cesariana anteriores, trauma perineal em parto anterior, IU prévia, IA prévia e atual, estado nutricional, FMAP, exercícios perineais e maior peso do RN em parto anterior e valor-p, Guarulhos, SP 2012-2014

Tabela 15 - Valores da média, desvio-padrão (d.p.), intervalo de confiança de 95\% (95\% IC), mediana, mínimo, máximo e valor-p da IA nas etapas 1, 2 e 3 da coorte, conforme a idade materna, número de gestações, aborto, partos vaginais e cesarianas anteriores e maior peso do RN em parto anterior, Guarulhos, SP - 2012-2014

Tabela 16 - Distribuição das gestantes nas etapas 1, 2 e 3 da coorte, conforme a IA e a faixa etária, cor da pele, escolaridade, ocupação, situação conjugal, gestação, aborto, parto vaginal e cesariana anteriores, trauma perineal em parto anterior, IU atual e prévia, IA prévia, estado nutricional, FMAP, exercícios perineais e maior peso do RN em parto anterior e valor-p, Guarulhos, SP 2012-2014

Tabela 17 - Modelos inicial e final da análise multivariada da FMAP, Guarulhos, SP - 2012-2014

Tabela 18 - Modelos inicial e final da análise multivariada da IU, Guarulhos, SP - 2012-2014

Tabela 19 - Modelos inicial e final da análise multivariada da IA, Guarulhos, SP - 2012-2014 


\section{LISTA DE ABREVIATURAS E SIGLAS}

95\%IC Intervalo de Confiança de 95\%

AFA Avaliação Funcional do Assoalho Pélvico

ANOVA Análise de Variância

AP Assolho Pélvico

$\mathrm{cm} \quad$ centímetro

$\mathrm{cmH} 2 \mathrm{O} \quad$ centimetros de água

CT Cinesioterapia

DAP Disfunção do Assoalho Pélvico

DMG Diabetes Mellitus Gestacional

FMAP Força dos Múculos do Assolho Pélvico

GEE Equações de Estimação Generalizadas

HIV Vírus da Imunodeficiência Humana

HR Hazard Ratio

KHQ King's Health Questionnaire

LMM Modelo Linear de Efeitos Mistos

IA Incontinência Anal

ICIQ-SF International Consultation on Incontinence Questionnaire-Short Form

IIQ-7 Incontinence Impact Questionaire-7

IMC Índice de Massa Corpórea

ISI Incontinence Severity Index

IU Incontinência Urinária

IUE Incontinência Urinária de Esforço

IUU Incontinência Urinária de Urgência

IUM Incontinência Urinária Mista

MOS-SF36 Medical Outcomes Study-Short Form-36

OR Odds Ratio

PFDI-20 Pelvic Floor Distress Inventory-20

POPDI-6 Pelvic Organ Prolapse Distress Inventory-6

RN Recém-Nascido

SPSS Statistical Package for the Social Sciences

UDI-6 Urogenital Distress Inventory-6

VDRL Venereal Disease Research Laboratory (sorologia para sífilis)

TCLE Termo de Consentimento Livre e Esclarecido 


\section{SUMÁRIO}

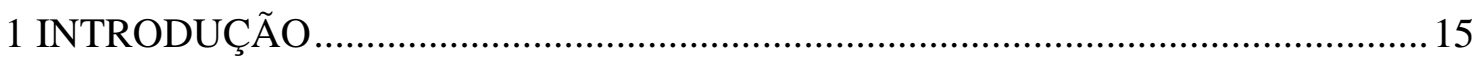

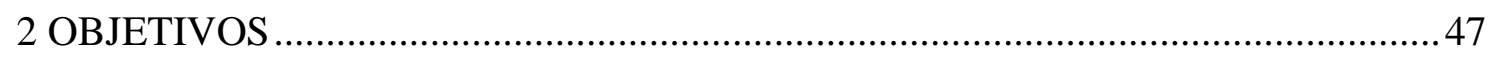

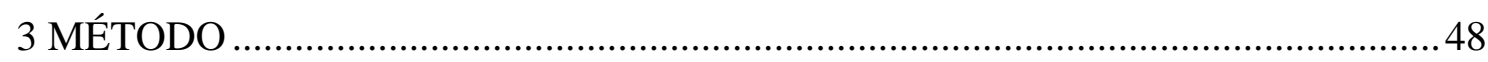

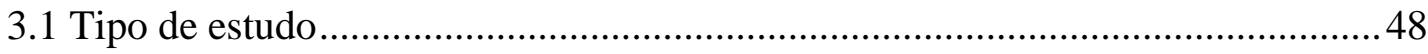

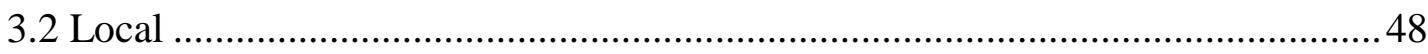

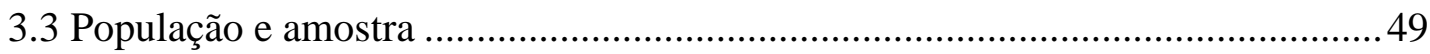

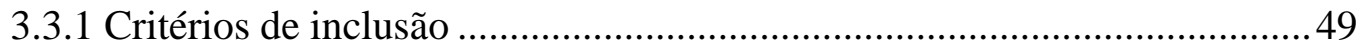

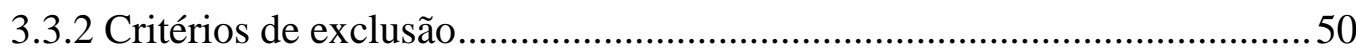

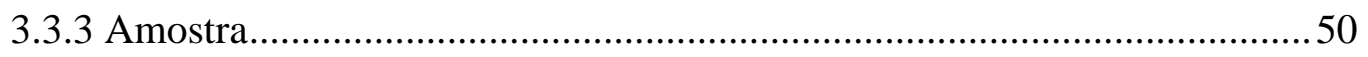

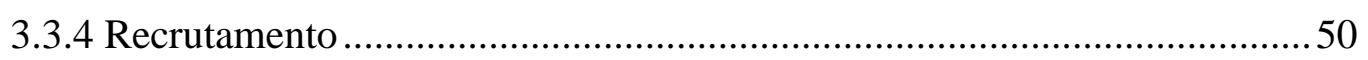

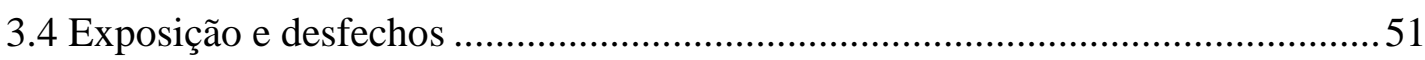

3.5 Medidas e instrumentos de avaliação dos desfechos .......................................51

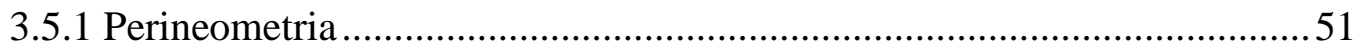

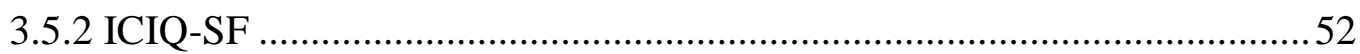

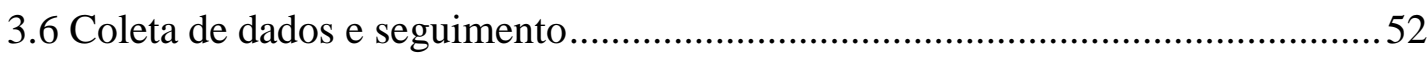

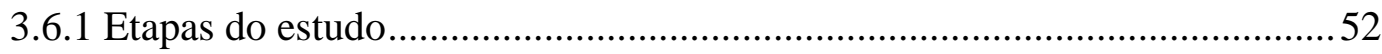

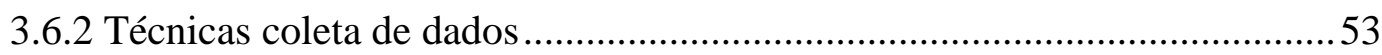

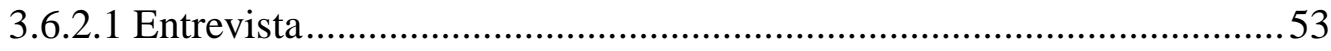

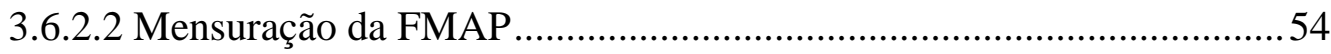

3.6.2.3 Aplicação do ICIQ-SF ............................................................... 55

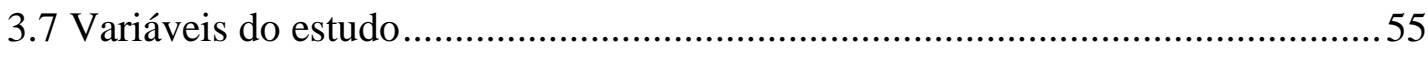

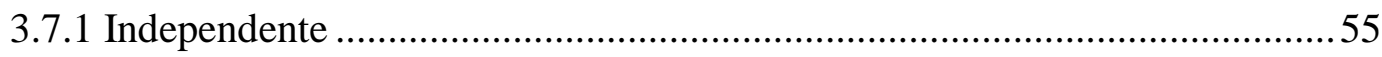

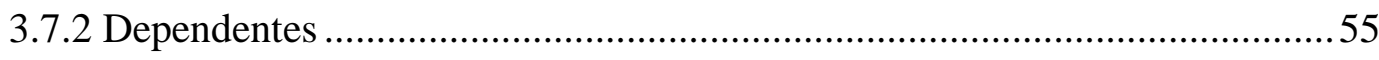

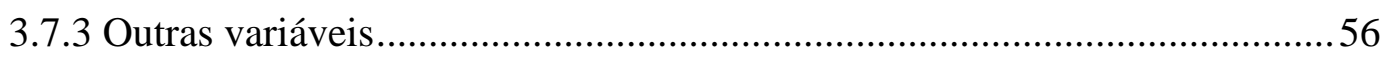

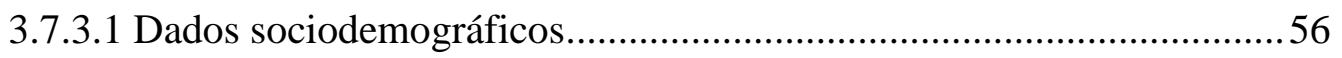




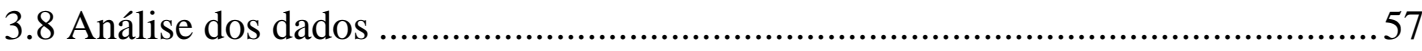

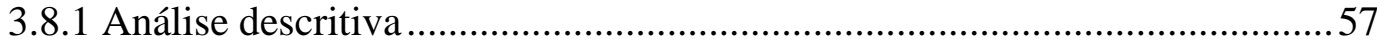

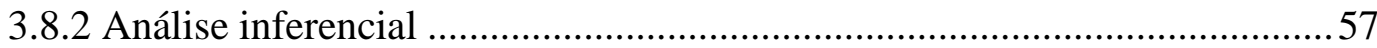

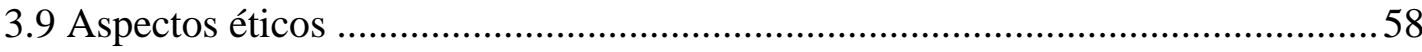

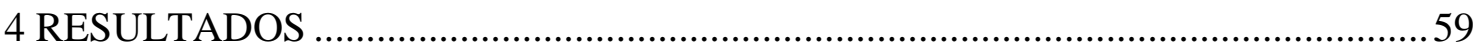

4.1 Análise da perda de seguimento das participantes............................................61

4.2 Caracterização das gestantes participantes da coorte .......................................64 64

4.3 Análise bivariada da FMAP, IU, ICIQ-SF e IA ao longo da gestação .................68

4.4 Análise multivariada da FMAP, IU e IA ao longo da gestação.......................... 85

5 DISCUSSÃO

5.1 FMAP, IU e IA ao longo da gestação .............................................................. 92

5.2 Limitações do estudo ..............................................................................101

5.3 Implicações para a pesquisa e a prática ............................................................102

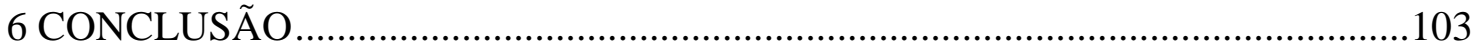

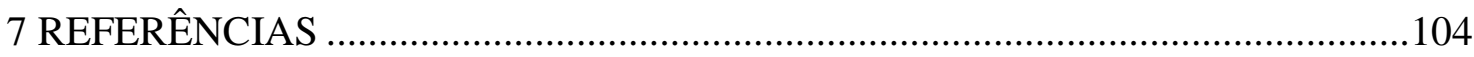

APÊNDICE A - Termo de Consentimento Livre e Esclarecido.................................110

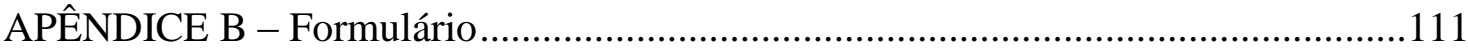

APÊNDICE C - Guia de Exercícios Perineais Durante a Gestação e Depois do Parto

APÊNDICE D - Termo de Autorização para a Realização de Pesquisa Científica.....116

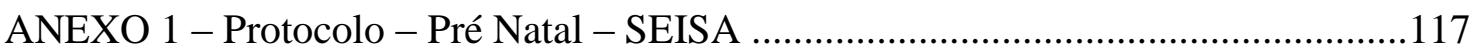

ANEXO 2 - International Consultation on Incontinence Questionnaire-Short Form

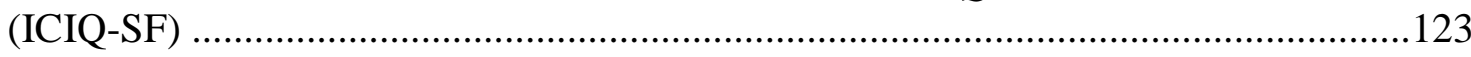

ANEXO 3 - Parecer do Comitê de Ética em Pesquisa................................................ 124 


\section{INTRODUÇÃO}

Na mulher, a IU é um tema que vem sendo estudado ao longo dos anos, pois acarreta desconforto e interfere diretamente nas atividades diárias (Oliveira et al. 2013; Bo et al. 2012). Entre as causas da IU estão a gestação, parto, IMC, constipação, prática de esportes, hábitos de vida, como o fumo, e vários outros fatores (Sangsawang, 2014; Steen, 2013). A IA também acarreta desconfortos e constrangimentos, tanto pela perda de flatus como de fezes (Abrams et al. 2010). Dentre as causas de IA estão a lesão do esfíncter anal durante o parto vaginal, principalmente em partos com expulsivo prolongado e partos instrumentais, neuropatia do pudendo e distúrbios neurológicos (Brarucha et al., 2006).

A IU é considerada uma das DAP e, dentre as DAP, é possível citar também a IA, o prolapso dos órgãos pélvicos, anormalidades sensoriais do trato urinário inferior e dor crônica relacionada aos órgãos pélvicos (Lavy et al., 2012; Luthander et al., 2011; Sung; Hampton, 2009; Chiarelli; Murphy; Cockburn, 2003;). Além de afetarem a saúde física, as DAP produzem repercussões na saúde sexual, psicológica e social da mulher e, assim, podem afetar a sexualidade, os relacionamentos e a qualidade de vida (Torrisi et al., 2012; Barrett et al., 1999).

A IU tem por definição a queixa de perda involuntária de qualquer quantidade de urina (Abrams et al., 2010).

Para Bruschini (2005), a IU pode ser desencadeada por uma série de doenças e disfunções do trato urinário inferior, e as causas mais comuns são a bexiga hiperativa e a incompetência esfincteriana. $\mathrm{O}$ autor supracitado refere que, nas mulheres, a incompetência esfincteriana está muito relacionada a traumas maternos decorrentes do parto e à fraqueza pélvica e perineal, além de involução uretral após a menopausa.

Conforme a International Continence Society, a IU é classificada de acordo com os sintomas da perda urinária como: incontinência urinária de urgência (IUU) que é a queixa de perda involuntária de urina de forma urgente. Acontece pela presença de contrações do músculo detrusor durante a fase de enchimento da bexiga, desencadeada espontaneamente ou em resposta ao estímulo da mulher tentar inibir a contração; incontinência urinária de esforço (IUE) que é a queixa de qualquer perda involuntária de urina durante o esforço físico, tosse ou espirro, na ausência da contração do músculo detrusor; ocorre por aumento da pressão intra-abdominal e incontinência urinária mista 
(IUM), que é a queixa de perda involuntária de urina associada à urgência e também ao esforço físico ou tosse, ou espirro (Abrams et al., 2010).

IA tem como definição a perda involuntária de fezes ou flatos e pode ser dividida em incontinência fecal, quando há qualquer perda involuntária de fezes, e incontinência de flatos, quando há qualquer perda de gases (Abrams et al., 2010).

A IA tem maior prevalência entre as mulheres do que entre os homens e, embora a incidência seja menor do que a IU, os desconfortos causados são maiores (Hay-Smith et al. 2011). A literatura apresenta incidência em torno de 5\% de incontinência fecal e $28 \%$ de incontinência de flatos, segundo Stafne et al. (2012). Hay-Smith et al. (2011) apontam revisão sistemática com prevalência de IA entre $2 \%$ e 5\% para incontinência fecal, entre $13 \%$ e $27 \%$ para incontinência de flatos. Chantarasorn, Shek e Dietz (2011) relataram $16,4 \%$ de incontinência de fezes e $22,9 \%$ de incontinência de flatos. SolansDomènech, Sanchez e Espuña-Pons (2010) referem incidência acumulada de IA de 10,3\% em gestantes nulíparas.

Entender as alterações da gestação e parto em relação ao AP e a função do esfíncter uretral e anal é importante para propiciar cuidados especiais para a mulher no período gravídico e puerperal.

Ao longo da gestação, a incidência e prevalência de IU variam muito. Sangsawang (2014) apresenta prevalência de IUE na gestação entre $18 \%$ e $75 \%$. Cerruto et al. (2013) encontraram prevalência de IU entre $14,1 \%$ e $68,8 \%$ e referem que a idade materna foi fator de aumento da IU. Oliveira et al. (2013) apontam que de 495 mulheres avaliadas no dia do parto, 71,1\% referiram IU nas quatro últimas semanas que antecederam o parto. B $\emptyset$ et al. (2012) apresentam estudo com prevalência de $26 \%$ a 45\%, em gestantes com 28 semanas de gestação. Wesnes, Hunskaar e Rortveit (2012) identificaram incidência de IU de $11 \%$ a $50 \%$, entre nulíparas, e de $8 \%$ a $57 \%$, entre multíparas. Hansen et al. (2012) referem prevalência de IU de 32,1\% entre as primíparas e 13,8\% entre nulíparas. Wijma et al. (2001) identificaram prevalência de $16 \%$ de IU em gestantes, entre 12 e 16 semanas de gestação, e $30 \%$, entre 36 e 38 semanas.

Sangswang (2014) e Fritel et al. (2012) referem que a IUE tem maior prevalência na gestação, que devem ser considerados outros fatores de risco, como a obesidade, tabagismo, constipação, redução da FMAP, fatores genéticos, idade materna, IUE prévia e diabetes gestacional.

Friet el al. (2012) citam que é importante entender que as funções fisiológicas e a história natural do processo do envelhecimento podem explicar a IUE. Fatores como 
questões congênitas, obesidade, envelhecimento, gestação e parto podem afetar parte do complexo do esfíncter uretral e produzir IU, e esse fator leva à IU em algum momento da vida. Os autores ainda mencionam que esses fatores podem ser contínuos ou reversíveis.

O mecanismo de continência urinária ocorre por meio do posicionamento e tamanho adequado da uretra e da funcionalidade do AP. O AP suporta ativamente os órgãos pélvicos, favorecendo o fechamento do esfíncter uretral durante o processo de micção, pela contração do músculo destrutor da bexiga. Algumas atividades favorecem o aumento da pressão intra-abdominal, como por exemplo, tossir, espirrar, rir ou simplesmente caminhar, e esta pressão é transmitida para a bexiga. Quando a pressão interna da bexiga é maior que a pressão de fechamento uretral, associada com a fraqueza do esfincter uretral, o resultado é a perda de urina ou IUE (Sangswang, 2014; Stein, 2013; Ciofu; Haab, 2005).

Sabe-se que a gestação e o parto são fatores que causam fragilidade da musculatura do AP, mas os estudos são contraditórios quanto à diminuição ou preservação dessa força durante a gestação e após o parto. Alguns estudos citam que a diminuição da FMAP favorece a IU, (Sangswang, 2014; Frederice, Amaral, Ferreira, 2013; Wesnes, Lose, 2014; Baracho et al., 2012; Hilde et al., 2012). Por sua vez, a gestação favorece a diminuição da FMAP, explicando, em parte, a maior incidência e prevalência de IU nesse período (Elenskaia et al., 2011; Gameiro et al., 2011; Fritel et al., 2012).

Valeton e Amaral (2011) identificaram que a FMAP foi significantemente menor no pós-parto, independente do tipo de parto. Mas, Caroci et al., (2010) identificaram que não houve redução estatisticamente significante na média da força perineal em mulheres nulíparas durante a gestação e no pós-parto. Igualmente, Ferederice, Amaral e Ferreira (2011) identificaram que não houve diminuição da função da musculatura do AP, 60 dias após o parto de mulheres que tiveram parto normal com episiotomia ou cesariana após trabalho de parto.

Para Liang et al. (2007), após o parto, as alterações das estruturas do AP tendem a regredir gradualmente em um período de até doze meses, voltando ao estado prégestacional. Mas a IU pode surgir após o parto e permanecer por um tempo ainda não bem estabelecido.

Identificar a FMAP não é simples. Alguns métodos e equipamentos são utilizados para medir essa força, avaliando objetiva e subjetivamente a pressão da contração muscular sobre a parede vaginal, sua intensidade e duração; porém Bø e Sherburn (2005) 
e Guaderrama et al. (2005) referem que não é possível saber se o valor detectado corresponde ao valor real da contração no dia a dia da mulher.

Dentre os métodos e equipamentos utilizados para avaliação da FMAP estão: manômetro ou perineômetro, dinamômetro, eletromiógrafo, cone vaginal, avaliação funcional do AP (AFA), pela palpação digital da musculatura vaginal, ultrassonografia e ressonância magnética (Bø e Sherburn, 2005).

Barbosa et al. (2009) compararam valores obtidos da mensuração da FMAP por três diferentes perineômetros: Neurodyn Evolution ${ }^{\mathrm{TM}}$, SensuPower ${ }^{\mathrm{TM}}$ e Peritron ${ }^{\mathrm{TM}}$. Os autores concluíram que há uma variabilidade importante entre essas marcas de perineômetro e sugerem que as metanálises devem agrupar apenas os resultados obtidos com as mesmas marcas de perineômetro, utilizados nos diversos estudos.

A diminuição da FMAP é um fator negativo para a gestação e o parto, promover o fortalecimento perineal favorece a prevenção e a diminuição da IU e da IA. Vários estudos confirmam que gestantes que realizam exercícios perineais de forma rotineira apresentam queixa menor de IU ano longo da gestação, promovendo a prevenção e tratamento da IU (Morkverd e Bo, 2014; Sangswang e Sangswang, 2013; Wesnes e Lose, 2013; Baracho et al.,2012; Hay-Smith et al.,2011; Ko et al., 2011; Sangsawang e Serisathien, 2011). B $\varnothing$ e Haakstad (2011) referem que os exercícios físicos generalizados não previnem IU ou IA, e é necessário que se tenha foco nos exercícios perineais.

Os exercícios também estão indicados como tratamento inicial nos casos de IA (Abrams et al., 2010). Stefane et al. (2012) relataram que gestantes que realizaram exercícios perineais sob supervisão de um fisioterapeuta, por 12 semanas, apresentaram menos relato de incontinência fecal $(3 \%$ contra $5 \%$, entre gestantes que não foram acompanhadas pelo profissional). Hay-Smith et al. (2011) em revisão sistemática, apresentaram que exercícios perineais realizados de forma regular reduzem a prevalência de IA.

A técnica para a realização de exercícios para o AP também denominada cinesioterapia do AP, foi descrita pela primeira vez em 1948, por Arnold Kegel. Ele identificou que este tipo de exercício auxilia na restauração das funções da musculatura pélvica (Kegel, 1948). Desde então, o autor acreditava que o desuso, a debilidade e a hipotonicidade dos músculos do AP contribuem para a incapacidade orgástica e que sua reabilitação e fortalecimento têm efeito positivo na vida sexual das mulheres (Piassarolli et al., 2010). 
A CT do AP é baseada em movimentos voluntários e repetidos para gerar força muscular. Ela previne a rigidez muscular, mantém ou recupera a força, restitui a imagem motora e a nutrição dos tecidos e melhora a autoestima (Oliveira et al., 2007). Sua prática fortalece a musculatura AP e, com o tempo, o exercício diário provoca uma adaptação neural, de modo que os músculos fiquem contraídos automaticamente, prevenindo sua descida durante a pressão abdominal (Bø, 2004).

Gameiro, Moreira e Amaro (2005) referem que os exercícios devem ser realizados entre a $20^{\mathrm{a}}$ e $36^{\mathrm{a}}$ semanas de gestação, o que está de acordo com a recomendação da Sociedade Internacional de Urologia (Abrams et al., 2010).

Chiverton et al. (1996) apontam que a IU pode afetar negativamente a qualidade de vida da mulher nos aspectos psicológico, social, físico, pessoal e sexual em qualquer fase da vida. Eles demonstraram que as mulheres com IU apresentaram maior incidência de depressão. Franco at al. (2014) referem que a perda de urina afeta a qualidade de vida das gestantes física, mental e socialmente.

Lopes e Praça (2012) identificaram em estudo sobre a IU no pós-parto que 28,2\% das puérperas apontaram constrangimento, desconforto e prejuízo no relacionamento sexual, como fatores que prejudicavam sua qualidade de vida. Outro aspecto interessante apontado no estudo foram as causas da IU, atribuídas por 63,4\% das mulheres incontinentes, a saber: falta de preparo do períneo durante a gestação; parto fórceps; episiotomia; força realizada durante o trabalho de parto e peso elevado do recém-nascido.

Torrisi et al. (2012) relacionaram a IU com a qualidade de vida utilizando o instrumento do International Consultation on Incontinence Questionnaire-Short Form (ICIQ-SF). Os autores afirmam que estratégias para se identificar precocemente estas condições são necessárias para prevenir e melhorar a qualidade de vida das mulheres.

Existem vários instrumentos que avaliam a qualidade de vida da mulher com IU. Esta avaliação torna-se importante, pois quanto mais precoce for identificada a condição clínica na mulher melhor serão o tratamento e o prognóstico.

Donavan et al. (2000) referem que a maioria dos questionários utilizados para avaliar o impacto da IU é longo e de aplicação demorada. Avery et al. (2004) citam que questionários curtos e simples são ideais para aplicação rotineira.

O desenvolvimento e validação do questionário abreviado ICIQ-SF ocorreu por incentivo da Organização Mundial de Saúde, em 1998, diante da necessidade da criação de um instrumento que fosse rápido e de fácil aplicação e que medisse de modo preciso a qualidade de vida dos indivíduos com queixa de perda urinária (Avery et al., 2004). Os 
mesmos autores afirmam que este é um instrumento capaz de medir os sintomas e o impacto da IU e é adequado para o uso na clínica e na pesquisa. Possui uma abordagem prática e permite que sua aplicação seja feita em grupos ou individualmente. O ICIQ-SF foi traduzido em 35 idiomas e sua tradução e validação no Brasil foram realizadas por Tamanini et al. (2004).

No presente estudo, para avaliar os desfechos propostos serão utilizados os instrumentos mais recentemente empregados nas pesquisas sobre a mesma temática. Assim, para avaliar a FMAP o perineômetro digital Peritron ${ }^{\mathrm{TM}}$ será utilizado, adotado em estudos recentes com mulheres na gestação e no pós-parto (Ferreira et al., 2011; Dinc Beji Yalcin, 2009). Para avaliação da IU e qualidade de vida relacionada, o instrumento de escolha é o ICIQ-SF (Torrisi et al., 2012; Tamanini et al., 2004;).

Dada a magnitude da IU e IA na gestação e sua possível relação com a FMAP, estudos longitudinais em todos os trimestres da gestação podem contribuir para o avanço do conhecimento e a melhoria do cuidado à mulher.

Por fim, os principais estudos referidos nesta Introdução estão sumarizados nos dados do Quadro 1, a seguir. 
Quadro 1 - Estudos sobre FMAP, IU e IA na gestação*

\begin{tabular}{|c|c|c|c|}
\hline $\begin{array}{l}\text { Autor } \\
\text { Ano } \\
\text { País }\end{array}$ & Objetivos & $\begin{array}{c}\text { Método } \\
\text { Desenho/População/Amostra/Coleta de } \\
\text { dados/Intervenção/Análise dos dados }\end{array}$ & Principais resultados \\
\hline $\begin{array}{l}\text { Franco et al. } \\
2014 \\
\text { Espanha }\end{array}$ & $\begin{array}{l}\text { Determinar a prevalência e a } \\
\text { severidade da IU e identificar se } \\
\text { há diferenças entre o primeiro e o } \\
\text { primeiro e o terceiro trimestre de } \\
\text { gestação. }\end{array}$ & $\begin{array}{l}\text { Desenho: estudo transversal } \\
\text { População: todas a gestantes atendidas no } \\
\text { hospital e que estavam com menos de } 13 \\
\text { semanas, } 1^{\circ} \text { trimestres de gestação (grupo 1), } \\
\text { no dia da consulta e com mais de } 28 \text { semanas, } \\
3^{\circ} \text { trimestres de gestação (grupo } 2 \text { ), de março } \\
\text { a maio de } 2012 \\
\text { Amostra: } 224 \text { gestantes, grupo } 1 \text { (58) e grupo } \\
2 \text { (166) } \\
\text { Coleta de dados: todas a gestantes } \\
\text { responderam um questionário auto respondido } \\
\text { com os seguintes instrumentos ICIQ-SF, } \\
\text { PFDI-20 (UDI-6, POPDI-6) e SF-36 } \\
\text { Análise de dados: descritiva, inferencial e } \\
\text { multivariada }\end{array}$ & $\begin{array}{l}\text { A incidência de IU durante a } \\
\text { gestação foi diferente no } 1^{\circ} \text { e no } 3^{\circ} \\
\text { trimestre de gestação, com valor } \\
\text { significante, } 18.96 \% \text { (11 de 58) } \\
\text { and } 39.76 \% \text { (66 de } 166)(\mathrm{p}=0.008) \text {. } \\
100 \% \text { e } 84 \% \text { das gestantes com IU } \\
\text { no } 1^{\circ} \text { trimestre de gestação no } 1^{\circ} \text { e } \\
3^{\circ} \text { trimestre de gestação } \\
\text { respectivamente perdem uma } \\
\text { pequena quantidade de urina. Em } \\
15,87 \% \text { das gestantes do grupo B } \\
\text { perdem uma quantidade moderada } \\
\text { de urina. A IUE aconteceu em } \\
78,3 \% \text { das gestantes e IUU } \\
\text { aconteceu em } 12,16 \% \text { das } \\
\text { gestantes. A perda de urina afeta a } \\
\text { qualidade de vida das gestantes } \\
\text { física, mental e socialmente. }\end{array}$ \\
\hline
\end{tabular}

(continua)

*Extraído e adaptado de Riesco MLG et al. Cuidado perineal na gestação e após o parto: prevenção e morbidade relacionadas à força muscular
perineal, função sexual e continência urinária [relatório de pesquisa]. São Paulo: Escola de Enfermagem, Universidade de São Paulo; 2015. 
Quadro 1

(cont.)

\begin{tabular}{|c|c|c|c|}
\hline $\begin{array}{c}\text { Autor } \\
\text { Ano } \\
\text { País } \\
\end{array}$ & Objetivos & $\begin{array}{c}\text { Método } \\
\text { Desenho/População/Amostra/Coleta de } \\
\text { dados/Intervenção/Análise dos dados }\end{array}$ & Principais resultados \\
\hline $\begin{array}{l}\text { Mørkved e Bø } \\
2014\end{array}$ & $\begin{array}{l}\text { Avaliar o efeito dos exercícios } \\
\text { perineais durante a gestação e } \\
\text { após o parto como prevenção e } \\
\text { tratamento de IU. }\end{array}$ & $\begin{array}{l}\text { Desenho: revisão sistemática } \\
\text { População: estudos randomizados ou quasi- } \\
\text { experimentais publicados em língua inglesa, } \\
\text { realizados com gestantes ou puérperas, em } \\
\text { que a intervenção tenha sido exercício } \\
\text { perineal com ou sem biofeedback, cone } \\
\text { vaginal ou eletroestimulação } \\
\text { Amostra: } 22 \text { estudos } \\
\text { Análise de dados: descritiva }\end{array}$ & $\begin{array}{l}\text { Com base nos estudos com } \\
\text { amostra relevante, boa adesão ao } \\
\text { protocolo de treinamento do AP e } \\
\text { bom acompanhamento, foi } \\
\text { identificado que exercício perineal } \\
\text { durante e após o parto podem } \\
\text { prevenir e tratar IU. Um protocolo } \\
\text { de treinamento dos músculos do } \\
\text { AP, enfatizando contração máxima } \\
\text { e duradoura por oito semanas, deve } \\
\text { ser recomendado. }\end{array}$ \\
\hline $\begin{array}{l}\text { Riesco et al. } \\
2014 \\
\text { Brasil }\end{array}$ & $\begin{array}{l}\text { Analisar a FMAP, continência } \\
\text { urinária e a qualidade de vida } \\
\text { associada a IU em mulheres no } \\
\text { primeiro trimestre da gestação. }\end{array}$ & $\begin{array}{l}\text { Desenho: estudo transversal } \\
\text { População: gestantes com até } 12 \text { semanas e } 6 \\
\text { dias de gestação } \\
\text { Amostra: } 500 \text { gestantes } \\
\text { Coleta de dados: formulário com informações } \\
\text { sociodemográficas, antecedentes clínicos e } \\
\text { obstétricos e condições na gestação atual, } \\
\text { ICQ-SF e perineometria (Peritron) } \\
\text { Análise de dados: descritiva, inferencial e } \\
\text { multivariada }\end{array}$ & $\begin{array}{l}\text { A idade materna (OR=1,06; } \\
\text { 95\%IC 1,02-1,01) e IU prévia } \\
(\mathrm{OR}=15,12 ; 95 \% \text { IC } 8,19-27,92) \\
\text { são as variáveis que, em conjunto, } \\
\text { melhor explicam a ocorrência de } \\
\text { IU no início da gestação. A média } \\
\text { do escore do ICIQ-SF foi 8,2 } \\
(\text { d.p.=3,9). }\end{array}$ \\
\hline
\end{tabular}


Quadro 1

(cont.)

\begin{tabular}{|c|c|c|c|}
\hline $\begin{array}{c}\text { Autor } \\
\text { Ano } \\
\text { País } \\
\end{array}$ & Objetivos & $\begin{array}{c}\text { Método } \\
\text { Desenho/População/Amostra/Coleta de } \\
\text { dados/Intervenção/Análise dos dados }\end{array}$ & Principais resultados \\
\hline $\begin{array}{l}\text { Sangsawang, } \\
2014\end{array}$ & $\begin{array}{l}\text { Identificar os fatores de risco } \\
\text { para o desenvolvimento de IUE } \\
\text { em gestantes. }\end{array}$ & $\begin{array}{l}\text { Desenho: revisão } \\
\text { População: artigos sobre IUE publicados de } \\
\text { janeiro de } 1990 \text { a setembro de } 2013 \\
\text { Amostra: } 13 \text { artigos } \\
\text { Análise de dados: descritiva }\end{array}$ & $\begin{array}{l}\text { A prevalência de IUE na gestação } \\
\text { variou de } 18,6 \% \text { a } 75 \% \text { e } \\
\text { aumentou com a idade gestacional. } \\
\text { A qualidade de vida foi afetada em } \\
54,3 \% \text { das gestantes. A gestação } \\
\text { foi um dos principais fatores de } \\
\text { risco para IUE em mulheres } \\
\text { jovens. Outros fatores de risco são: } \\
\text { obesidade, tabagismo, constipação, } \\
\text { redução da FMAP, fatores } \\
\text { genéticos, idade, IUE prévia e } \\
\text { diabetes gestacional. }\end{array}$ \\
\hline $\begin{array}{l}\text { Cerruto et al. } \\
2013 \\
\text { Europa }\end{array}$ & $\begin{array}{l}\text { Identificar taxas de prevalência e } \\
\text { incidência de IU na Europa, } \\
\text { especificar os subtipos de IU e o } \\
\text { efeito dos fatores obstétricos na } \\
\text { IU após o parto. }\end{array}$ & $\begin{array}{l}\text { Desenho: revisão sistemática } \\
\text { População: estudos epidemiológicos } \\
\text { publicados de } 2000 \text { a } 2010 \\
\text { Amostra: } 138 \text { artigos (133 revisões } \\
\text { sistemáticas e } 5 \text { ensaios clínicos randomizados } \\
\text { e controlados) } \\
\text { Análise de dados: descritiva e metanálise }\end{array}$ & $\begin{array}{l}\text { A prevalência de IU variou de } \\
14,1 \% \text { a } 68,8 \% \text { e aumentou com a } \\
\text { idade. Os fatores de risco } \\
\text { significantes para IU na gestação } \\
\text { foram: idade materna } \geq 35 \text { anos, } \\
\text { aumento do IMC na gestação, } \\
\text { antecedentes de IU e paridade. }\end{array}$ \\
\hline
\end{tabular}

(continua) 
Quadro 1

(cont.)

\begin{tabular}{|c|c|c|c|}
\hline $\begin{array}{c}\text { Autor } \\
\text { Ano } \\
\text { País }\end{array}$ & Objetivos & $\begin{array}{c}\text { Método } \\
\text { Desenho/População/Amostra/Coleta de } \\
\text { dados/Intervenção/Análise dos dados }\end{array}$ & Principais resultados \\
\hline $\begin{array}{l}\text { Frederice, } \\
\text { Amaral e } \\
\text { Ferreira } \\
2013 \\
\text { Brasil }\end{array}$ & $\begin{array}{l}\text { Avaliar a associação entre FMAP } \\
\text { e os sintomas urinários de } \\
\text { gestantes nulíparas no terceiro } \\
\text { trimestre da gravidez. }\end{array}$ & $\begin{array}{l}\text { Desenho: estudo transversal } \\
\text { População: primigestas com feto único, entre } \\
30 \text { e } 34 \text { semanas de gestação } \\
\text { Amostra: } 91 \text { gestantes } \\
\text { Coleta de dados: eletromiografia de } \\
\text { superfície, palpação vaginal digital e } \\
\text { entrevista sobre sintomas urinários } \\
\text { Análise de dados: descritiva e inferencial }\end{array}$ & $\begin{array}{l}\text { O tônus basal da FMAP foi menor } \\
\text { entre gestantes com aumento da } \\
\text { frequência urinária e IUU. A IUE } \\
\text { foi mais frequente entre gestantes } \\
\text { de cor branca. Não houve } \\
\text { associação estatisticamente } \\
\text { significante entre IU e nos } \\
\text { seguintes componentes da FMAP: } \\
\text { contração voluntária máxima, } \\
\text { contração sustentada e palpação } \\
\text { vaginal digital. A noctúria foi } \\
\text { referida por } 80,2 \% \text { das gestantes, } \\
\text { seguida do aumento da frequência } \\
\text { urinária }(59,3 \%) \text {, IUE (50,5\%) e } \\
\text { IUU }(25,3 \%) \text {. }\end{array}$ \\
\hline $\begin{array}{l}\text { Oliveira et al. } \\
2013 \\
\text { Brasil }\end{array}$ & $\begin{array}{l}\text { Investigar a ocorrência de IU em } \\
\text { mulheres grávidas e a relação } \\
\text { com variáveis sociodemográficas } \\
\text { e a qualidade de vida. }\end{array}$ & $\begin{array}{l}\text { Desenho: estudo transversal multicêntrico } \\
\text { Amostra: } 495 \text { mulheres } \\
\text { Coleta de dados: coletados no dia do parto, } \\
\text { nas maternidades elegidas e aplicado o ICIQ- } \\
\text { SF } \\
\text { Análise de dados: análise descritiva, } \\
\text { inferencial e multivariada, com comparação } \\
\text { entre os grupos } 1 \text { (incontinente) e } 2 \\
\text { (continente) }\end{array}$ & $\begin{array}{l}71,1 \% \text { das mulheres apresentaram IU } \\
\text { nas últimas quatro semanas. No grupo } \\
1 \text { o escore do ICIQ-SF de } 12,1 \\
\text { (min=3; máx=21), considerado de } \\
\text { impacto severo na qualidade de vida. } \\
\text { Análise multivariada houve maior } \\
\text { relação entre o relato de IU com: } \\
\text { escolaridade abaixo de oito anos } \\
(\mathrm{OR}=2,99 ; \mathrm{p}<0,001) \text {, raça negra } \\
(\mathrm{OR}=2,32 ; \mathrm{p}=0,005) \text {, mais de três } \\
\text { filhos }(\mathrm{OR}=4,93 ; \mathrm{p}<0,001) \text {, obesidade } \\
(\mathrm{OR}=4,22 ; \mathrm{p}<0,001) \text { e parto normal } \\
(\mathrm{OR}=2,59 ; \mathrm{p}<0,001) \text {. }\end{array}$ \\
\hline
\end{tabular}

(continua) 
Quadro 1

(cont.)

\begin{tabular}{|c|c|c|c|}
\hline $\begin{array}{l}\text { Autor } \\
\text { Ano } \\
\text { País }\end{array}$ & Objetivos & $\begin{array}{c}\text { Método } \\
\text { Desenho/População/Amostra/Coleta de } \\
\text { dados/Intervenção/Análise dos dados }\end{array}$ & Principais resultados \\
\hline $\begin{array}{l}\text { Sangsawang e } \\
\text { Sangsawang } \\
2013\end{array}$ & $\begin{array}{l}\text { Explicar a fisiopatologia, } \\
\text { prevalência e tratamento da IUE } \\
\text { em gestantes. }\end{array}$ & $\begin{array}{l}\text { Desenho: revisão } \\
\text { População: artigos publicados de janeiro de } \\
1990 \text { a setembro de } 2012 \\
\text { Amostra: } 28 \text { artigos } \\
\text { Análise de dados: descritiva }\end{array}$ & $\begin{array}{l}41 \% \text { de prevalência de IUE na } \\
\text { gestação }(18,6 \% \text { a } 60 \%) \text { e } \\
\text { aumentou com a idade gestacional. } \\
\text { Aumento do útero causa pressão } \\
\text { AP pelo aumento e o peso do feto, } \\
\text { associada às alterações hormonais } \\
\text { da gestação, pode diminuir FMAP, } \\
\text { a sustentação do AP e a } \\
\text { competência do esfíncter uretral. } \\
\text { Exercício perineal é tratamento } \\
\text { seguro sem efeitos adversos } \\
\text { significantes para IUE }\end{array}$ \\
\hline $\begin{array}{l}\text { Wesnes e } \\
\text { Lose } \\
2013\end{array}$ & $\begin{array}{l}\text { Identificar os fatores de risco de } \\
\text { IU modificáveis na gestação e no } \\
\text { pós-parto. }\end{array}$ & $\begin{array}{l}\text { Desenho: revisão } \\
\text { População: artigos recuperados da base de } \\
\text { dados MEDLINE, registro de ensaios } \\
\text { clínicos da Colaboração Cochrane e da base } \\
\text { de dados de revisões sistemáticas da } \\
\text { Cochrane, até setembro de } 2012 \\
\text { Análise de dados: descritiva }\end{array}$ & $\begin{array}{l}\text { Recomendações para prevenir IU na } \\
\text { gestação e no pós-parto classificadas } \\
\text { de grau A a grau D (A: obrigatória, } \\
\text { deve ser sempre seguida; B: } \\
\text { recomendada, deve ser usualmente } \\
\text { seguida; C: opcional; D: não é possível } \\
\text { recomendar), com os seguintes } \\
\text { resultados: Grau A: orientar as } \\
\text { mulheres a fazer exercícios perineais } \\
\text { durante a gestação e após o parto; Grau } \\
\text { B: estado nutricional adequado antes } \\
\text { da gestação, realizar atividade física de } \\
\text { baixo impacto, evitar constipação; } \\
\text { Grau C: evitar constipação no pós } \\
\text { parto; Grau D: não indicar cesariana } \\
\text { para prevenir IU. }\end{array}$ \\
\hline
\end{tabular}

(continua) 
Quadro 1

(cont.)

\begin{tabular}{|c|c|c|c|}
\hline $\begin{array}{c}\text { Autor } \\
\text { Ano } \\
\text { País } \\
\end{array}$ & Objetivos & $\begin{array}{c}\text { Método } \\
\text { Desenho/População/Amostra/Coleta de } \\
\text { dados/Intervenção/Análise dos dados }\end{array}$ & Principais resultados \\
\hline $\begin{array}{l}\text { Baracho et al. } \\
2012 \\
\text { Brasil }\end{array}$ & $\begin{array}{l}\text { Investigar os preditores } \\
\text { obstétricos, neonatais e clínicos } \\
\text { para IUE em mulheres primíparas } \\
\text { com parto vaginal. }\end{array}$ & $\begin{array}{l}\text { Desenho: estudo transversal } \\
\text { População: primíparas com parto vaginal de } \\
\text { feto único e apresentação cefálica } \\
\text { Amostra: prontuário, entrevista entre cinco e } \\
\text { sete meses após o parto e perineometria } \\
\text { (Peritron) } \\
\text { Coleta de dados: } 192 \text { mulheres } \\
\text { Análise de dados: descritiva, inferencial e } \\
\text { multivariada. }\end{array}$ & $\begin{array}{l}\text { FMAP foi um forte preditor da } \\
\text { IUE. A combinação da FMAP } \\
\geq 35,5 \mathrm{cmH}_{2} \mathrm{O} \text { e IU prévia, peso do } \\
\text { RN maior que } 2.988 \text { g e IUE na } \\
\text { gestação foram preditores de IUE } \\
\text { após o parto. }\end{array}$ \\
\hline $\begin{array}{l}\text { B } \varnothing \text { et al. } \\
2012 \\
\text { Noruega }\end{array}$ & $\begin{array}{l}\text { Investigar prevalência de IU em } \\
\text { uma população multiétnica de } \\
\text { mulheres grávidas e analisar } \\
\text { possíveis associações dos fatores } \\
\text { de risco. }\end{array}$ & $\begin{array}{l}\text { Desenho: Estudo transversal } \\
\text { População: Gestantes entre } 26 \text { e } 28 \text { semanas } \\
\text { de gestação } \\
\text { Amostra: } 722 \text { gestantes } \\
\text { Coleta de dados: ICIQ-SF, questionário com } \\
\text { informações socioeconômicas, demográficas, } \\
\text { clínicas e obstétricas } \\
\text { Análise de dados: descritiva e inferencial }\end{array}$ & $\begin{array}{l}\text { Prevalência de IU com } 28 \text { semanas de } \\
\text { gestação variou de } 26 \% \text { a } 45 \% \\
\text { considerando as origens africana, do } \\
\text { oriente médio, asiática, européia e } \\
\text { norte americana. Houve diferença } \\
\text { estatisticamente significante entre as } \\
\text { africanas e europeias/norte } \\
\text { americanas (p=0,011) e entre } \\
\text { africanas e sul asiáticas ( } \mathrm{p}=0,035 \text { ). } \\
\text { Mulheres de origem africana tiveram } \\
58 \% \text { menos chance de IU. Mulheres } \\
\text { do leste asiático e africanas referiram } \\
\text { alto impacto da IU na gestação } \\
\text { (escore do ICIQ-SF de } 8,6 \pm 4,2 \text { e } \\
8,5 \pm 5,5 \text {, respectivamente). Houve } \\
\text { associação positiva da prevalência de } \\
\text { IU com idade materna e paridade. }\end{array}$ \\
\hline
\end{tabular}




\begin{tabular}{|c|c|c|c|}
\hline $\begin{array}{l}\text { Autor } \\
\text { Ano } \\
\text { País }\end{array}$ & Objetivos & $\begin{array}{c}\text { Método } \\
\text { Desenho/População/Amostra/Coleta de } \\
\text { dados/Intervenção/Análise dos dados }\end{array}$ & Principais resultados \\
\hline $\begin{array}{l}\text { Fritel et al. } \\
2012\end{array}$ & $\begin{array}{l}\text { Analisar a literatura que embasa } \\
\text { a teoria do trauma obstétrico e } \\
\text { formular hipóteses que podem } \\
\text { explicar adequadamente a IU } \\
\text { em mulheres. }\end{array}$ & $\begin{array}{l}\text { Desenho: revisão } \\
\text { População: artigos de estudos clínicos e } \\
\text { epidemiológicos } \\
\text { Amostra: } 22 \text { artigos de coorte } \\
\text { Análise de dados: descritiva e analítica, com } \\
\text { modelo teórico sobre efeito da paridade e tipo } \\
\text { de parto }\end{array}$ & $\begin{array}{l}\text { Ao longo da vida da mulher, pelo menos } \\
\text { cinco fatores etiológicos ajudam a } \\
\text { explicar a IUE: fatores congênitos, } \\
\text { obesidade, envelhecimento, gestação e } \\
\text { parto vaginal. Esses fatores, que podem } \\
\text { ser contínuos (envelhecimento), } \\
\text { ocasionais (gestação) e reversíveis } \\
\text { (ganho de peso), podem afetar diferentes } \\
\text { partes do complexo do esfíncter uretral. } \\
\text { Faltam estudos conclusivos sobre a } \\
\text { relação causal entre cesariana e menores } \\
\text { taxas de IUE. }\end{array}$ \\
\hline $\begin{array}{l}\text { Hansen et al. } \\
2012 \\
\text { Dinamarca }\end{array}$ & $\begin{array}{l}\text { Investigar o impacto da primeira } \\
\text { gestação e parto na prevalência e } \\
\text { tipos de IU durante a gestação e } \\
\text { um ano após o parto. }\end{array}$ & $\begin{array}{l}\text { Desenho: coorte prospectiva de primíparas com } \\
\text { grupo controle de nulíparas } \\
\text { População: primíparas que deram à luz entre } \\
\text { junho de } 2003 \text { a julho de } 2005 \text { e mulheres } \\
\text { nulíparas residentes na mesma área geográfica, } \\
\text { selecionadas aleatoriamente e pareadas por idade } \\
\text { Amostra: } 1.018 \text { primíparas e } 1.836 \text { nulíparas } \\
\text { Coleta de Dados: questionário com variáveis } \\
\text { sociodemográficas, clínicas, obstétricas e ICIQ- } \\
\text { SF, respondidos pelas primíparas 2-3 dias após o } \\
\text { parto; as nulíparas foram selecionadas através do } \\
\text { registro civil e os questionários foram enviados } \\
\text { via correio; após um ano, as mesmas mulheres de } \\
\text { ambos os grupos receberam os mesmos } \\
\text { questionários via correio } \\
\text { Análise de dados: descritiva, inferencial e } \\
\text { multivariada }\end{array}$ & $\begin{array}{l}\text { Na gestação, a prevalência de IU entre } \\
\text { as nulíparas foi } 13,8 \% \text { e entre as } \\
\text { primíparas foi } 32,1 \% \text { (OR=3,3; } 95 \% \text { IC } \\
2,4-4,4) \text {. Um ano após, a prevalência de } \\
\text { IU entre as nulíparas foi } 16,6 \% \text { e entre } \\
\text { as primíparas foi } 29,3 \%(\mathrm{OR}=2,5 ; \\
95 \% \text { IC } 1,8-3,5) \text {. A média do escore do } \\
\text { ICIQ-SF variou de } 5,8 \text { a } 6,2 \text {, sem } \\
\text { diferença estatisticamente significante } \\
\text { entre os grupos. }\end{array}$ \\
\hline
\end{tabular}


Quadro 1

(cont.)

\begin{tabular}{|c|c|c|c|}
\hline $\begin{array}{l}\text { Autor } \\
\text { Ano } \\
\text { País }\end{array}$ & Objetivos & $\begin{array}{c}\text { Método } \\
\text { Desenho/População/Amostra/Coleta de } \\
\text { dados/Intervenção/Análise dos dados }\end{array}$ & Principais resultados \\
\hline $\begin{array}{l}\text { Hilde et al. } \\
2012 \\
\text { Noruega }\end{array}$ & $\begin{array}{l}\text { Investigar o conhecimento de } \\
\text { gestantes nulíparas sobre os } \\
\text { exercícios perineais e sua prática. } \\
\text { Avaliar sua FMAP e habilidade } \\
\text { para realizar a contração perineal } \\
\text { correta. } \\
\text { Comparar a pressão de repouso, a } \\
\text { força e a resistência dos } \\
\text { músculos do AP em mulheres } \\
\text { continentes e incontinentes. }\end{array}$ & $\begin{array}{l}\text { Desenho: estudo transversal } \\
\text { População: nulíparas com idade gestacional } \\
\text { entre } 18 \text { e } 22 \text { semanas } \\
\text { Amostra: } 300 \text { gestantes } \\
\text { Coleta de dados: ICIQ-SF e avaliação da } \\
\text { função da musculatura do AP (pressão vaginal } \\
\text { de repouso, FMAP e resistência) pela } \\
\text { perineometria (balão vaginal) } \\
\text { Análise de dados: descritiva e inferencial }\end{array}$ & $\begin{array}{l}89 \% \text { das mulheres tinham } \\
\text { informação sobre exercícios } \\
\text { perineais e } 35 \% \text { realizavam uma } \\
\text { ou mais vezes por semana; } 35 \% \\
\text { referiram IU, das quais } 48 \% \\
\text { realizavam exercícios perineais } \\
\text { uma ou mais vezes por semana. } \\
\text { Mulheres continentes tiveram } \\
\text { força e resistência muscular do AP } \\
\text { maior que aquelas com IU, com } \\
\text { diferença estatisticamente } \\
\text { significante. FMAP, em cmH } \mathrm{cm}_{2} \mathrm{O} \text { : } \\
\text { sem IU=37,7 (d.p.=18,0); com } \\
\text { IUE=30,3 (d.p.=17,2); } \mathrm{p}=0,001 \text {. }\end{array}$ \\
\hline $\begin{array}{l}\text { Leroy e Lopes } \\
2012 \\
\text { Brasil }\end{array}$ & $\begin{array}{l}\text { Avaliar se a IU após o parto } \\
\text { compromete a qualidade de vida } \\
\text { relacionada à saúde. }\end{array}$ & $\begin{array}{l}\text { Desenho: estudo de caso-controle } \\
\text { População: mulheres até } 90 \text { dias após o parto, } \\
\text { sem IU prévia à gestação } \\
\text { Amostra: } 74 \text { casos (mulheres com IU) e } 222 \\
\text { controles (mulheres sem IU) } \\
\text { Coleta de dados: ICIQ-SF; KHQ; MOS-SF36 } \\
\text { Análise dos dados: análise descritiva e } \\
\text { inferencial }\end{array}$ & $\begin{array}{l}\text { Sintomas irritativos mais frequentes } \\
\text { foram: frequência }(88,3 \%) \text {, noctúria } \\
(87 \%) \text { e urgência }(54,5 \%) \text {. A } \\
\text { urgência estava associada a IU } \\
\text { mista, mas não a IU de esforço. Pela } \\
\text { aplicação do ICIQ-SF identificou-se } \\
\text { que a perda de urina no puerpério é, } \\
\text { embora geralmente pequena, é } \\
\text { frequente e o impacto na vida diária } \\
\text { elevado. Conclui-se que a IU afeta } \\
\text { significantemente a saúde física e } \\
\text { mental de puérperas }\end{array}$ \\
\hline
\end{tabular}


Quadro 1

\begin{tabular}{|c|c|c|c|}
\hline $\begin{array}{l}\text { Autor } \\
\text { Ano } \\
\text { País }\end{array}$ & Objetivos & $\begin{array}{c}\text { Método } \\
\text { Desenho/População/Amostra/Coleta de } \\
\text { dados/Intervenção/Análise dos dados }\end{array}$ & Principais resultados \\
\hline $\begin{array}{l}\text { Lopes e Praça } \\
2012 \\
\text { Brasil }\end{array}$ & $\begin{array}{l}\text { Caracterizar a ocorrência de } \\
\text { IU autorreferida pela mulher } \\
\text { no período pós-parto. }\end{array}$ & $\begin{array}{l}\text { Desenho: estudo transversal } \\
\text { População: mulheres de qualquer paridade, entre } \\
30 \text { dias e seis meses após o parto } \\
\text { Amostra: } 288 \text { mulheres } \\
\text { Coleta de dados: entrevista } \\
\text { Análise de dados: descritiva e inferencial }\end{array}$ & $\begin{array}{l}\text { IU: prevalência }=74,6 \% ; \\
\text { gravidade }=74,7 \% \text { moderada; } \\
43,3 \% \text { mulheres de cor branca } \\
(\mathrm{p}=0,0043) ; 14,1 \% \text { informaram a } \\
\text { IU ao profissional de saúde; } 28,2 \% \\
\text { referiram interferência da IU na } \\
\text { qualidade de vida; } 63,4 \% \\
\text { atribuíram como causa aspectos } \\
\text { relacionados à gestação e parto }\end{array}$ \\
\hline $\begin{array}{l}\text { Stafne et al. } \\
2012 \\
\text { Noruega }\end{array}$ & $\begin{array}{l}\text { Avaliar se as gestantes com } \\
\text { seguimento de exercícios } \\
\text { gerais, incluindo exercícios } \\
\text { perineais, eram menos } \\
\text { propensas a relatar IU e IA no } \\
\text { final da gestação, em } \\
\text { comparação com gestantes que } \\
\text { receberam o cuidado pré-natal } \\
\text { padrão. }\end{array}$ & $\begin{array}{l}\text { Desenho: ensaio clínico } \\
\text { População: gestantes de baixo risco com feto único e } \\
\text { idade maior ou igual a } 18 \text { anos } \\
\text { Amostra: } 855 \text { gestantes ( } 397 \text { no grupo intervenção e } \\
365 \text { no grupo controle) } \\
\text { Coleta de dados: questionário com questões } \\
\text { relacionadas à IU e IA, respondido antes (18-22 } \\
\text { semanas de gestação) e após a intervenção (32-36 } \\
\text { semanas de gestação) } \\
\text { Intervenção: sessões semanais de } 60 \text { minutos de } \\
\text { exercícios, acompanhadas por fisioterapeuta, por } 12 \\
\text { semanas; as sessões incluíram instruç̃̃es sobre } \\
\text { anatomia e contração do AP e as gestantes foram a } \\
\text { realizar os exercícios em casa, três vezes por semana } \\
\text { ou mais; as gestantes do grupo controle receberam o } \\
\text { acompanhamento pré-natal padrão; todas gestantes } \\
\text { receberam orientação sobre FMAP por escrito } \\
\text { Análise de dados: inferencial e multivariada }\end{array}$ & $\begin{array}{l}\text { Entre as gestantes do grupo } \\
\text { intervenção: melhor adesão aos } \\
\text { exercícios em casa; menor } \\
\text { prevalência de IU nas nulíparas; } \\
\text { menos mulheres relataram IU } \\
(11 \% \text { contra } 19 \%, \mathrm{p}=0,004) ; \\
\text { menos mulheres relataram } \\
\text { incontinência fecal (3\% contra } \\
5 \%), \text { mas essa diferença não foi } \\
\text { estatisticamente significante. } \\
\text { Exercícios perineais previnem e } \\
\text { tratam IU e IA na gravidez; as } \\
\text { instruções devem ser completas, } \\
\text { com orientação sobre AP nas aulas } \\
\text { de ginástica para mulheres } \\
\text { grávidas. }\end{array}$ \\
\hline
\end{tabular}

(continua) 
Quadro 1

(cont.)

\begin{tabular}{|c|c|c|c|}
\hline $\begin{array}{l}\text { Autor } \\
\text { Ano } \\
\text { País }\end{array}$ & Objetivos & $\begin{array}{c}\text { Método } \\
\text { Desenho/População/Amostra/Coleta de } \\
\text { dados/Intervenção/Análise dos dados }\end{array}$ & Principais resultados \\
\hline $\begin{array}{l}\text { Torrisi et al. } \\
2012 \\
\text { Itália }\end{array}$ & $\begin{array}{l}\text { Estimar a prevalência e o } \\
\text { impacto da IU e IA na qualidade } \\
\text { de vida das mulheres. } \\
\text { Identificar os riscos } \\
\text { constitucionais e obstétricos } \\
\text { relacionados à IU e IA com foco } \\
\text { da análise nas mulheres } \\
\text { sintomáticas após o parto. } \\
\text { Avaliar as possíveis mudanças no } \\
\text { comportamento sexual e } \\
\text { modificações constitucionais do } \\
\text { AP após o parto. }\end{array}$ & $\begin{array}{l}\text { Desenho: estudo prospectivo, multicêntrico } \\
\text { População: nulíparas que acabaram de ter } \\
\text { bebes de termo } \\
\text { Amostra: } 960 \text { mulheres ( } 744 \text { incluídas) } \\
\text { Coleta de dados: ICIQ-SF, escala Wernex } \\
\text { Continence Garding (avalia incontinência anal } \\
\text { e quatro questões que avaliam o impacto do } \\
\text { parto na vida sexual nas últimas } 8 \text { semanas } \\
\text { antes do parto). Mulheres avaliadas em 2-3 } \\
\text { dias após o parto e por } 3 \text { meses depois } \\
\text { Análise dos dados: descritiva, inferencial e } \\
\text { regressão logística }\end{array}$ & $\begin{array}{l}\text { Perda estatisticamente significante } \\
\text { após } 3 \text { meses de seguimento em } \\
\text { relação às características } \\
\text { Na primeira avaliação IU e IA } \\
\text { apareceu em } 21,6 \% \text { e } 16,3 \% \text { e } \\
5,8 \% \text { referiu os dois tipos } \\
\text { Após } 3 \text { meses a IU foi citada por } \\
61 \% \text { das mulheres, destes, } 15,5 \% \\
\text { IU de urgência e } 12,4 \% \text { mista. A } \\
\text { IU durante a gestação foi um } \\
\text { preditor independente para UI } \\
\text { persistente. IA antes da gestação } \\
\text { apareceu em } 33 \% \text {, após o parto } \\
39 \% \text { e após } 3 \text { meses do parto } 27 \% \text {. } \\
\text { O parto vaginal foi um forte fator } \\
\text { para a IU. }\end{array}$ \\
\hline
\end{tabular}




\begin{tabular}{|c|c|c|c|}
\hline $\begin{array}{c}\text { Autor } \\
\text { Ano } \\
\text { País }\end{array}$ & Objetivos & $\begin{array}{c}\text { Método } \\
\text { Desenho/População/Amostra/Coleta de } \\
\text { dados/Intervenção/Análise dos dados }\end{array}$ & Principais resultados \\
\hline $\begin{array}{l}\text { Wesnes, } \\
\text { Hunskaar e } \\
\text { Rortveit } \\
2012\end{array}$ & $\begin{array}{l}\text { Analisar a incidência e } \\
\text { prevalência de IU na gestação e } \\
\text { após o parto e as diferenças } \\
\text { metodológicas entre as pesquisas } \\
\text { sobre IU. }\end{array}$ & $\begin{array}{l}\text { Desenho: capítulo de livro sobre revisão de } \\
\text { literatura } \\
\text { População: artigos selecionados com base na } \\
\text { relevância, qualidade, citação e tamanho da } \\
\text { amostra } \\
\text { Amostra: } 19 \text { artigos sobre a incidência de IU } \\
\text { na gestação ( } 11 \text { coortes e } 8 \text { estudos } \\
\text { transversais) e } 21 \text { artigos sobre prevalência de } \\
\text { IU na gestação (12 coortes e } 9 \text { estudos } \\
\text { transversais) } \\
\text { Análise de dados: descritiva }\end{array}$ & $\begin{array}{l}\text { A incidência de IU na gestação } \\
\text { variou de } 11-50 \% \text { nas nulíparas e } \\
\text { de } 8-57 \% \text { nas multíparas; na } \\
\text { maioria dos estudos, a variação foi } \\
\text { de } 28-45 \% \text { e } 45-54 \% \text {, } \\
\text { respectivamente. A prevalência } \\
\text { variou de } 4-70 \% \text { nas nulíparas e de } \\
14-85 \% \text { nas multíparas; na maioria } \\
\text { dos estudos, a variação foi de 35- } \\
55 \% \text { e de } 24-67 \% \text {, } \\
\text { respectivamente. Os fatores que } \\
\text { contribuem para variação nas taxas } \\
\text { de incidência e prevalência de IU } \\
\text { na gestação são: diferença de } \\
\text { definições, tipo de estudo, métodos } \\
\text { de coleta de dados, momento e } \\
\text { tipo de informação coletada, } \\
\text { população estudada, tipo de IU, } \\
\text { questionários usados e viés de } \\
\text { seleção. }\end{array}$ \\
\hline
\end{tabular}


Quadro 1

(cont.)

\begin{tabular}{|c|c|c|c|}
\hline $\begin{array}{l}\text { Autor } \\
\text { Ano } \\
\text { País }\end{array}$ & Objetivos & $\begin{array}{c}\text { Método } \\
\text { Desenho/População/Amostra/Coleta de } \\
\text { dados/Intervenção/Análise dos dados }\end{array}$ & Principais resultados \\
\hline $\begin{array}{l}\text { Barbosa et al. } \\
2011 \\
\text { Brasil }\end{array}$ & $\begin{array}{l}\text { Avaliar a prevalência de } \\
\text { incontinência urinária e a FMP } \\
\text { em primíparas dois anos após a } \\
\text { cesariana em mulheres com e } \\
\text { sem diabetes mellitus gestacional } \\
\text { (DMG) prévio }\end{array}$ & $\begin{array}{l}\text { Desenho: estudo transversal } \\
\text { População: mulheres primíparas, dois anos } \\
\text { após a cesariana } \\
\text { Amostra: } 63 \text { mulheres com DMG e } 98 \text { sem } \\
\text { DMG } \\
\text { Coleta de dados: entrevista; ICQ-SF; } \\
\text { perineometria (Perina) } \\
\text { Análise de dados: descritiva, inferencial e } \\
\text { multivariada }\end{array}$ & $\begin{array}{l}\text { UI: prevalência > entre mulheres com } \\
\text { DMG ( } 50,8 \% \text { contra } 31,6 \% \text {, na } \\
\text { gestação; } 44,8 \% \text { contra } 18,4 \% \text {, dois } \\
\text { anos depois da cesariana); FMP: } \\
\text { diminuição significativamente maior } \\
\text { entre mulheres com DMG }(53,9 \% \\
\text { contra } 37,8 \%) \text {. Ganho de peso } \\
\text { materno e peso do RN: fatores de } \\
\text { risco para redução da FMAP } \\
\text { (OR=1,3). Idade materna, IU na } \\
\text { gestação e FMAP reduzida: fatores de } \\
\text { risco para IU dois anos depois da } \\
\text { cesariana }(\mathrm{OR}=1,2 ; 5,0 ; 20,4, \\
\text { respectivamente). DMG foi um fator } \\
\text { de risco independente para a IU na } \\
\text { gestação (OR=2,3) }\end{array}$ \\
\hline $\begin{array}{l}\text { Bø e Haakstad } \\
2011 \\
\text { Noruega }\end{array}$ & $\begin{array}{l}\text { Avaliar os efeitos do treinamento } \\
\text { da musculatura do AP como } \\
\text { parte de uma aula de exercícios } \\
\text { para gestantes com o objetivo de } \\
\text { prevenir e tratar IU e IA. }\end{array}$ & $\begin{array}{l}\text { Desenho: ensaio clínico controlado e cego } \\
\text { População: gestantes primíparas sedentárias } \\
\text { Amostra: } 105 \text { gestantes ( } 53 \text { no grupo de estudo e } \\
52 \text { no grupo controle) } \\
\text { Coleta de dados: ICIQ-SF e ISI, no início e ao } \\
\text { término do programa de exercícios e entre seis e } \\
\text { oito semanas pós-parto } \\
\text { Intervenção: gestantes do grupo de estudo } \\
\text { receberam aulas, com exercícios para o } \\
\text { fortalecimento do AP, por doze semanas; aquelas } \\
\text { do grupo controle receberam cuidado usual } \\
\text { Análise de dados: descritiva e inferencial }\end{array}$ & $\begin{array}{l}\text { Perda da amostra de } 19 \% \text { no grupo } \\
\text { intervenção e } 21 \% \text { no grupo } \\
\text { controle. Não houve diferença } \\
\text { significante entre as mulheres que } \\
\text { se queixaram de IU e IA, nos dois } \\
\text { grupos. }\end{array}$ \\
\hline
\end{tabular}


Quadro 1

\begin{tabular}{|c|c|c|c|}
\hline $\begin{array}{c}\text { Autor } \\
\text { Ano } \\
\text { País } \\
\end{array}$ & Objetivos & $\begin{array}{c}\text { Método } \\
\text { Desenho/População/Amostra/Coleta de } \\
\text { dados/Intervenção/Análise dos dados }\end{array}$ & Principais resultados \\
\hline $\begin{array}{l}\text { Elenskaia et } \\
\text { al. } \\
2011 \\
\text { Reino Unido }\end{array}$ & $\begin{array}{l}\text { Avaliar a função dos músculos } \\
\text { do AP no primeiro e segundo } \\
\text { trimestres da gestação e após o } \\
\text { parto. }\end{array}$ & $\begin{array}{l}\text { Desenho: coorte prospectiva } \\
\text { População: gestantes de baixo risco com } \\
\text { gestação única } \\
\text { Amostra: } 403 \text { gestantes (182 nulíparas e } 221 \\
\text { multíparas) } \\
\text { Coleta de dados: informações demográficas, } \\
\text { clínica, obstétricas e sobre realização de } \\
\text { exercícios perineais, perineometria (balão } \\
\text { vaginal) e palpação digital, avaliadas no } \\
\text { segundo e terceiro trimestres da gestação } \\
\text { Análise de dados: descritiva e inferencial }\end{array}$ & $\begin{array}{l}\text { Na perineometria, a pressão de } \\
\text { repouso e de contração máxima } \\
\text { aumentou significativamente } \\
\text { durante a gestação, tanto nas } \\
\text { primíparas como nas multíparas. O } \\
\text { aumento da pressão de contração } \\
\text { máxima foi maior entre as } \\
\text { gestantes que realizaram exercícios } \\
\text { perineais regularmente. }\end{array}$ \\
\hline $\begin{array}{l}\text { Gameiro et al. } \\
2011 \\
\text { Brasil }\end{array}$ & $\begin{array}{l}\text { Comparar a FMAP entre } \\
\text { mulheres nulíparas e multíparas. }\end{array}$ & $\begin{array}{l}\text { Desenho: estudo prospectivo } \\
\text { População: gestantes nulíparas e primíparas } \\
\text { continentes antes da gestação } \\
\text { Amostra: } 100 \text { mulheres ( } 50 \text { nulíparas e } 50 \\
\text { multíparas) } \\
\text { Coleta de dados: questionário clínico, } \\
\text { perineometria (Dynamed) e palpação digital } \\
\text { no segundo e terceiro trimestres de gestação, } \\
\text { em diferentes posições (deitada com as pernas } \\
\text { estendidas, fletidas e sentada) } \\
\text { Análise de dados: descritiva, inferencial e } \\
\text { multivariada }\end{array}$ & $\begin{array}{l}\text { Entre as primíparas, } 19 \% \text { relataram } \\
\text { IU no segundo trimestre de } \\
\text { gestação e } 27 \% \text {, no terceiro } \\
\text { trimestre. Na perineometria, não } \\
\text { houve diferença estatisticamente } \\
\text { significante entre as nulíparas e } \\
\text { primíparas no segundo e terceiro } \\
\text { trimestres de gestação. }\end{array}$ \\
\hline
\end{tabular}

(continua) 
Quadro 1

(cont.)

\begin{tabular}{|l|l|l|l|}
\hline \multicolumn{1}{|c|}{$\begin{array}{c}\text { Autor } \\
\text { Ano } \\
\text { País }\end{array}$} & \multicolumn{1}{|c|}{ Objetivos } & \multicolumn{1}{c|}{$\begin{array}{c}\text { Método } \\
\text { Desenho/População/Amostra/Coleta de } \\
\text { dados/Intervenção/Análise dos dados }\end{array}$} & \multicolumn{1}{c|}{ Principais resultados } \\
\hline $\begin{array}{l}\text { Hay-Smith et } \\
\text { al. }\end{array} 2011$ & $\begin{array}{l}\text { Determinar o efeito do } \\
\text { treinamento dos músculos do AP } \\
\text { na IU, comparado aos cuidados } \\
\text { usuais no pré-natal e pós-parto. }\end{array}$ & $\begin{array}{l}\text { Desenho: revisão sistemática Cochrane } \\
\text { População: ensaios clínicos randomizados e } \\
\text { quasi-randomizados na gestação e no pós- } \\
\text { parto, em que todos os estudos utilizaram } \\
\text { treinamento da FMAP } \\
\text { Amostra: 16 estudos, envolvendo 6.181 } \\
\text { mulheres (3.040 no grupo intervenção e 3.141 } \\
\text { no grupo controle) } \\
\text { Análise de dados: descritiva e metanálise }\end{array}$ & $\begin{array}{l}\text { Há alguma evidência de que } \\
\text { exercícios perineais em mulheres } \\
\text { primíparas podem evitar IU no } \\
\text { final da gravidez e após o parto. } \\
\text { Gestantes sem IU que foram } \\
\text { randomizadas para o programa de } \\
\text { exercícios perineais no pré-natal } \\
\text { foram menos propensas a relatar } \\
\text { IU no final da gestação que } \\
\text { aquelas randomizadas para } \\
\text { cuidados usuais (cerca de 56\% } \\
\text { menos; RR=0,44; } 95 \% \text { IC 0,30- } \\
0,65) \text {. É possível que os efeitos do } \\
\text { treinamento sejam maiores na } \\
\text { população-alvo, mas não em } \\
\text { mulheres que tiveram } \\
\text { hipermobilidade do colo da bexiga } \\
\text { no início da gravidez, bebê grande, } \\
\text { ou parto fórceps. São necessários } \\
\text { mais estudos para determinar a } \\
\text { eficácia em longo prazo. }\end{array}$ \\
\end{tabular}

(continua) 
Quadro 1

\begin{tabular}{|c|c|c|c|}
\hline & & & \\
\hline $\begin{array}{l}\text { Autor } \\
\text { Ano } \\
\text { País }\end{array}$ & Objetivos & $\begin{array}{c}\text { Método } \\
\text { Desenho/População/Amostra/Coleta de } \\
\text { dados/Intervencão/Análise dos dados }\end{array}$ & Principais resultados \\
\hline $\begin{array}{l}\text { Ko et al. } \\
2011 \\
\text { Taiwan }\end{array}$ & $\begin{array}{l}\text { Avaliar o efeito do exercício da } \\
\text { musculatura do AP durante o pré- } \\
\text { natal na prevenção e no } \\
\text { tratamento da IU durante a } \\
\text { gravidez e após o parto. }\end{array}$ & $\begin{array}{l}\text { Desenho: ensaio clínico } \\
\text { População: gestantes nulíparas entre } 16 \text { e } 24 \\
\text { semanas de gestação única } \\
\text { Amostra: } 300 \text { gestantes ( } 150 \text { no grupo de } \\
\text { intervenção e } 150 \text { no grupo controle) } \\
\text { Coleta de dados: entrevista com os } \\
\text { questionários IIQ-7 e UDI-6 e mais duas } \\
\text { questões sobre perda de urina; todas as } \\
\text { mulheres foram entrevistadas com } 36 \text { semanas } \\
\text { de gestação e três dias pós-parto, } \\
\text { pessoalmente por enfermeiras, e seis semanas } \\
\text { e seis meses após parto, via telefone } \\
\text { Intervenção: orientação, exercícios realizados } \\
\text { em casa, duas vezes ao dia, e treinamento em } \\
\text { grupo com } 10 \text { gestantes, uma vez por semana, } \\
\text { acompanhado por fisioterapeuta, e } \\
\text { preenchimento de diário de exercícios; as } \\
\text { gestantes do grupo controle receberam } \\
\text { cuidado usual } \\
\text { Análise de dados: descritiva, inferencial e } \\
\text { multivariada }\end{array}$ & $\begin{array}{l}\text { No grupo de intervenção: } \\
\text { pontuações menores no IIQ-7 e } \\
\text { UDI-6, ao final da gravidez e no } \\
\text { período pós-parto, e menor } \\
\text { incidência de IU, no final da } \\
\text { gravidez e no sexto mês pós-parto. } \\
\text { Mulheres com parto vaginal foram } \\
\text { mais predispostas a desenvolver IU } \\
\text { no pós-parto. No sexto mês pós- } \\
\text { parto, não houve diferença } \\
\text { estatisticamente significante no } \\
\text { grupo que realizou exercícios } \\
\text { perineais. Os exercícios da } \\
\text { musculatura do AP durante a } \\
\text { gravidez são efetivos na prevenção } \\
\text { e no tratamento da IU. }\end{array}$ \\
\hline
\end{tabular}

(continua) 
Quadro 1

(cont.)

\begin{tabular}{|c|c|c|c|}
\hline $\begin{array}{l}\text { Autor } \\
\text { Ano } \\
\text { País }\end{array}$ & Objetivos & $\begin{array}{c}\text { Método } \\
\text { Desenho/População/Amostra/Coleta de } \\
\text { dados/Intervencão/Análise dos dados }\end{array}$ & Principais resultados \\
\hline $\begin{array}{l}\text { Sangsawang e } \\
\text { Serisathien } \\
2011 \\
\text { Tailândia }\end{array}$ & $\begin{array}{l}\text { Examinar os efeitos de um programa } \\
\text { de exercícios da musculatura do AP } \\
\text { na IU de esforço severa, em } \\
\text { mulheres grávidas. }\end{array}$ & $\begin{array}{l}\text { Desenho: ensaio clínico quasi-experimental } \\
\text { População: gestantes com queixa de IU de estresse } \\
\text { durante a gestação (moderada ou severa) } \\
\text { Amostra: } 66 \text { gestantes ( } 31 \text { no grupo experimental- } \\
\text { GE- e } 35 \text { no grupo controle-GC) } \\
\text { Coleta de dados: grupo experimental realizou } \\
\text { programa de treinamento para a musculatura do } \\
\text { AP e grupo controle recebeu os cuidados usuais } \\
\text { Intervenção: programa de treinamento do AP } \\
\text { quinzenal, entre } 20 \text { e } 30 \text { semanas de gestação, } \\
\text { durante seis semanas, em grupos de duas a cinco } \\
\text { gestantes, em sessões de } 45 \text { minutos; a realização } \\
\text { dos exercícios foi registrada em um diário; grupo } \\
\text { controle recebeu cuidado usual } \\
\text { Análise de dados: descritiva, inferencial e } \\
\text { multivariada }\end{array}$ & $\begin{array}{l}\text { A quantidade da perda de urina no GE } \\
\text { foi significantemente menor que antes } \\
\text { da intervenção. Um terço das } \\
\text { mulheres não apresentou perda de } \\
\text { urina. Houve diminuição da } \\
\text { frequência e do volume de IU por } \\
\text { esforço. A média do escore da } \\
\text { percepção da severidade da perda de } \\
\text { urina por estresse teve diferenças } \\
\text { estatisticamente significantes, em } \\
\text { comparação com as mulheres do GC. } \\
\text { A média da frequência da IUE no } \\
\text { grupo controle foi significantemente } \\
\text { aumentado em relação a volume, } \\
\text { frequência e percepção da severidade } \\
\text { da perda de urina. O programa de } \\
\text { treinamento do AP de seis semanas é } \\
\text { capaz de reduzir a severidade dos } \\
\text { sintomas de IU por estresse na mulher } \\
\text { gestante. }\end{array}$ \\
\hline $\begin{array}{l}\text { Valeton e } \\
\text { Amaral } \\
2011 \\
\text { Brasil }\end{array}$ & $\begin{array}{l}\text { Determinar a prevalência de IU no } \\
\text { terceiro trimestre da gestação e no } \\
\text { período pós-parto avaliar a FMAP e a } \\
\text { qualidade de vida. }\end{array}$ & $\begin{array}{l}\text { Desenho: estudo prospectivo } \\
\text { População: gestantes de um serviço de pré-natal } \\
\text { Amostra: } 343 \text { mulheres, com } 28 \text { semanas de } \\
\text { gestação, sem infecção urinária, problemas } \\
\text { ginecológicos e história cirúrgica ginecológica } \\
\text { Coleta de dados: avaliação fisioterapêutica para } \\
\text { identificar IU; avaliação da função do AP com } \\
\text { perineômetro (Perina), em posição litotômica; } \\
\text { aplicação do KQH, nas mulheres com IU } \\
\text { Análise de dados: descritiva, inferencial e } \\
\text { multivariada }\end{array}$ & 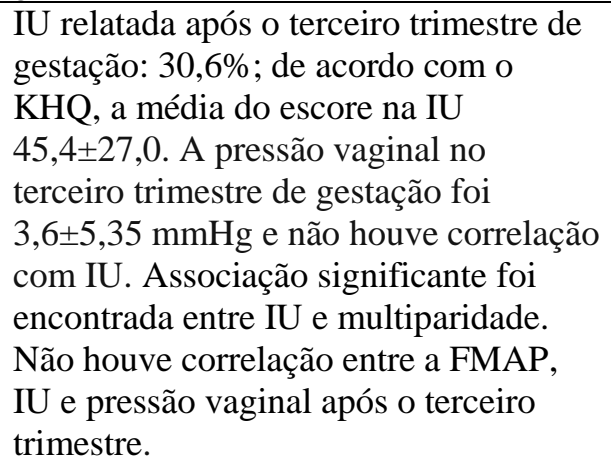 \\
\hline
\end{tabular}

(continua) 


\begin{tabular}{|c|c|c|c|}
\hline $\begin{array}{l}\text { Autor } \\
\text { Ano } \\
\text { País }\end{array}$ & Objetivos & $\begin{array}{c}\text { Método } \\
\text { Desenho/População/Amostra/Coleta de } \\
\text { dados/Intervenção/Análise dos dados }\end{array}$ & Principais resultados \\
\hline $\begin{array}{l}\text { Caroci et al. } \\
2010 \\
\text { Brasil }\end{array}$ & $\begin{array}{l}\text { Comparar as medidas da FMAP } \\
\text { durante a gestação e no período } \\
\text { pós-parto segundo idade materna, } \\
\text { cor da pele, situação marital, dor } \\
\text { na relação sexual, estado } \\
\text { nutricional, características das } \\
\text { fezes, tipo de parto, condição do } \\
\text { períneo e peso do recém-nascido. }\end{array}$ & $\begin{array}{l}\text { Desenho: coorte prospectiva } \\
\text { População: gestantes nulíparas com até } 12 \\
\text { semanas de gestação } \\
\text { Amostra: } 226 \text { gestantes incluídas, com } \\
\text { segmento de } 110 \text { mulheres até o final do } \\
\text { estudo } \\
\text { Coleta de dados: entrevista estruturada, } \\
\text { avaliação da FMAP com o perineometria } \\
\text { (Perina) e palpação digital vaginal (escala } \\
\text { de Oxford); os dados foram coletados em } \\
\text { quatro etapas (até } 12 \text { semanas de gestação; } \\
\text { entre } 36-40 \text { semanas de gestação; } 48 \mathrm{~h} \text { após } \\
\text { o parto; } 42 \text { a } 60 \text { dias após o parto) } \\
\text { Análise de dados: descritiva e inferencial }\end{array}$ & $\begin{array}{l}\text { Não houve variação significante entre } \\
\text { a FMAP no início, no final da } \\
\text { gestação e no período pós-parto. Nas } \\
\text { etapas } 1,2 \text { e } 4 \text { do estudo, a média da } \\
\text { FMAP, em mmHg, foi } 15,9 ; 15,2 ; \\
14,7 \text {, respectivamente, com Oxford de } \\
0-3 \text {. }\end{array}$ \\
\hline $\begin{array}{l}\text { Huerbner, } \\
\text { Antolic e } \\
\text { Tunn } \\
2010 \\
\text { Alemanha }\end{array}$ & $\begin{array}{l}\text { Identificar mulheres que tiveram } \\
\text { IU antes, durante e após a } \\
\text { gestação e identificar se as } \\
\text { mulheres que tiveram sintomas } \\
\text { durante a gestação são as mesmas } \\
\text { que tiveram IU no pós-parto. }\end{array}$ & $\begin{array}{l}\text { Desenho: coorte } \\
\text { População: } 1.677 \text { mulheres, correspondendo a } \\
\text { todas as gestantes que tiveram parto no ano de } \\
\text { 1999, em um hospital em Berlin } \\
\text { Amostra: } 610 \text { gestantes } \\
\text { Coleta de dados: todas as mulheres que fizeram } \\
\text { ultrassom no início da gestação receberam um } \\
\text { questionário com questões específicas sobre a } \\
\text { função do AP incluindo UI; os sintomas de UI } \\
\text { foram avaliados em cinco momentos diferentes } \\
\text { durante a gestação e no pós-parto } \\
\text { Análise de dados: análise descritiva e } \\
\text { inferencial }\end{array}$ & $\begin{array}{l}\text { O questionário foi respondido por } 411 \\
\text { gestantes; a prevalência de IU aumentou } \\
\text { significativamente na segunda metade da } \\
\text { gestação }(26,3 \% ; \mathrm{p}<0,001) \text {. Praticamente } \\
\text { o mesmo número de mulheres que relatou } \\
\text { IU na segunda metade da gestação, } \\
\text { reportou a queixa dentro de seis semanas } \\
\text { após o parto. O grupo de mulheres que } \\
\text { relatou IU antes do parto foi diferente do } \\
\text { grupo que relatou após o parto e vice- } \\
\text { versa. A gestação, por si só, pode } \\
\text { influenciar na função do AP de diferentes } \\
\text { maneiras, quando comparada com o parto } \\
\text { vaginal. }\end{array}$ \\
\hline
\end{tabular}


Quadro 1

(cont.)

\begin{tabular}{|c|c|c|c|}
\hline $\begin{array}{c}\text { Autor } \\
\text { Ano } \\
\text { País }\end{array}$ & Objetivos & $\begin{array}{c}\text { Método } \\
\text { Desenho/População/Amostra/Coleta de } \\
\text { dados/Intervenção/Análise dos dados }\end{array}$ & Principais resultados \\
\hline $\begin{array}{l}\text { Solans- } \\
\text { Domènech, } \\
\text { Sanchez e } \\
\text { Espuna-Pons } \\
2010 \\
\text { Espanha }\end{array}$ & $\begin{array}{l}\text { Estimar a frequência e severidade e } \\
\text { identificar os fatores de risco de IU } \\
\text { e IA durante a gestação e após o } \\
\text { parto. }\end{array}$ & $\begin{array}{l}\text { Desenho: coorte } \\
\text { População: gestantes nulíparas continentes } \\
\text { atendidas no serviço público de saúde } \\
\text { Amostra: } 1128 \text { gestantes nulíparas continentes } \\
\text { Coleta de dados: informações } \\
\text { sociodemográficas, clínicas e obstétricas, ISI e } \\
\text { ICIQ-SF para IA e Jorge e Wexner Faecal } \\
\text { Continence Grading Scale, aplicados no } \\
\text { primeiro, segundo e terceiro trimestres da } \\
\text { gestação e no pós-parto. } \\
\text { Análise de dados: descritiva e multivariada }\end{array}$ & 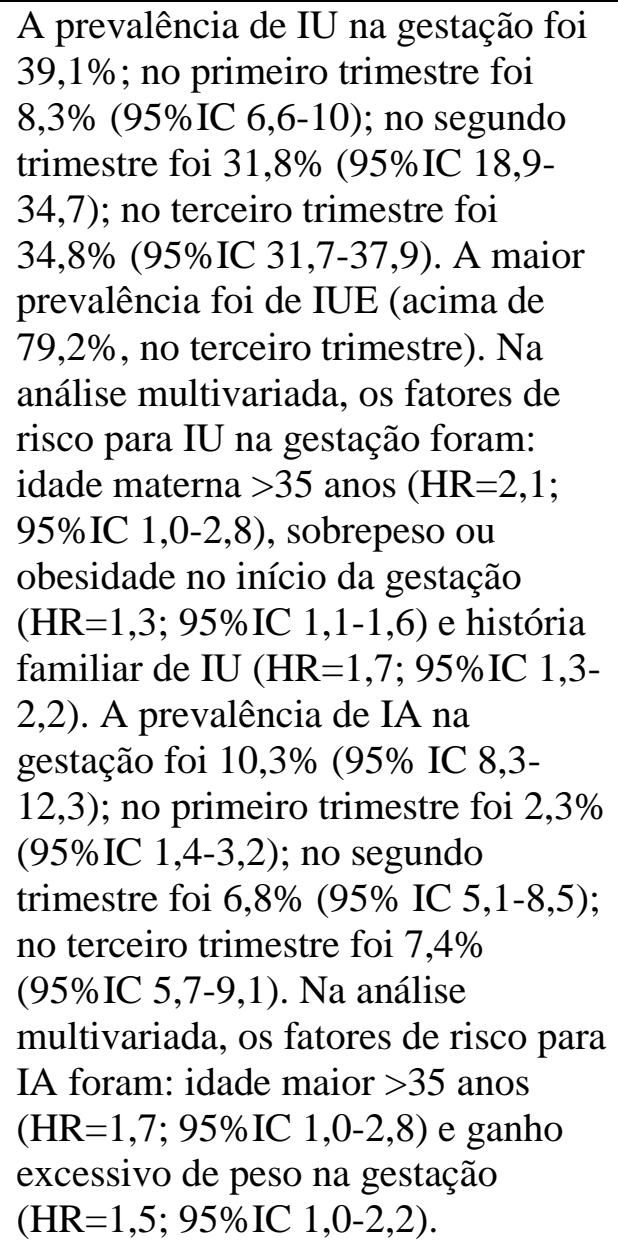 \\
\hline
\end{tabular}

(continua) 
Quadro 1

\begin{tabular}{|c|c|c|}
\hline $\begin{array}{l}\text { Autor } \\
\text { Ano } \\
\text { País }\end{array}$ & Objetivos & $\begin{array}{c}\text { Método } \\
\text { Desenho/População/Amostra/Coleta de } \\
\text { dados/Intervenção/Análise dos dados }\end{array}$ \\
\hline $\begin{array}{l}\text { Dinc, Beji e } \\
\text { Yalcin } \\
2009 \\
\text { Turquia }\end{array}$ & $\begin{array}{l}\text { Determinar a eficácia de } \\
\text { exercícios para os músculos do } \\
\text { AP sobre a IU durante a gravidez } \\
\text { e no período pós-parto. }\end{array}$ & $\begin{array}{l}\text { Desenho: ensaio clínico } \\
\text { População: mulheres com IU na gestação } \\
\text { Amostra: } 78 \text { gestantes ( } 33 \text { no grupo controle e } \\
35 \text { no grupo de intervenção) } \\
\text { Coleta de dados: avaliação da FMAP com } \\
\text { perineômetro (Peritron), 1-h de padtests, } \\
\text { palpação digital e diário miccional } \\
\text { Intervenção: as mulheres foram orientadas } \\
\text { quanto à realização da contração dos músculos } \\
\text { do AP antes da avaliação; aquelas do grupo de } \\
\text { estudo foram treinadas para realizarem a } \\
\text { contração corretamente e só depois foram } \\
\text { incluídas no protocolo de treinamento com } \\
\text { exercicios diários e graduais para serem } \\
\text { realizados em casa; uma semana depois, essas } \\
\text { mulheres foram avaliadas novamente e as que } \\
\text { realizaram de forma incorreta a contração } \\
\text { foram submetidas novamente ao treinamento e } \\
\text { reavaliadas após uma semana; os exercícios } \\
\text { também eram verificados durante as consultas } \\
\text { de pré-natal; o grupo controle não recebeu } \\
\text { orientações para realização dos exercícios; a } \\
\text { avaliação da FMAP foi realizada entre } 36 \text { e } 38 \\
\text { semanas de gestação e entre seis e oito } \\
\text { semanas após o parto, em ambos os grupos } \\
\text { Análise de dados: descritiva, inferencial e } \\
\text { multivariada }\end{array}$ \\
\hline
\end{tabular}

\section{Principais resultados}

Prevalência de IU de $48,8 \%$ no primeiro trimestre; $25 \%$ tinham IU antes da gestação, $32,5 \%$

começaram a ter IU no segundo trimestre e 18,8\% desenvolveram no terceiro trimestre. A média da perineometria, em $\mathrm{cmH}_{2} \mathrm{O}$, foi: $28,1 \pm 13,0$ (grupo intervenção) e $30,1 \pm 11,1$ (grupo controle). Houve redução estatisticamente significante dos episódios de IU no grupo intervenção. Os resultados mostraram que os exercícios para o AP durante a gestação e no pósparto têm o mesmo efeito para prevenir e tratar IU, por melhorar a FMAP. Porém, não é possível afirmar que é a única causa que reduz a incontinência. 
Quadro 1

(cont.)

\begin{tabular}{|c|c|c|c|}
\hline $\begin{array}{c}\text { Autor } \\
\text { Ano } \\
\text { País } \\
\end{array}$ & Objetivos & $\begin{array}{c}\text { Método } \\
\text { Desenho/População/Amostra/Coleta de } \\
\text { dados/Intervenção/Análise dos dados }\end{array}$ & Principais resultados \\
\hline $\begin{array}{l}\text { Ismail } \\
2009 \\
\text { Reino Unido }\end{array}$ & $\begin{array}{l}\text { Auditoria sobre a consciência das } \\
\text { gestantes e o cumprimento das } \\
\text { diretrizes do National Institute } \\
\text { for Health and Clinical } \\
\text { Excellence (NICE) sobre os } \\
\text { exercícios do AP durante a } \\
\text { gestação. }\end{array}$ & $\begin{array}{l}\text { Desenho: transversal } \\
\text { População: } 400 \text { gestantes receberam o } \\
\text { questionário } \\
\text { Amostra: } 223 \text { questionários retornaram } \\
\text { Coleta de dados: questionários } \\
\text { autorespondidos, distribuídos a mulheres que } \\
\text { tiveram o primeiro parto em um período de até } \\
\text { seis meses após o parto, no período de março a } \\
\text { setembro de } 2007 \\
\text { Análise de dados: descritiva }\end{array}$ & $\begin{array}{l}\text { Os questionários foram } \\
\text { respondidos por } 223 \text { mulheres. A } \\
\text { maioria recebeu informações sobre } \\
\text { FMAP }(95,1 \%) \text {; em } 50 \% \text { dos } \\
\text { casos, a orientação foi realizada } \\
\text { pela parteira e } 66,4 \% \text { receberam } \\
\text { orientação do livro da gestação } \\
\text { (fornecido pelo serviço de saúde). } \\
\text { A orientações dadas, na maioria } \\
\text { das vezes, não estavam corretas, } \\
\text { em relação a quantidade de } \\
\text { exercícios e a forma de sua } \\
\text { realização; a minoria praticou os } \\
\text { exercícios de AP. O material } \\
\text { impresso mostrou ser muito } \\
\text { influente para comunicar a } \\
\text { mensagem. É importante que se dê } \\
\text { a informação correta no início da } \\
\text { gestação. Percebeu-se que a } \\
\text { conscientização e a prática de } \\
\text { exercícios para AP no pré-natal } \\
\text { não atenderam às diretrizes do } \\
\text { NICE. É necessário melhorar as } \\
\text { estratégias de sensibilização e } \\
\text { adesão. }\end{array}$ \\
\hline
\end{tabular}


Quadro 1

\begin{tabular}{|c|c|c|c|}
\hline $\begin{array}{l}\text { Autor } \\
\text { Ano } \\
\text { País }\end{array}$ & Objetivos & $\begin{array}{c}\text { Método } \\
\begin{array}{c}\text { Desenho/População/Amostra/Coleta de } \\
\text { dados/Intervenção/Análise dos dados }\end{array}\end{array}$ & Principais resultados \\
\hline $\begin{array}{l}\text { Klovning et } \\
\text { al. } \\
2009 \\
\text { Noruega }\end{array}$ & $\begin{array}{l}\text { Comparar o ICIQ-SF com o ISI e } \\
\text { propor intervalos para os quatro } \\
\text { níveis de severidade do ICIQ-SF. }\end{array}$ & $\begin{array}{l}\text { Desenho: estudo transversal } \\
\text { População: mulheres usuárias de internet } \\
\text { Amostra: } 1.812 \text { mulheres } \\
\text { Coleta de dados: amostra por conveniência, } \\
\text { recrutada via Internet para responder } \\
\text { questionário na web sobre saúde da mulher; } \\
\text { aquelas com IU responderam o ICIQ-SF e o } \\
\text { ISI } \\
\text { Análise de dados: descritiva e inferencial }\end{array}$ & $\begin{array}{l}\text { A IU foi referida por } 19 \% \text { das } \\
\text { mulheres. Houve alta correlação } \\
\text { entre os scores do ISI e ICIQ-SF } \\
\text { (coeficiente de Spearman=0,62; } \\
\text { p<0,01). ICIQ-SF pode ser } \\
\text { dividido nas seguintes níveis e } \\
\text { severidade: leve (1-5), moderado } \\
(6-12) \text {, severo (13-18) e muito } \\
\text { severo (19-21). }\end{array}$ \\
\hline $\begin{array}{l}\text { Ekstron et al. } \\
2008 \\
\text { Suiça }\end{array}$ & $\begin{array}{l}\text { Comparar a prevalência e o risco } \\
\text { de sintomas do trato urinário em } \\
\text { primíparas em relação ao parto } \\
\text { vaginal e cesariana eletiva } 9 \\
\text { meses após o parto. }\end{array}$ & $\begin{array}{l}\text { Desenho: coorte } \\
\text { População: mulheres que deram à luz no } \\
\text { período de janeiro de } 2003 \text { a junho de } 2005 \text {. } \\
\text { Amosta: } 220 \text { mulheres que tiveram cesariana } \\
\text { eletiva e } 215 \text { mulheres que tiveram parto via } \\
\text { vaginal } \\
\text { Coleta de dados: questionário sobre sobre } \\
\text { sintomas do trato urinário inferior no final da } \\
\text { gestação e em } 3 \text { e } 9 \text { meses após o parto. } \\
\text { Análise de dados: descritiva, inferencial e } \\
\text { multivariada }\end{array}$ & $\begin{array}{l}\text { Para quem teve parto vaginal, os } \\
\text { sintomas do trato urinário inferior } \\
\text { aumentaram significativamente até } \\
\text { os } 9 \text { meses pós-parto. Comparado } \\
\text { com a cesárea eletiva, a } \\
\text { prevalência de IUE aumentou tanto } \\
\text { com } 3 \text { meses (p<0,001) como com } \\
9 \text { meses (p=0,001). No modelo } \\
\text { multivariado o parto vaginal foi o } \\
\text { único preditor para a IUE após } 9 \\
\text { meses do parto. Parto vaginal foi } \\
\text { associado com maior risco de } \\
\text { sintomas urinários do trato inferior } \\
\text { após } 9 \text { meses do parto quando } \\
\text { comparado com a cesariana } \\
\text { eletiva. }\end{array}$ \\
\hline
\end{tabular}

(continua) 
Quadro 1

(cont.)

\begin{tabular}{|c|c|c|c|}
\hline $\begin{array}{l}\text { Autor } \\
\text { Ano } \\
\text { País }\end{array}$ & Objetivos & $\begin{array}{c}\text { Método } \\
\text { Desenho/População/Amostra/Coleta de } \\
\text { dados/Intervenção/Análise dos dados }\end{array}$ & Principais resultados \\
\hline $\begin{array}{l}\text { Higa e Lopes; } \\
\text { Reis } \\
2008\end{array}$ & $\begin{array}{l}\text { Identificar os principais fatores } \\
\text { de risco de IU na mulher }\end{array}$ & $\begin{array}{l}\text { Desenho: revisão } \\
\text { População: artigos publicados de } 1983 \text { a } \\
\text { 2003, recuperados nas bases de dados } \\
\text { LILACS e MEDLINE } \\
\text { Amostra: } 38 \text { artigos, sendo três com população } \\
\text { brasileira } \\
\text { Análise de dados: descritiva }\end{array}$ & $\begin{array}{l}\text { Principais fatores de risco ou } \\
\text { associados à IU foram: idade, } \\
\text { obesidade, paridade, tipo de parto, } \\
\text { uso de anestesia no parto, peso do } \\
\text { RN, menopausa, cirurgias } \\
\text { ginecológicas, constipação } \\
\text { intestinal, doenças crônicas, fatores } \\
\text { hereditários, uso de drogas, } \\
\text { consumo de cafeína, tabagismo e } \\
\text { exercícios físicos. }\end{array}$ \\
\hline $\begin{array}{l}\text { Lemos et al. } \\
2008\end{array}$ & $\begin{array}{l}\text { Avaliar os efeitos de exercícios } \\
\text { perineais durante a gravidez na } \\
\text { prevenção de IU. }\end{array}$ & $\begin{array}{l}\text { Desenho: revisão sistemática Cochrane } \\
\text { População: ensaios clínicos sobre exercícios } \\
\text { perineais na gestação de baixo risco } \\
\text { (primíparas ou nulíparas), publicados de } 1966 \\
\text { a 2007; estudos com uso de cone vaginal, } \\
\text { eletroestimulação ou biofeedback foram } \\
\text { excluídos } \\
\text { Amostra: quatro estudos ensaios clínicos; em } \\
\text { todos o investigador era cego } \\
\text { Análise de dados: descritiva }\end{array}$ & $\begin{array}{l}\text { Exercícios do AP durante a } \\
\text { gestação foram associados com } \\
\text { menor risco de desenvolver IU } \\
\text { entre seis meses de gestação e três } \\
\text { meses após o parto. Não houve } \\
\text { diferença no risco de IU segundo o } \\
\text { tipo de parto. Os exercícios } \\
\text { perineais podem reduzir a IU no } \\
\text { pós-parto e os efeitos durante a } \\
\text { gestação ainda não são claros. }\end{array}$ \\
\hline
\end{tabular}


Quadro 1

\begin{tabular}{|c|c|c|c|}
\hline $\begin{array}{l}\text { Autor } \\
\text { Ano } \\
\text { País }\end{array}$ & Objetivos & $\begin{array}{c}\text { Método } \\
\text { Desenho/População/Amostra/Coleta de } \\
\text { dados/Intervenção/Análise dos dados }\end{array}$ & Principais resultados \\
\hline $\begin{array}{l}\text { Scarpa et al. } \\
2008 \\
\text { Brasil }\end{array}$ & $\begin{array}{l}\text { Avaliar o impacto da gestação e } \\
\text { do parto no desencadeamento de } \\
\text { IU e de sintomas do trato urinário } \\
\text { inferior e sua associação com o } \\
\text { desconforto social e higiênico. }\end{array}$ & $\begin{array}{l}\text { Desenho: prospectivo } \\
\text { População: gestantes a partir da } 26^{\mathrm{a}} \text { semana } \\
\text { de gestação } \\
\text { Amostra: } 340 \text { gestantes e, posteriormente, } 133 \\
\text { mulheres } \\
\text { Coleta de dados: entrevista com questões } \\
\text { sobre sintomas do trato urinário inferior, na } \\
\text { gestação e três anos após a primeira entrevista } \\
\text { Análise de dados: descritiva }\end{array}$ & $\begin{array}{l}\text { Mulheres com UI na gestação } \\
\text { tornaram-se assintomáticas }(56,5 \%) \text { e } \\
\text { a remissão do sintoma ocorreu até três } \\
\text { meses após o parto, em } 87,2 \% \text { dos } \\
\text { casos. Entre as mulheres } \\
\text { assintomáticas na gestação, } 13,7 \% \\
\text { desencadearam IU pós-parto. A } \\
\text { gestação, mais do que o parto, foi } \\
\text { responsável pelo desencadeamento da } \\
\text { IU e da noctúria, enquanto a IUU } \\
\text { surgiu com frequência } \\
\text { significativamente maior após o parto. } \\
\text { A sensação de IU, associada a } \\
\text { sintomas do trato urinário inferior, } \\
\text { aumentou significativamente a } \\
\text { sensação de desconforto social. }\end{array}$ \\
\hline $\begin{array}{l}\text { Oliveira et al. } \\
2007 \\
\text { Brasil }\end{array}$ & $\begin{array}{l}\text { Avaliar os efeitos do treinamento } \\
\text { da FMAP em gestantes nulíparas. }\end{array}$ & $\begin{array}{l}\text { Desenho: estudo comparativo, prospectivo, não } \\
\text { randomizado e controlado } \\
\text { População: gestantes nulíparas de baixo risco, até } \\
20 \text { semanas de gestação } \\
\text { Amostra: } 46 \text { gestantes } \\
\text { Coleta de dados: entrevista, perineometria (Perina) } \\
\text { e palpação digital } \\
\text { Coleta de dados: todas as gestantes passaram por } \\
\text { duas avaliaçães na gestação: a primeira com } 20 \\
\text { semanas e a segunda com } 36 \text { semanas } \\
\text { Intervenção: as gestantes do grupo de exercícios } \\
\text { foram submetidas à CT do AP com duração de } 60 \\
\text { minutos semanais, na clínica de pré-natal } \\
\text { Análise de dados: inferencial e multivariada }\end{array}$ & $\begin{array}{l}\text { Avaliação funcional do AP: ambos } \\
\text { os grupos com aumento } \\
\text { significativo da primeira para a } \\
\text { segunda avaliação. Perineometria } \\
\text { sem biofeedback: na segunda } \\
\text { avaliação, somente o grupo de } \\
\text { exercícios teve aumento } \\
\text { significativo. Perineometria com } \\
\text { biofeedback: ambos os grupos com } \\
\text { aumento significativo; a diferença } \\
\text { percentual foi maior no grupo de } \\
\text { exercícios. }\end{array}$ \\
\hline
\end{tabular}

(continua) 
Quadro 1

(cont.)

\begin{tabular}{|c|c|c|c|}
\hline & & & (cont. \\
\hline $\begin{array}{l}\text { Autor } \\
\text { Ano } \\
\text { País }\end{array}$ & Objetivos & $\begin{array}{c}\text { Método } \\
\text { Desenho/População/Amostra/Coleta de } \\
\text { dados/Intervenção/Análise dos dados }\end{array}$ & Principais resultados \\
\hline $\begin{array}{l}\text { Whitford, } \\
\text { Alder e Jones } \\
2007 \\
\text { Escócia }\end{array}$ & $\begin{array}{l}\text { Estabelecer níveis de conhecimento } \\
\text { sobre os exercícios de FMAP } \\
\text { durante a gravidez; relatar a prática } \\
\text { de exercícios perineais; analisar a } \\
\text { prevalência de IU de esforço em } \\
\text { mulheres no terceiro trimestre de } \\
\text { gravidez. }\end{array}$ & $\begin{array}{l}\text { Desenho: estudo transversal } \\
\text { População: } 735 \text { gestantes com mais de } 16 \text { anos e } \\
\text { mais de } 30 \text { semanas de gestação, atendidas em } \\
\text { cinco clínicas de pré-natal no norte da Escócia, } \\
\text { entre de julho } 1999 \text { a março de } 2000 \\
\text { Amostra: } 350 \text { gestantes } \\
\text { Coleta de dados: entrevista estruturada na } 30^{\mathrm{a}} \\
\text { semana de gestação, sobre orientação de exercícios } \\
\text { perineais e exercícios de relaxamento e sobre } \\
\text { informações recebidas na gestação, questões } \\
\text { relacionadas à IU antes e durante a gestação } \\
\text { Análise de dados: análise descritiva e inferencial }\end{array}$ & $\begin{array}{l}7,9 \% \text { das gestantes relataram ter } \\
\text { recebido informações sobre exercícios } \\
\text { do AP na gestação atual, os livros } \\
\text { foram a fonte de informações mais } \\
\text { citada e as parteiras foram os } \\
\text { profissionais de saúde mais propensos } \\
\text { a dar informações. A prática dos } \\
\text { exercícios na gestação foi relatada por } \\
54 \% \text { das gestantes e } 26,3 \% \text { relataram } \\
\text { realizar mais de uma vez ao dia. } \\
\text { Aquelas mais jovens e as provenientes } \\
\text { de meios mais desfavorecidos } \\
\text { relataram menos a prática de } \\
\text { exercícios. Mais da metade ( } 54,3 \%) \\
\text { relataram IU durante a gestação atual. } \\
\text { Não foi encontrada relação entre a } \\
\text { prática de exercícios perineais e a } \\
\text { IUE. }\end{array}$ \\
\hline $\begin{array}{l}\text { Woldringhet et } \\
\text { al. } \\
2007 \\
\text { Países Baixos }\end{array}$ & $\begin{array}{l}\text { Testar os efeitos de curto e longo } \\
\text { prazo dos exercícios musculares do } \\
\text { AP em gestantes de risco que } \\
\text { apresentaram IU durante a gestação. }\end{array}$ & $\begin{array}{l}\text { Desenho: ensaio clínico randomizado } \\
\text { População: gestantes de } 17 \text { a } 20 \text { semanas com IU } \\
\text { Amostra: } 264 \text { gestantes ( } 112 \text { no grupo de estudo e } \\
152 \text { no grupo controle) } \\
\text { Coleta de dados: escala PRAFAB, que determina a } \\
\text { severidade da IU, Incontinence Impact Questionnaire } \\
\text { (IIQ) e diário miccional } \\
\text { Intervenção: terapia individual de três sessões } \\
\text { quinzenais de exercícios, entre } 23 \text { e } 30 \text { semanas de } \\
\text { gestação, e uma sessão na sexta semana após o parto; } \\
\text { o grupo controle recebeu o cuidado habitual } \\
\text { Análise de dados: descritiva, inferencial e } \\
\text { multivariada }\end{array}$ & $\begin{array}{l}\text { Não foi demonstrado efeito positivo do } \\
\text { treinamento da musculatura do AP e no } \\
\text { impacto da IU diária, nas mulheres que } \\
\text { já possuíam IU severa durante a } \\
\text { gestação. A IU diminuiu após o parto. } \\
\text { Não foi demonstrado efeito dos } \\
\text { exercícios em um ano e meio após o } \\
\text { parto. }\end{array}$ \\
\hline
\end{tabular}




\begin{tabular}{|c|c|c|c|}
\hline $\begin{array}{l}\text { Autor } \\
\text { Ano } \\
\text { País }\end{array}$ & Objetivos & $\begin{array}{c}\text { Método } \\
\text { Desenho/População/Amostra/Coleta de } \\
\text { dados/Intervenção/Análise dos dados }\end{array}$ & Principais resultados \\
\hline $\begin{array}{l}\text { Brummen et } \\
\text { al. } \\
2006 \\
\text { Holanda }\end{array}$ & $\begin{array}{l}\text { Descrever as mudanças na } \\
\text { prevalência dos sintomas } \\
\text { urogenitais durante a gestação e } \\
\text { avaliar a quantidade de mulheres } \\
\text { nulíparas que experimentaram } \\
\text { esses desconfortos. }\end{array}$ & $\begin{array}{l}\text { Desenho: coorte prospectiva } \\
\text { População: } 1.366 \text { gestantes nulíparas de } \\
\text { baixo risco } \\
\text { Amostra: } 515 \text { gestantes. } \\
\text { Coleta de dados: questionário autorespondido } \\
\text { com } 12,24 \text { e } 36 \text { semanas de gestação e três e } \\
\text { seis meses após o parto e questionário } \\
\text { Urogeniral Distress Inventory (UDI) } \\
\text { Análise de dados: descritiva, inferencial e } \\
\text { multivariada }\end{array}$ & $\begin{array}{l}\text { A prevalência de sintomas de frequência } \\
\text { e urgência urinária foi alta com } 12 \\
\text { semanas de gestação ( } 74 \% \text { e } 63 \% \text {, } \\
\text { respectivamente) e permaneceu estável } \\
\text { durante a gestação A prevalência de UI e } \\
\text { a dificuldade miccional aumentaram com } \\
\text { a idade gestacional. Houve diminuição } \\
\text { da frequência urinária em } 12 \% \text { das } \\
\text { gestantes, urgência em } 22 \% \text { e IUE em } \\
23 \% \text {, no final da gestação. A prevalência } \\
\text { de incômodos da frequência miccional } \\
\text { foi maior que a IU. }\end{array}$ \\
\hline $\begin{array}{l}\text { Scarpa et al. } \\
2006 \\
\text { Brasil }\end{array}$ & $\begin{array}{l}\text { Avaliar a prevalência de IU no } \\
\text { terceiro trimestre de gestação em } \\
\text { uma amostra populacional. }\end{array}$ & $\begin{array}{l}\text { Desenho: estudo transversal } \\
\text { População: gestantes no terceiro trimestre de } \\
\text { gestação } \\
\text { Amostra: } 340 \text { gestantes } \\
\text { Coleta de dados: questionário estruturado } \\
\text { com perguntas em relação à quantidade, } \\
\text { frequência e intensidade da perda de urina } \\
\text { Análise de dados: descritiva, inferencial e } \\
\text { multivariada }\end{array}$ & $\begin{array}{l}\text { IU em } 50 \% \text { da amostra ( } 34,5 \% \text { nulíparas; } \\
27,1 \% \text { primíparas; } 28,8 \text { multíparas até } \\
\text { três partos; } 9,4 \% \text { multíparas com quatro } \\
\text { ou mais partos); } 50 \% \text { das multíparas com } \\
\text { quatro ou mais partos referiram IU } \\
\text { prévia; nos outros grupos, a prevalência } \\
\text { de IU prévia foi } 13,6 \%, 8,7 \% \text { e } 14,3 \%, \\
\text { respectivamente. As multíparas com } \\
\text { quatro ou mais partos foram afetadas } \\
\text { pela IUE e as nulíparas tiveram alta } \\
\text { porcentagem de sintomas ( } 45,5 \%) \text { e risco } \\
\text { elevado para IUE na gestação. Houve } \\
\text { correlação entre paridade e frequência da } \\
\text { perda urinária, com alta significância nos } \\
\text { episódios diários de IUE nas multíparas } \\
\text { com quatro ou mais partos ( } 2,1 \text { vezes } \\
\text { mais chance de perda de urina que } \\
\text { nulíparas). O fator gestação, mais do que } \\
\text { o parto, representa risco para IU. }\end{array}$ \\
\hline
\end{tabular}


Quadro 1

(cont.)

\begin{tabular}{|c|c|c|c|}
\hline $\begin{array}{l}\text { Autor } \\
\text { Ano } \\
\text { País }\end{array}$ & Objetivos & $\begin{array}{c}\text { Método } \\
\text { Desenho/População/Amostra/Coleta de } \\
\text { dados/Intervenão/Análise dos dados }\end{array}$ & Principais resultados \\
\hline $\begin{array}{l}\text { Mørkved, } \\
\text { Salvesene e } \\
\text { Bø } \\
2004 \\
\text { Noruega }\end{array}$ & $\begin{array}{l}\text { Medir a função dos músculos do } \\
\text { AP, utilizando métodos para } \\
\text { avaliar espessura e resistência em } \\
\text { primigestas com e sem } \\
\text { incontinência. }\end{array}$ & $\begin{array}{l}\text { Desenho: ensaio clínico randomizado } \\
\text { População: primigestas de } 18 \text { a } 20 \text { semanas de } \\
\text { gestação } \\
\text { Amostra: } 103 \text { gestantes } \\
\text { Coleta de dados: entrevista para a } \\
\text { classificação de continentes ou incontinentes, } \\
\text { ultrassonografia perineal e avaliações da } \\
\text { FMAP, por palpação digital, observação da } \\
\text { contração da musculatura da vaginal e } \\
\text { perineometria (balão vaginal) } \\
\text { Análise de dados: descritiva, inferencial e } \\
\text { multivariada }\end{array}$ & $\begin{array}{l}\text { Houve diferença estatisticamente } \\
\text { significante na função da } \\
\text { musculatura pélvica, medida pela } \\
\text { força, e na espessura do músculo } \\
\text { pélvico, entre as gestantes } \\
\text { nulíparas continentes, comparadas } \\
\text { com aquelas consideradas } \\
\text { incontinentes. }\end{array}$ \\
\hline $\begin{array}{l}\text { Mørkved et } \\
\text { al. } \\
2003 \\
\text { Noruega }\end{array}$ & $\begin{array}{l}\text { Avaliar se } 12 \text { semanas de } \\
\text { treinamento intensivo para a } \\
\text { musculatura do AP durante a } \\
\text { gravidez pode prevenir IU na } \\
\text { gestação e após o parto. }\end{array}$ & $\begin{array}{l}\text { Desenho: ensaio clínico randomizado } \\
\text { População: gestantes nulíparas } \\
\text { Amostra: } 301 \text { gestantes } \\
\text { Coleta de dados: entrevistas estruturadas, } \\
\text { avaliação da FMAP pela perineometria (balão } \\
\text { vaginal) e diário de exercícios } \\
\text { Intervenção: o grupo experimental recebeu } \\
\text { treinamento do AP com fisioterapeutas, com } \\
\text { duração de } 60 \text { minutos, por } 12 \text { semanas, entre } \\
20 \text { e } 36 \text { semanas de gestação; o grupo controle } \\
\text { recebeu cuidado usual } \\
\text { Análise de dados: descritiva e inferencial }\end{array}$ & $\begin{array}{l}\text { A FMAP foi significantemente } \\
\text { maior e o número de mulheres } \\
\text { incontinentes significantemente } \\
\text { menor no grupo experimental. } \\
\text { Porém, os resultados só provaram } \\
\text { benefícios durante a gravidez e nos } \\
\text { três meses pós-parto. }\end{array}$ \\
\hline
\end{tabular}




\section{OBJETIVOS}

\section{Objetivo Geral}

- Avaliar a IU, a IA e a FMAP ao longo da gestação e sua evolução clínica nos três trimestres gestacionais.

\section{Objetivos Específicos}

- Analisar a força dos músculos do assoalho pélvico (FMAP) de mulheres durante a gestação.

- Analisar a incontinência urinária (IU) e anal (IA) em mulheres durante a gestação.

- Identificar a interferência da IU na vida da gestante. 


\section{MÉTODO 1}

\subsection{Tipo de estudo}

Estudo de longitudinal, prospectivo, analítico sobre a FMAP, a IU e a IA em mulheres no período gestacional.

Este estudo integra a coorte "Cuidado perineal na gestação e após o parto: prevenção e morbidade relacionadas à força muscular perineal, função sexual e continência urinária", foi realizado no mesmo local e com a mesma amostra deste estudo.

Além dos objetivos do presente estudo, a pesquisa principal tem como objetivos: analisar a FMAP e a continência urinária em mulheres nos primeiros 6 meses após o parto; analisar a função sexual de mulheres durante a gestação e nos seis primeiros meses após o parto; comparar o efeito da cinesioterapia (CT) supervisionada e não supervisionada do AP na continência urinária, na função sexual e na FMAP em mulheres incontinentes durante a gestação e nos 6 primeiros meses após o parto; verificar a adesão das mulheres à CT do AP durante a gestação e nos 6 primeiros meses após o parto.

\subsection{Local}

SEISA Assistência Médica, empresa do Setor de Saúde Suplementar, localizada no município de Guarulhos, São Paulo.

A SEISA atua no segmento de saúde em Guarulhos, desde a década de 1970. Possui uma rede própria de serviços e mantêm convênios nas diversas áreas da saúde, em Guarulhos, municípios da região do Alto Tietê e em São Paulo. Para assistência na gestação e pós-parto dispõe exclusivamente de unidades próprias. Para assistência ao parto, conta com hospitais da rede própria e conveniada. Oferece planos de saúde individuais, familiares e empresariais, sendo esta a modalidade com maior número de clientes. Em 2013, a SEISA foi incorporada à empresa AMIL UnitedHealth Group.

\footnotetext{
${ }^{1}$ Parte da descrição do Método foi extraída de: Riesco MLG et al. Cuidado perineal na gestação e após o parto: prevenção e morbidade relacionadas à força muscular perineal, função sexual e continência urinária [relatório de pesquisa]. São Paulo: Escola de Enfermagem, Universidade de São Paulo; 2015.
} 
Até 2013, a assistência pré-natal era realizada no Centro Clínico de Obstetrícia e Pré-Natal. A partir de 2014, essa unidade foi incorporada ao Centro Clínico da Mulher, com a denominação de NextClínica Mulher e Pré-Natal.

O acompanhamento pré-natal segue o protocolo institucional, estabelecido pelas equipes médica e de enfermagem (Anexo 1). Após o resultado positivo do teste de gravidez, as gestantes procuram o serviço por meio da central de atendimento. Para marcar consultas e iniciar o acompanhamento pré-natal. A primeira consulta é realizada pela enfermeira obstetra ou obstetriz, com anamnese, exame físico geral e específico, solicitação de exames de rotina (hemograma completo; tipagem sanguínea e fator $\mathrm{Rh}$; glicemia de jejum; urina tipo 1, urocultura e antibiograma; proctoparasitológico de fezes; sorologia para HIV, VDRL, toxoplasmose, rubéola, hepatite B e C; ultrassonografia; colpocitologia oncótica, caso não tenha realizado esse exame há menos de um ano). São realizadas orientações gerais e específicas a respeito da gestação, especificamente, sobre o primeiro trimestre. Se necessário, são prescritos medicamentos de acordo com o protocolo. As consultas subsequentes são realizadas pelo médico obstetra e a gestante retorna para consulta pré-natal com a enfermeira obstetra ou obstetriz no segundo trimestre de gestação, para orientações sobre aleitamento materno, e no terceiro trimestre, para orientações sobre trabalho de parto e parto.

\subsection{População e amostra}

A população constituiu-se de mulheres usuárias do NextClínica Mulher e PréNatal que atenderam aos critérios de inclusão.

\subsubsection{Critérios de inclusão}

- 18 anos ou mais;

- Ensino fundamental completo;

- $\quad$ IMC menor que 35;

- Idade gestacional de até 12 semanas e 6 dias, calculada pela data da última menstruação e confirmada pela ultrassonografia;

- Gestação única, considerada de risco habitual;

- Sem cirurgia urogenital prévia; 
- Sem doenças que possam interferir na FMAP (prolapso de órgão pélvico, doenças neurológicas, diabetes, lesão pélvica ou da coluna vertebral);

- Não oferecer resistência à inserção da sonda do perineômetro na vagina;

- Não realizar manobra de Valsalva à medição da FMAP;

- Sem dificuldade no entendimento do idioma português ou na comunicação.

\subsubsection{Critérios de exclusão}

- Complicações obstétricas ou clínicas durante a gestação;

- Manobra de Valsalva à medição da FMAP.

\subsubsection{Amostra}

A amostra constituiu-se de todas as gestantes que iniciaram o acompanhamento pré-natal e atenderam aos critérios de inclusão, no período ininterrupto entre 21 de novembro de 2012 e 17 de setembro de 2013.

Previamente ao início da coorte, verificou-se que, entre janeiro e março de 2012, 300 mulheres com idade igual ou superior a 18 anos iniciaram o pré-natal no primeiro trimestre de gestação.

Considerando a demanda de gestantes no local de estudo e os critérios de inclusão na coorte, o tamanho amostral de 500 gestantes foi definido, em função do período total de 24 meses para a realização da coorte, com seguimento das mulheres desde o primeiro trimestre da gestação até 180 dias após o parto.

\subsubsection{Recrutamento}

As gestantes foram recrutadas durante a primeira consulta de pré-natal. Aquelas que atenderam aos critérios de inclusão foram convidadas a participar do estudo pela enfermeira obstetra ou obstetriz que realizou a consulta. As gestantes que aceitaram participar assinaram o Termo de Consentimento Livre e Esclarecido (TCLE) e a coleta de dados foi iniciada ao durante a consulta (Apêndice A). 


\subsection{Exposição e desfechos}

A idade gestacional foi considerada como exposição. A FMAP, a continência urinária e anal e a interferência da IU na vida da gestante foram consideradas como desfechos.

\subsection{Medidas e instrumentos de avaliação dos desfechos}

\subsubsection{Perineometria}

Um perineômetro eletrônico de pressão modelo Peritron ${ }^{\mathrm{TM}}$, da Laborie, Canadá, que registra as contrações musculares do AP por meio de sensor localizado em uma sonda vaginal de silicone de $8 \mathrm{~cm}$ de comprimento e $3 \mathrm{~cm}$ de diâmetro foi utilizado. $\mathrm{O}$ sensor está ligado a um microprocessador portátil que mensura a contração da FMAP, numericamente, de 0,1 a $300 \mathrm{cmH}_{2} \mathrm{O}$. Esse aparelho não diferencia as contrações dos músculos do períneo e do abdome. O fabricante supõe que o aparelho seja mais preciso do que os outros disponíveis no mercado, pois na leitura efetuada pelo Peritron ${ }^{\mathrm{TM}}$, o erro não supera $1 \mathrm{cmH}_{2} \mathrm{O}$ (Figura 1).

Figura 1 - Peritron ${ }^{\mathrm{TM}}$ com sensor vaginal

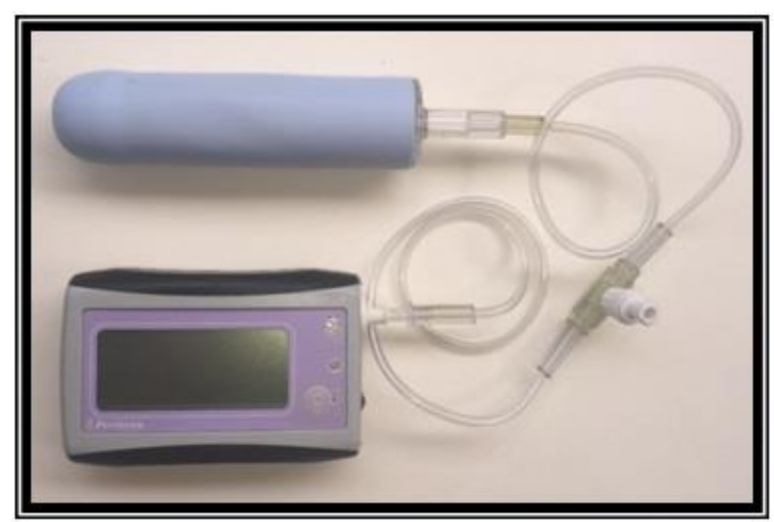

Fonte: a pesquisadora 


\subsubsection{ICIQ-SF (Anexo 2)}

Consiste de quatro questões relativas à frequência e quantidade da perda urinária, interferência dessa perda na vida diária e situações em que a IU pode ocorrer. Para as respostas das três primeiras questões, são atribuídos valores, com escore final que varia de 0 a 21 . A última questão (situações em que a IU pode ocorrer) possui oito alternativas de resposta qualitativa. Quanto maior a pontuação pior o Score de classificação do ICIQSF. Este questionário foi aplicado apenas às mulheres que referiram IU, em cada etapa do estudo.

\subsection{Coleta de dados e seguimento}

A coleta de dados foi realizada por uma equipe de pesquisa formada por 11 profissionais (sete obstetrizes, três enfermeiras e uma fisioterapeuta) previamente treinadas. Uma enfermeira obstetra e uma obstetriz da equipe de pesquisa integravam a equipe de profissionais do pré-natal da SEISA.

Antes do início da coleta de dados, as pesquisadoras apresentaram o estudo aos profissionais do serviço, visando a obter a aceitação, colaboração e integração dos profissionais com a pesquisa.

Os dados foram coletados em três etapas, no período entre 21 de novembro de 2012 e 17 de abril de 2014, conforme cronograma especificado nos dados do Quadro 1.

Quadro 2 - Cronograma das etapas de coleta de dados, Guarulhos - 2012-2014

\begin{tabular}{lll}
\hline Etapa & Início & Encerramento \\
\hline $\mathbf{1}$ & 21 de novembro de 2012 & 17 de setembro de 2013 \\
$\mathbf{2}$ & 15 de fevereiro de 2013 & 23 de dezembro de 2013 \\
$\mathbf{3}$ & 6 de maio de 2013 & 17 de abril de 2014 \\
\hline
\end{tabular}

\subsubsection{Etapas do estudo}

- Etapa 1: com mulheres até 12 semanas e 6 dias de gestação. A mensuração da FMAP, do peso e da estatura corporal foi realizada, sendo aplicados os seguintes instrumentos: formulário de identificação, de dados clínicos e obstétricos e de sintomas do trato urinário 
e anal (Apêndice B) e ICIQ-SF. Todas as gestantes receberam orientação por escrito para a realização da CT do AP em casa (Apêndice C).

- Etapa 2: com as mesmas mulheres da etapa anterior, entre 20 e 27 semanas de gestação, esta etapa coincidiu com o retorno das gestantes para consulta com a enfermeira obstetra ou obstetriz, conforme protocolo do serviço sendo realizada a mensuração da FMAP e do peso corporal. Novamente, o ICIQ-SF foi aplicado e perguntado sobre IA e a frequência de realização dos exercícios perineais. As gestantes com IU foram aleatorizadas para participar de ensaio clínico. No grupo experimental, as gestantes participaram de sessões quinzenais de CT do AP supervisionada por fisioterapeuta.

- Etapa 3: com as mesmas mulheres das etapas anteriores, entre 31 e 38 semanas de gestação. Esta etapa coincidiu com o retorno das gestantes para consulta com a enfermeira obstetra ou obstetriz, conforme protocolo do serviço. Foi realizada a mensuração da FMAP e do peso corporal, foi feita; sendo novamente aplicado o ICIQ-SF e perguntado sobre a IA e a frequência de realização dos exercícios perineais.

Ao final da consulta, em todas as etapas, cada gestante recebeu um encaminhamento para marcação do retorno na data estimada para a etapa seguinte. Previamente à data prevista para o retorno, foi feito contato telefônico com as gestantes, para confirmar sua presença na consulta marcada. Em caso de falta, as pesquisadoras entravam em contato com a participante para remarcar a consulta.

Nessa etapa, além da orientação para manter a CT do AP, as mulheres foram orientadas a retornar para consulta após o parto.

\subsubsection{Técnicas coleta de dados}

\subsubsection{Entrevista}

Inicialmente, foi preenchido o formulário com dados clínicos e obstétricos, de sintomas do trato urinário e anal e de frequência de realização dos exercícios perineais, de acordo com as etapas do estudo. Para esse preenchimento, foi realizada entrevista no consultório de enfermagem. 


\subsubsection{Mensuração da FMAP}

A seguir, foi feita a mensuração da FMAP, no consultório de enfermagem, conforme os seguintes procedimentos:

1. Solicitar que a gestante esvazie a bexiga;

2. Colocar a gestante em posição ginecológica, com a região genital e os membros inferiores descobertos;

3. Ensinar a gestante a fazer contrações como se estivesse "segurando" a urina, usando somente os músculos do AP, evitando contrair os músculos abdominais, da coxa e das nádegas;

4. Puxar o êmbolo da seringa até $20 \mathrm{ml}$ e conectá-la ao aparelho;

5. Revestir a sonda elástica com um preservativo descartável não lubrificado;

6. Calçar luvas de procedimentos;

7. Lubrificar o preservativo com gel à base de água;

8. Instruir a gestante a relaxar os músculos do AP;

9. Ligar o perineômetro;

10. Introduzir 4 a $6 \mathrm{~cm}$ da sonda na vagina, de modo que, aproximadamente, $1,5 \mathrm{~cm}$ desta seja visualizada;

11. Retirar a luva da mão dominante para manusear o aparelho;

12. Insuflar o perineômetro até que a escala atinja $100 \mathrm{cmH}_{2} \mathrm{O}$

13. Zerar o aparelho, apertando o botão na parte anterior do aparelho, conforme recomendação do fabricante;

14. Girar a chave lateral do aparelho para verificar se foi zerado (se não estiver zerado, apertar o botão da parte anterior do aparelho novamente);

15. Solicitar que a gestante contraia e mantenha, por 5 segundos, a contração voluntária dos músculos perineais ao redor da sonda vaginal;

16. Observar a movimentação da sonda perineal na direção cranial, que indica que a contração foi realizada corretamente (caso não haja movimentação da sonda, orientar novamente a gestante, realizando o exame vaginal digital);

17. Registrar o valor acusado no aparelho;

18. Repetir os passos 13 a 17, por duas vezes, com intervalo de 30 segundos entre as medições; 


\section{Observações:}

- O valor acusado (vide item 17, acima) corresponde ao valor máximo da contração registrada na memória do aparelho. No entanto, memória do aparelho não registra valores inferiores a 5,0 $\mathrm{cmH}_{2} \mathrm{O}$. Nesses casos, considerar o valor máximo observado durante a perineometria, mesmo que este valor não seja registrado pela memória do aparelho.

- Confirmar a realização da manobra de Valsalva, realizando o exame vaginal digital. Nesse caso, a gestante deve ser excluída do estudo.

\subsubsection{Aplicacão do ICIQ-SF}

Por fim, foi aplicado o ICIQ-SF. Dado que esse instrumento é autoaplicado, as gestantes receberam orientação sobre o preenchimento, imediatamente após a mensuração da FMAP. O questionário foi fornecido com uma prancheta e caneta e seu preenchimento foi realizado na sala de espera do pré-natal.

\subsection{Variáveis do estudo}

\subsubsection{Independente}

- Idade gestacional - semanas completas.

\subsubsection{Dependentes}

- FMAP - contração da musculatura do $\mathrm{AP}$, avaliada em $\mathrm{cmH}_{2} \mathrm{O}$ por meio da perineometria;

- Continência urinária - sem perda involuntária de urina, independentemente da frequência, quantidade ou situação;

- IU na gestação atual - frequência e quantidade da perda urinária e interferência dessa perda na vida diária (escala numérica de 0 a 10 , sendo $0=$ não interfere; $10=$ interfere muito), nas 4 semanas anteriores, avaliada por meio do ICIQ-SF, com escore entre 0 e 21;

- Continência anal - sem perda involuntária de flatos ou fezes, independentemente da frequência, quantidade ou situação; 


\subsubsection{Outras variáveis}

\subsubsection{Dados sociodemográficos}

- Idade - anos;

- Cor da pele - referida pela mulher, classificada como branca, negra, parda, amarela e vermelha;

- Escolaridade - ensino fundamental completo ou ensino médio incompleto; médio completo ou superior incompleto; superior completo;

- Ocupação - trabalho remunerado, do lar e estudante;

- Situação conjugal - vive ou não com o parceiro.

\subsubsection{Dados obstétricos e clínicos e sintomas do trato urinário}

- Número de gestações anteriores;

- Número e tipo de parto(s) anterior(es) - vaginal e cesariana;

- Trauma perineal em partos anteriores - sim (epsiotomia ou laceração espontânea) ou não (períneo íntegro);

- Maior peso do recém-nascido $(\mathbf{R N})$ em parto anterior - gramas, imediatamente, após o nascimento;

- Estado nutricional - classificado de acordo com o IMC, em baixo peso, adequado, sobrepeso e obesidade, considerando a idade gestacional (Atalah et al., 1997).

- IU prévia - referência à perda de urina em qualquer quantidade, frequência ou motivo, prévia à gestação atual, considerando: somente durante gravidez anterior; em gravidez anterior e que persiste; antes da gravidez atual e que persiste;

- Situações em que a perda de urina acontece na gestação atual - avaliada pelo ICIQ-SF;

- IA prévia - referência à perda de flatos ou fezes em qualquer quantidade, frequência ou motivo, prévia à gestação, considerando: somente durante gravidez anterior; em gravidez anterior e que persiste; antes da gravidez atual e que persiste;

- Frequência de realização dos exercícios perineais não supervisionados na gestação (CT não supervisionada do AP) - nunca ou esporadicamente (não realiza ou 
realiza menos que duas vezes por semana); regularmente (realiza, pelo menos, duas vezes por semana);

- Exercícios perineais supervisionados na gestação (CT supervisionada do AP) participação no grupo experimental do ensaio clínico aninhado à coorte; a intervenção consistiu de seis sessões quinzenais de CT do AP supervisionadas por fisioterapeuta, com duração de 45 minutos cada sessão, realizadas entre 21 e 27 semanas de gestação.

\subsection{Análise dos dados}

Os dados foram digitados em um banco no aplicativo Excel, em planilhas separadas para cada etapa da coorte, perdas de seguimento, participantes excluídas da coorte e ensaio clínico. $\mathrm{O}$ banco foi submetido à análise de consistência, em que para cada variável foi verificada a ocorrência de códigos não permitidos para o campo e conferidos com o instrumento correspondente (formulário de coleta de dados e ICIQ-SF). As inconsistências foram corrigidas, de acordo com as informações do instrumento.

\subsubsection{Análise descritiva}

Para a análise descritiva das variáveis qualitativas e quantitativas, foram calculadas as frequências absolutas e relativas e as medidas de tendência central e dispersão, respectivamente. Além da prevalência de IU e IA, foi calculada também a incidência de IU e IA na gestação e em cada trimestre, separadamente.

\subsubsection{Análise inferencial}

$\mathrm{Na}$ análise bivariada, para análise da perda de seguimento das gestantes da coorte, que envolveu quatro grupos independentes, foram usados o teste Qui-quadrado, para as variáveis categóricas, o teste Kruskal-Wallis e a análise de variância (ANOVA) a um fator, para as variáveis quantitativas.

$\mathrm{Na}$ análise bivariada realizada nas três etapas da coorte, quando a análise envolveu variáveis quantitativas (FMAP e ICIQ-SF), foi utilizado o Modelo Linear de Efeitos Mistos (LMM) e a correlação de Pearson. A análise que envolveu variáveis categóricas (IU, IA e FMAP categorizada), foi usada a metodologia de Modelos Lineares 
Generalizados para medidas repetidas, pelo modelo de Equações de Estimação Generalizadas (GEE) (Zeger; Liang; Albert, 1988).

A análise multivariada foi feitapelo modelo de regressão logística longitudinal. Para determinar os fatores associados à FMAP foi usado o LMM; para determinar os fatores associados à IU e IA foi utilizado o GEE. Em ambas as análises foi adotado o processo backward, com todas as variáveis que apresentaram valor-p $\leq 0,20$, na análise bivariada.

As variáveis aborto, parto vaginal e cesariana anteriores e trauma perineal em parto anterior, quando apresentaram valor- $\mathrm{p} \leq 0,20$ não foram incluídas no modelo multivariado, por estarem altamente correlacionadas entre si e com o parâmetro gestações anteriores, que foi a variável adotada no modelo. A exceção foi para a IA, em cujo modelo foram incluídas as variáveis parto vaginal anterior e exercício perineal não supervisionado, mesmo com valor-p $>0,20$, dada sua importância para este desfecho.

Para as frequências, médias e odds ratio (OR), o intervalo de confiança de $95 \%$ (95\% IC) foi calculado.

Todos os testes foram realizados na forma bicaudal, admitindo-se a probabilidade de ocorrência de erro de primeira espécie de $5 \%$ (valor-p=0,05).

As análises foram feitas utilizando pacote estatístico, SPSS (Statistical Package for the Social Sciences) para Windows (versão 22.0).

\subsection{Aspectos éticos}

O estudo foi aprovado pelo Comitê de Ética em Pesquisa da Escola de Enfermagem da USP (CAAE:05096412.7.0000.5392) (Anexo 3), dado que à época de aprovação do estudo, a SEISA Assistência Médica não dispunha de Comitê de Ética em Pesquisa.

A realização da pesquisa foi autorizada pela gerência geral da SEISA, mediante Termo de Autorização para a Realização da Pesquisa Científica (Apêndice D). Conforme referido no item 3.3.4 Recrutamento, as mulheres foram incluídas no estudo somente depois de receberem informações e após a leitura e assinatura do TCLE.

Cumpre salientar que nenhuma das participantes da equipe de pesquisa tinha qualquer vínculo com os fabricantes ou distribuidores do equipamento utilizado neste estudo. 


\section{RESULTADOS}

No período entre 21 de novembro de 2012 e 17 de setembro de 2013, 1.266 gestantes iniciaram o pré-natal no local de estudo. Todas foram avaliadas para elegibilidade, e 648 não atenderam aos critérios de inclusão e 118 recusaram-se a participar do estudo. Desse modo, 500 mulheres foram incluídas na coorte e foram acompanhadas no primeiro (etapa 1), segundo (etapa 2) e terceiro (etapa 3 ) trimestres da gestação, conforme relatado no Método e apresentados na Figura 2. A mesma Figura mostra o total de gestantes avaliadas em cada etapa e os motivos de exclusão das gestantes, abandono do estudo ou perda de seguimento em cada etapa.

Os motivos de exclusão das mulheres ( $\mathrm{n}=95)$ foram: 61 por abortamento, 31 por complicações obstétricas ou clínicas (hipertensão arterial, parto prematuro ou ameaça de trabalho de parto prematuro, diabetes, oligoâmnio, polidrâmnio, má formação fetal suspeita ou confirmada, óbito fetal, depressão, pneumonia) e três por manobra de Valsava à medição da FMAP. Os motivos para abandono do estudo $(n=79)$ foram: 27 por desistência, 27 por mudança de cidade ou serviço de pré-natal e 25 por cancelamento do convênio.

Em relação às mulheres elegíveis para as etapas $2(n=371)$ e $3(n=326)$ da coorte, foram avaliadas 226 e 187 gestantes, respectivamente. A perda de seguimento destas mulheres (145 na etapa 2; 139 na etapa 3) foi por falta ao retorno marcado, impossibilidade da gestante a comparecer no período previsto para retorno ou insucesso no contato telefônico estabelecido para marcar o retorno. Vale reiterar que as mulheres que faltaram na etapa 2 foram contatadas para o retorno na etapa 3 , como todas as demais gestantes elegíveis. 
Figura 2 - Fluxograma das participantes do estudo, Guarulhos, SP - 2012-2014

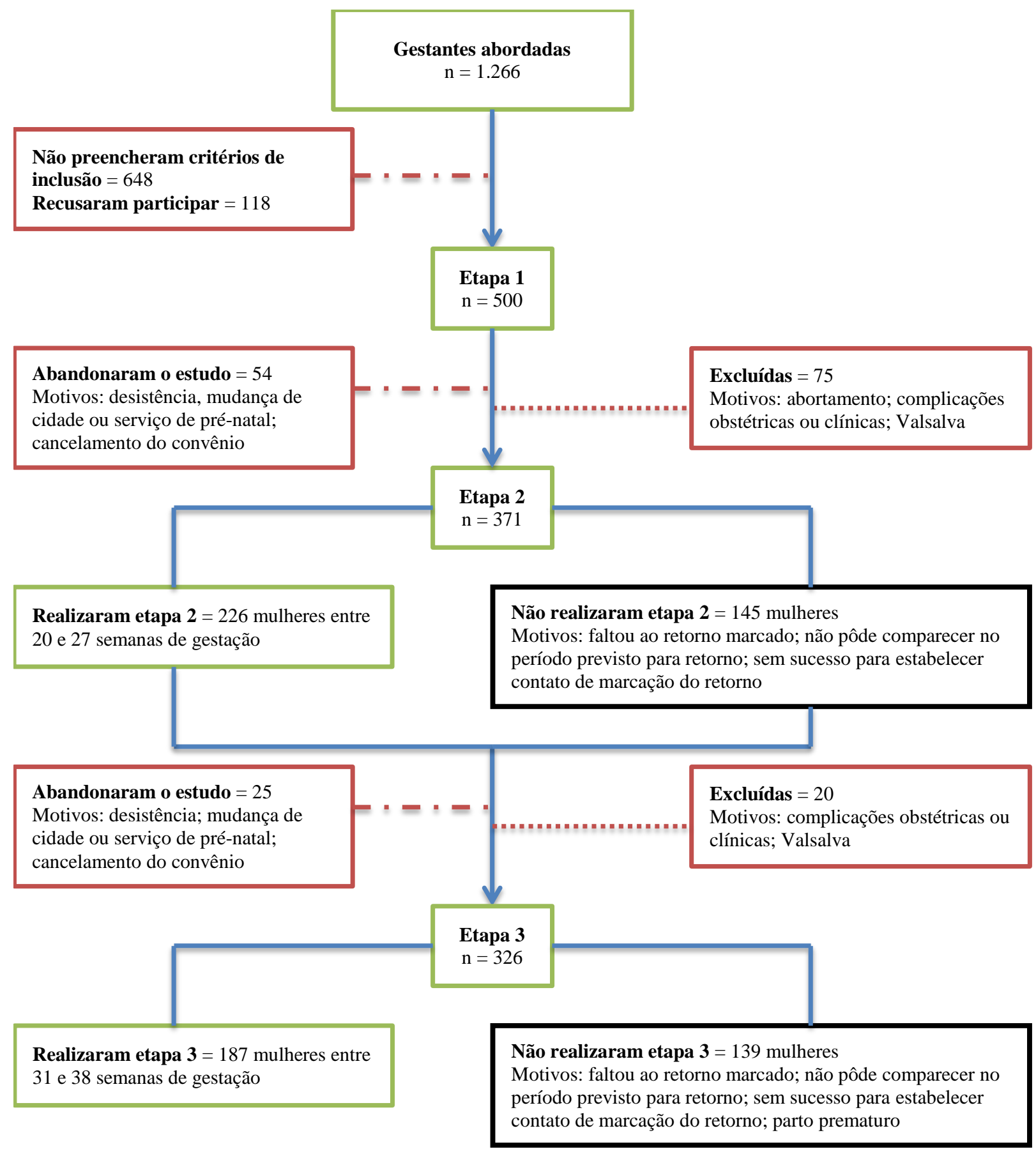

Fonte: a pesquisadora 
A seguir, os resultados são apresentados de acordo com itens: 4.1 Análise da perda de seguimento das participantes (Tabelas 1 a 3); 4.2 Caracterização das gestantes participantes da coorte (Tabelas 4 a 7); 4.3 Análise bivariada da FMAP, IU, ICIQ-SF e IA ao longo da gestação (Tabelas 8 a 16); 4.4 Análise multivariada da FMAP, IU e IA ao longo da gestação (Tabelas 17 a 19 e Figuras 3 e 4).

\subsection{Análise da perda de seguimento das participantes}

Para análise da perda de seguimento das participantes na coorte, as gestantes foram agrupadas de acordo com a participação em cada etapa. No grupo A, foram incluídas as que realizaram todas as etapas, no grupo $\mathrm{B}$, as que não realizaram a segunda etapa (entre 20 e 27 semanas), no grupo $C$, aquelas que não realizaram a terceira etapa (entre 31 e 38 semanas) e no grupo $\mathrm{D}$, as que não realizaram ambas as etapas.

Os dados da Tabela 1 mostra que prevaleceram as gestantes que deixaram de cumprir as etapas no segundo e terceiro trimestres da gestação $(46,0 \%)$, ou seja, não foram seguidas ao longo da gravidez. A proporção de gestantes que deixaram de cumprir a etapa no terceiro trimestre $(16,6 \%)$ foi maior que aquelas que deixaram de cumprir a etapa no segundo trimestre $(8,8 \%)$.

Os dados das Tabelas 2 e 3 apresentam a distribuição das gestantes nos quatro grupos, conforme as variáveis quantitativas e qualitativas avaliadas na etapa 1, respectivamente. Para a maioria das variáveis, os grupos mostraram-se homogêneos, com diferença estatisticamente significante apenas para antecedentes de gestação $(p=0,043)$ e parto $(\mathrm{p}=0,040)$. A cor da pele mostrou diferença marginal entre os grupos $(\mathrm{p}=0,051)$.

Em relação aos desfechos da coorte - FMAP, continência urinária e anal e interferência da IU na vida da gestante - não houve diferença estatisticamente significante entre as mulheres que cumpriram todas as etapas da coorte e aquelas que deixaram de realizar qualquer etapa. Nesse sentido, pode-se considerar que as perdas foram aleatórias e não influenciaram nos resultados, especialmente em relação aos referidos desfechos. 
Tabela 1 - Distribuição das gestantes da coorte conforme os grupos A, B, C, e D, Guarulhos, SP - 2012-2014

\begin{tabular}{lcc}
\hline Grupo & $\mathbf{n}$ & \% \\
\hline A: realizaram etapas 1, 2 e 3 & 143 & 28,6 \\
B: não realizaram etapa 2 & 44 & 8,8 \\
C: não realizaram etapa 3 & 83 & 16,6 \\
D: não realizaram etapas 2 e 3 & 230 & 46,0 \\
\hline Total & $\mathbf{5 0 0}$ & $\mathbf{1 0 0}$
\end{tabular}

Fonte: a pesquisadora

Tabela 2 - Distribuição das gestantes dos grupos A, B, C e D, conforme as variáveis quantitativas e valor-p, Guarulhos, SP - 2012-2014

\begin{tabular}{lccc}
\hline Variável & n & Média (d.p.) & Valor-p \\
\hline FMAP $\left(\mathrm{cmH}_{2} \mathrm{O}\right)$ & $\mathbf{5 0 0}$ & & \\
Grupo A & 143 & $28,9(15,1)$ & \\
Grupo B & 44 & $35,0(20,9)$ & $0,495^{*}$ \\
Grupo C & 83 & $29,5(15,0)$ & \\
Grupo D & 230 & $31,0(18,5)$ & \\
Escore ICIQ-SF & $\mathbf{9 0}$ & & \\
Grupo A & 23 & $7,4(3,4)$ & \\
Grupo B & 6 & $6,5(2,4)$ & $0,333^{*}$ \\
Grupo C & 13 & $7,9(4,1)$ & \\
Grupo D & 48 & $8,9(4,2)$ & \\
Idade materna (anos) & $\mathbf{5 0 0}$ & & \\
Grupo A & 143 & $27,4(5,8)$ & \\
Grupo B & 44 & $27,0(5,9)$ & \\
Grupo C & 83 & $27,4(5,6)$ & \\
Grupo D & 230 & $28,5(6,3)$ & \\
RN de maior peso $(\mathrm{g})$ & $\mathbf{2 1 5}$ & & \\
Grupo A & 52 & $3062,1(519,9)$ & \\
Grupo B & 21 & $3197,0(569,0)$ & $0,692 \dagger$ \\
Grupo C & 32 & $3207,0(567,0)$ & \\
Grupo D & 110 & $3131,5(639,2)$ & \\
\hline
\end{tabular}

*Teste Kruskal-Wallis; †ANOVA a um fator

Fonte: a pesquisadora 
Tabela 3 - Distribuição das gestantes dos grupos A, B, C e D, conforme as variáveis qualitativas e valor-p, Guarulhos, SP - 2012-2014

\begin{tabular}{|c|c|c|c|c|c|c|}
\hline \multirow[b]{2}{*}{ Variável } & \multirow[b]{2}{*}{$\mathbf{n}$} & \multicolumn{4}{|c|}{ Grupo } & \multirow[b]{2}{*}{$\begin{array}{c}\text { Valor- } \\
\mathbf{p}^{*}\end{array}$} \\
\hline & & $\frac{\mathrm{A}}{\mathrm{n}(\%)}$ & $\frac{\text { B }}{\text { n }(\%)}$ & $\frac{\mathrm{C}}{\mathrm{n}(\%)}$ & $\frac{\text { D }}{\mathrm{n}(\%)}$ & \\
\hline Cor da pele & 499 & & & & & \\
\hline Não branca & 313 & $89(28,4)$ & $36(11,5)$ & $51(16,3)$ & $137(43,8)$ & \multirow{2}{*}{0,051} \\
\hline Branca & 186 & $54(29,0)$ & $8(4,3)$ & $32(17,2)$ & $92(49,5)$ & \\
\hline Escolaridade & 499 & & & & & \\
\hline $\begin{array}{l}\text { Ensino } \\
\text { fundamental }\end{array}$ & 53 & $15(28,3)$ & $4(7,5)$ & $8(15,1)$ & $26(49,1)$ & \multirow{3}{*}{0,426} \\
\hline Ensino médio & 351 & $105(29,9)$ & $36(10,3)$ & $56(16,0)$ & $154(43,8)$ & \\
\hline Ensino superior & 95 & $23(24,2)$ & $4(4,2)$ & $19(20,0)$ & $49(51,6)$ & \\
\hline Ocupação & 499 & & & & & \\
\hline Trabalho remunerado & 389 & $108(27,8)$ & $34(8,7)$ & $62(15,9)$ & $185(47,6)$ & \multirow{2}{*}{0,610} \\
\hline Do lar ou estudante & 111 & $35(31,5)$ & $10(9,0)$ & $21(18,9)$ & $45(40,6)$ & \\
\hline Situação conjugal & 498 & & & & & \\
\hline Vive com parceiro & 431 & $118(27,4)$ & $41(9,5)$ & $69(16,0)$ & $203(47,1)$ & \multirow{2}{*}{0,127} \\
\hline Não vive & 67 & $25(37,3)$ & $3(4,5)$ & $14(20,9)$ & $25(37,3)$ & \\
\hline Gestação anterior & 500 & & & & & \\
\hline Sim & 246 & $56(22,8)$ & $23(9,3)$ & $45(18,3)$ & $122(49,6)$ & \multirow{2}{*}{0,043} \\
\hline Não & 254 & $87(34,3)$ & $21(8,3)$ & $38(15,0)$ & $108(42,4)$ & \\
\hline Parto anterior & 246 & & & & & \\
\hline Sim & 217 & $52(24,0)$ & $21(9,7)$ & $34(15,7)$ & $110(50,6)$ & \multirow{2}{*}{0,040} \\
\hline Não & 29 & $4(13,8)$ & $2(6,9)$ & $11(37,9)$ & $12(41,4)$ & \\
\hline $\begin{array}{l}\text { Parto vaginal } \\
\text { anterior }\end{array}$ & 217 & & & & & \\
\hline Sim & 121 & $25(20,7)$ & $13(10,7)$ & $19(15,7)$ & $64(52,9)$ & \multirow{2}{*}{0,609} \\
\hline Não & 96 & $27(28,1)$ & $8(8,3)$ & $15(15,6)$ & $46(48,0)$ & \\
\hline Cesariana anterior & 217 & & & & & \\
\hline $\operatorname{Sim}$ & 110 & $28(25,4)$ & $8(7,3)$ & $17(15,4)$ & $57(51,9)$ & \multirow{2}{*}{0,426} \\
\hline Não & 107 & $24(22,4)$ & $13(12,1)$ & $17(16,0)$ & $53(49,5)$ & \\
\hline Estado nutricional & 497 & & & & & \\
\hline Baixo peso & 46 & $22(47,8)$ & $4(8,7)$ & $8(17,4)$ & $12(26,1)$ & \multirow{4}{*}{0,068} \\
\hline Adequado & 227 & $64(28,2)$ & $22(9,7)$ & $33(14,5)$ & $108(47,6)$ & \\
\hline Sobrepeso & 163 & $40(24,5)$ & $15(9,2)$ & $34(20,9)$ & $74(45,4)$ & \\
\hline Obesidade & 61 & $17(27,9)$ & $3(4,9)$ & $8(13,1)$ & $33(54,1)$ & \\
\hline IU prévia & 499 & & & & & \\
\hline Sim & 195 & $53(27,2)$ & $18(9,2)$ & $31(15,9)$ & $93(47,7)$ & \multirow{2}{*}{0,888} \\
\hline Não & 304 & $90(29,6)$ & $26(8,6)$ & $52(17,1)$ & $136(44,7)$ & \\
\hline IU atual & 500 & & & & & \\
\hline Sim & 95 & $24(25,3)$ & $6(6,3)$ & $14(14,7)$ & $51(53,7)$ & \multirow{2}{*}{0,387} \\
\hline Não & 405 & $119(29,3)$ & $38(9,4)$ & $69(17,0)$ & $179(44,3)$ & \\
\hline IA prévia & 499 & & & & & \\
\hline $\operatorname{Sim}$ & 113 & $36(31,9)$ & $8(7,1)$ & $15(13,3)$ & $54(47,7)$ & \multirow{2}{*}{0,546} \\
\hline Não & 386 & $107(27,7)$ & $36(9,3)$ & $68(17,6)$ & $175(45,4)$ & \\
\hline IA atual & 499 & & & & & \\
\hline Sim & 50 & $20(40,0)$ & $2(4,0)$ & $8(16,0)$ & $20(40,0)$ & \multirow{2}{*}{0,222} \\
\hline Não & 449 & $123(27,4)$ & $42(9,4)$ & $75(16,7)$ & $209(46,5)$ & \\
\hline
\end{tabular}

*Teste Qui-quadrado

Fonte: a pesquisadora 


\subsection{Caracterização das gestantes participantes da coorte}

De acordo com os critérios estabelecidos, as gestantes foram incluídas na coorte com até 12 semanas de 6 dias de gravidez. As variáveis de caracterização das mulheres apresentadas nos dados das Tabelas 4 e 5 referem-se ao primeiro trimestre de gestação (etapa 1 da coorte).

A média de idade das gestantes foi de 27,9 (d.p.=6,0) anos, a idade mínima foi de 18 e a máxima de 46 anos; a maioria (78,2\%) tinha entre 20 e 35 anos. A metade das participantes $(50,1 \%)$ autodeclarou-se de cor parda; a grande maioria $(89,4 \%)$ tinha, pelo menos, o ensino médio completo e $77,8 \%$ exerciam atividade remunerada.

Em relação aos antecedentes obstétricos, a metade das participantes era primigesta $(50,8 \%)$, com média de 0,8 (d.p.=1,0) gestações por mulher, $14,0 \%$ tinham aborto anterior (média=0,3, dentre as mulheres com gestação anterior), 24,8\% tinham parto vaginal anterior (média $=0,8$, dentre as mulheres com parto vaginal ou cesariana anteriores), $21,8 \%$ tinham cesariana anterior (média $=0,6$, dentre as mulheres com parto vaginal ou cesariana anteriores) $23,9 \%$ haviam sofrido trauma perineal em parto anterior. A média de peso do recém-nascido $(\mathrm{RN})$, considerando aquele de maior peso em parto vaginal ou cesariana anterior, foi de 3.132,4 (d.p.=597,5) gramas.

Os antecedentes de IU e de IA foram referidos por 39,1\% e 22,6\% das mulheres, respectivamente, e $84,1 \%$ daquelas com IU e 95,6\% das com IA iniciaram a gestação atual com a respectiva queixa. No caso da IA, a quase totalidade das mulheres $(96,5 \%)$ apresentava exclusivamente incontinência de flatos.

Tabela 4 - Distribuição das gestantes na etapa 1 da coorte, conforme a idade materna, número de gestações, abortos, partos vaginais e cesarianas anteriores e maior peso do RN em parto anterior, Guarulhos, SP - 2012-2014

\begin{tabular}{lccccc}
\hline Variável & $\mathbf{n}$ & Média (d.p.) & Mediana & Mín & Máx \\
\hline Idade materna (anos) & $\mathbf{5 0 0}$ & $27,9(6,0)$ & 28,0 & 18 & 46 \\
Gestação anterior & $\mathbf{5 0 0}$ & $0,8(1,0)$ & 0,0 & 0 & 7 \\
Aborto anterior & $\mathbf{2 4 6}$ & $0,3(0,6)$ & 0,0 & 0 & 5 \\
Parto vaginal anterior & $\mathbf{2 1 7}$ & $0,8(0,9)$ & 1,0 & 0 & 5 \\
Cesariana anterior & $\mathbf{2 1 7}$ & $0,6(0,7)$ & 1,0 & 0 & 3 \\
RN de maior peso $(\mathrm{g})$ & $\mathbf{2 1 5}$ & $3132,4(597,5)$ & 3200,0 & 500 & 5.370 \\
\hline
\end{tabular}

Fonte: a pesquisadora 
Tabela 5 - Distribuição das gestantes na etapa 1 da coorte conforme a faixa etária, cor da pele, escolaridade, ocupação, gestação, aborto, parto vaginal e cesariana anteriores, trauma perineal em parto anterior, IU e IA prévias à gestação e momento da IU e IA, Guarulhos, SP - 2012-2014

\begin{tabular}{|c|c|c|}
\hline Variável & $\mathbf{n}$ & $\%$ \\
\hline Faixa etária (anos) & 500 & \\
\hline$<20$ & 37 & 7,4 \\
\hline $20 \vdash 25$ & 118 & 23,6 \\
\hline $25 \vdash 30$ & 152 & 30,4 \\
\hline $30 \vdash 35$ & 121 & 24,2 \\
\hline $35 \vdash 40$ & 54 & 10,8 \\
\hline$\geq 40$ & 18 & 3,6 \\
\hline Cor da pele & 499 & \\
\hline Parda & 250 & 50,1 \\
\hline Branca & 186 & 37,3 \\
\hline Negra & 59 & 11,8 \\
\hline Amarela & 4 & 0,8 \\
\hline Escolaridade & 499 & \\
\hline Ensino fundamental & 53 & 10,6 \\
\hline Ensino médio & 351 & 70,4 \\
\hline Ensino superior & 95 & 19,0 \\
\hline Ocupação & 500 & \\
\hline Trabalho remunerado & 389 & 77,8 \\
\hline Do lar & 108 & 21,6 \\
\hline Estudante & 3 & 0,6 \\
\hline Gestação anterior & 500 & \\
\hline Nenhuma & 254 & 50,8 \\
\hline Uma & 156 & 31,2 \\
\hline Duas & 62 & 12,4 \\
\hline Três ou mais & 28 & 5,6 \\
\hline Aborto anterior & 500 & \\
\hline Nenhum & 430 & 86,0 \\
\hline Um & 64 & 12,8 \\
\hline Dois & 5 & 1,0 \\
\hline Três ou mais & 1 & 0,2 \\
\hline Parto vaginal anterior & 500 & \\
\hline Nenhum & 376 & 75,2 \\
\hline $\mathrm{Um}$ & 90 & 18,0 \\
\hline Dois & 25 & 5,0 \\
\hline Três ou mais & 9 & 1,8 \\
\hline Cesariana anterior & 500 & \\
\hline Nenhuma & 381 & 76,2 \\
\hline Uma & 92 & 18,4 \\
\hline Duas & 15 & 3,0 \\
\hline Três & 2 & 0,4 \\
\hline Trauma perineal em parto anterior & 498 & \\
\hline Sim & 119 & 23,9 \\
\hline Não & 379 & $\begin{array}{r}76,1 \\
\quad \text { co }\end{array}$ \\
\hline
\end{tabular}




\begin{tabular}{lcc} 
Tabela 5 & & (cont.) \\
\hline Variável & $\mathbf{n}$ & $\mathbf{\%}$ \\
\hline IU prévia & $\mathbf{4 9 9}$ & 39,1 \\
Sim & 195 & 60,9 \\
Não & 304 & \\
Momento da IU prévia & $\mathbf{1 9 5}$ & 72,8 \\
Antes da gestação atual que persiste & 142 & 15,9 \\
Somente em gestação anterior & 31 & 11,3 \\
Em gestação anterior e que persiste & 22 & 22,6 \\
IA prévia & $\mathbf{4 9 9}$ & 77,4 \\
Sim* & 113 & \\
Não & 386 & 77,9 \\
Momento da IA prévia & $\mathbf{1 1 3}$ & 17,7 \\
Antes da gestação atual que persiste* & 88 & 4,4 \\
Em gestação anterior e que persiste & 20 & 5 \\
Somente em gestação anterior & 5 & \\
\hline
\end{tabular}

*Incontinência de flatos; quatro gestantes com incontinência de fezes.

Fonte: a pesquisadora

Os dados da Tabela 6 apresenta a média da idade gestacional das mulheres nas três etapas do estudo. As gestantes foram incluídas na coorte com idade gestacional mínima de 4 semanas e média de 8,6 (d.p.=1,9). Na etapa 2, a idade gestacional média foi de 22,9 (d.p.=1,3) semanas, com mínimo de 20 e máximo de 27. Na etapa 3, a média da idade gestacional foi de 34,7 (d.p.=1,3) semanas, variando entre 31 e 38 semanas.

Tabela 6 - Distribuição das gestantes nas etapas 1, 2 e 3 da coorte, conforme a idade gestacional, Guarulhos, SP - 2012-2014

\begin{tabular}{ccccccc}
\hline \multirow{2}{*}{ Etapa da coorte } & \multirow{2}{*}{$\mathbf{n}$} & \multicolumn{5}{c}{ Idade gestacional (semanas) } \\
\cline { 3 - 7 } & & Média (d.p.) & $\mathbf{9 5 \%}$ IC & Mediana & Mín & Máx \\
\hline 1 & $\mathbf{5 0 0}$ & $8,6(1,9)$ & $8,4-8,7$ & 8,0 & 4 & 12 \\
2 & $\mathbf{2 2 6}$ & $22,9(1,3)$ & $22,8-23,1$ & 23,0 & 20 & 27 \\
3 & $\mathbf{1 8 7}$ & $34,7(1,3)$ & $34,5-34,9$ & 35,0 & 31 & 38
\end{tabular}

Fonte: a pesquisadora

Nos dados da Tabela 7, são apresentadas as características das gestantes em relação às variáveis situação conjugal, estado nutricional e exercício perineal não supervisionado e supervisionado, coletadas em todas as etapas da coorte, ou seja, no primeiro, segundo e terceiro trimestres da gestação.

No primeiro trimestre da gestação, $86,5 \%$ das mulheres viviam com o parceiro e este percentual elevou-se para 98,2\% e 98,4\% nos trimestres seguintes. Em relação ao estado nutricional, no início da gestação, a faixa de peso predominante era adequada $(45,6 \%)$, próxima do sobrepeso e obesidade $(45,1 \%)$; no entanto, ao longo da gestação, 
essa proporção inverteu-se, com predomínio do sobrepeso e obesidade $(48,2 \%)$ no final da gestação e aumento do percentual de gestantes com baixo peso (9,3\% vs 12,8\%).

Conforme referido no Método, ao serem incluídas na coorte, todas as gestantes foram orientadas, verbalmente e por escrito, a realizarem exercícios perineais, denominados CT não supervisionada do AP. Os resultados indicaram que menos de um terço das mulheres aderiu à realização dos exercícios em casa, de forma regular, ou seja, no mínimo duas vezes por semana $(29,8 \%$ e $32,6 \%$, nos segundo e terceiro trimestres da gestação, respectivamente). Além disso, aquelas com IU foram convidadas a participar de sessões quinzenais de CT supervisionada do AP, realizadas entre as etapas 2 e 3 da coorte; do total de participantes da coorte, 12,8\% frequentaram pelo menos, quatro sessões.

Tabela 7 - Distribuição das gestantes nas etapas 1, 2 e 3 da coorte conforme a situação conjugal, estado nutricional e exercícios perineais, Guarulhos, SP - 2012-2014

\begin{tabular}{lcccccc}
\hline \multirow{2}{*}{ Variável } & \multicolumn{2}{c}{ Etapa 1 } & \multicolumn{2}{c}{ Etapa 2 } & \multicolumn{2}{c}{ Etapa 3 } \\
\cline { 2 - 7 } & $\mathbf{n}$ & $\mathbf{\%}$ & $\mathbf{n}$ & $\mathbf{\%}$ & $\mathbf{n}$ & $\mathbf{\%}$ \\
\hline Situação conjugal & $\mathbf{4 9 8}$ & & $\mathbf{2 2 6}$ & & $\mathbf{1 8 7}$ & \\
Vive com parceiro & 431 & 86,5 & 222 & 98,2 & 184 & 98,4 \\
Não vive com parceiro & 67 & 13,5 & 4 & 1,8 & 3 & 1,6 \\
Estado nutricional & $\mathbf{4 9 7}$ & & $\mathbf{2 2 5}$ & & $\mathbf{1 8 7}$ & \\
Baixo peso & 46 & 9,3 & 32 & 14,2 & 24 & 12,8 \\
Adequado & 227 & 45,6 & 86 & 38,2 & 73 & 39,0 \\
Sobrepeso & 163 & 32,8 & 81 & 36,0 & 57 & 30,5 \\
Obesidade & 61 & 12,3 & 26 & 11,6 & 33 & 17,7 \\
Exercício não supervisionado & & & $\mathbf{2 2 5}$ & & $\mathbf{1 8 7}$ & \\
Regularmente & - & - & 67 & 29,8 & 61 & 32,6 \\
Nunca ou esporadicamente & - & - & 158 & 70,2 & 126 & 67,4 \\
Exercício supervisionado & & & & & $\mathbf{1 8 7}$ & \\
Sim & - & - & - & - & 24 & 12,8 \\
Não & - & - & - & - & 163 & 87,2 \\
\hline
\end{tabular}

Fonte: a pesquisadora 


\subsection{Análise inferencial da FMAP, IU, ICIQ-SF e IA ao longo da gestação}

A variação da FMAP está apresentada nos dados da Tabela 8. Embora sem diferença estatisticamente significante e intervalos de confiança coincidentes, houve decréscimo progressivo na média da FMAP, ao longo da gestação, com redução de 1,8 $\mathrm{cmH}_{2} \mathrm{O}$. Considerando a totalidade das gestantes em cada etapa da coorte, a média da FMAP manteve-se entre 30,5 (d.p.=17,3) e 28,7 (d.p.=15,5) $\mathrm{cmH}_{2} \mathrm{O}$.

Em relação ao escore do ICIQ-SF, a média manteve-se entre 8,3 (d.p.=4,0) e 7,8 (d.p.=4,1), sem diferença estatisticamente significante e intervalos de confiança coincidentes, nas três etapas do estudo.

Tabela 8 - Valores da média, desvio-padrão (d.p.), intervalo de confiança de $95 \%$ (95\% IC), mediana, mínimo, máximo e valor-p da FMPA em $\mathrm{cmH}_{2} \mathrm{O}$ e do escore do ICIQ-SF das gestantes nas etapas 1, 2 e 3 da coorte, Guarulhos, SP - 2012-2014

\begin{tabular}{lcccccc}
\hline Variável & N & Média (d.p.) & $\mathbf{9 5 \%}$ IC & Mediana & Mín & Máx \\
\hline FMAP $\left(\mathrm{cmH}_{2} \mathrm{O}\right)$ & & & & & & \\
Etapa 1 & $\mathbf{5 0 0}$ & $30,5(17,3)$ & $29,0-32,1$ & 27,6 & 1,5 & 121,0 \\
Etapa 2 & $\mathbf{2 1 8}$ & $29,2(14,9)$ & $27,2-31,2$ & 28,7 & 1,9 & 77,4 \\
Etapa 3 & $\mathbf{1 7 4}$ & $28,7(15,5)$ & $26,4-31,0$ & 26,0 & 2,9 & 86,6 \\
Valor-p* & & 0,342 & & & & \\
Escore ICIQ-SF & & & & & & \\
Etapa 1 & $\mathbf{9 0}$ & $8,2(3,9)$ & $7,4-9,0$ & 8,0 & 2 & 18 \\
Etapa 2 & $\mathbf{9 5}$ & $8,3(4,0)$ & $7,5-9,1$ & 8,0 & 3 & 21 \\
Etapa 3 & $\mathbf{6 4}$ & $7,8(4,1)$ & $6,8-8,8$ & 7,0 & 0 & 20 \\
Valor-p* & & 0,617 & & & & \\
\hline
\end{tabular}

*LMM

Fonte: a pesquisadora

Os dados da Tabela 9 apresentam a análise FMAP nas etapas da coorte, considerando o ponto de corte de $30 \mathrm{cmH}_{2} \mathrm{O}$; a proporção de gestantes com média da FMAP abaixo desse valor prevaleceu em todas as etapas, em especial, no último trimestre. Apesar dos intervalos de confiança coincidentes, não houve diferença estaticamente significante.

A mesma tabela mostra que houve diferença estatisticamente significante na prevalência de IU ao longo da gestação $(<0,001)$. No primeiro trimestre, 19,0\% das gestantes apresentavam IU. Esta proporção foi maior no segundo trimestre, afetando a 42,5\% das gestantes. Embora tenha ocorrido um declínio no último trimestre, mais de um terço das gestantes referia IU (35,3\%). Em relação à IA, a prevalência manteve-se entre $11,5 \%$ e $7,5 \%$, sem diferença estatisticamente significante nas três etapas da coorte (Tabela 9). 
Tabela 9 - Distribuição das gestantes nas etapas 1, 2 e 3 da coorte, conforme a FMAP, IU e IA e valor-p, Guarulhos, SP - 2012-2014

\begin{tabular}{|c|c|c|c|c|c|c|c|c|c|c|}
\hline \multirow{2}{*}{ Variável } & \multicolumn{3}{|c|}{ Etapa 1} & \multicolumn{3}{|c|}{ Etapa 2} & \multicolumn{3}{|c|}{ Etapa 3} & \multirow{2}{*}{$\begin{array}{c}\text { Valor- } \\
\mathbf{p}^{*}\end{array}$} \\
\hline & $\mathbf{n}$ & $\%$ & $95 \%$ IC & $\mathbf{n}$ & $\%$ & $95 \%$ IC & $\mathbf{n}$ & $\%$ & $95 \%$ IC & \\
\hline FMAP $(\mathrm{cmH} 2 \mathrm{O})$ & 500 & & & 218 & & & 174 & & & \\
\hline$<30$ & 277 & 55,4 & $51,1-59,8$ & 114 & 52,3 & $45,6-58,9$ & 101 & 58,0 & $50,7-65,4$ & \\
\hline$\geq 30$ & 223 & 44,6 & $40,2-49,0$ & 104 & 47,7 & $41,0-54,4$ & 73 & 42,0 & $34,5-49,4$ & 0,055 \\
\hline IU & 500 & & & 226 & & & 187 & & & \\
\hline Sim & 95 & 19,0 & $15,6-22,4$ & 96 & 42,5 & $36,0-48,9$ & 66 & 35,3 & $28,4-42,1$ & $<0001$ \\
\hline Não & 405 & 81,0 & - & 130 & 57,5 & - & 121 & 64,7 & - & $<0,001$ \\
\hline IA & 499 & & & 226 & & & 187 & & & \\
\hline $\operatorname{Sim}^{\dagger}$ & 50 & 10,0 & $7,4-12,7$ & 26 & 11,5 & $7,3-15,7$ & 14 & 7,5 & $3,7-11,3$ & 0.321 \\
\hline Não & 449 & 90,0 & - & 200 & 88,5 & - & 173 & 92,5 & - & \\
\hline
\end{tabular}

*GEE; †Incontinência de flatos, uma gestante na etapa 1 e duas gestantes na etapa 2 com incontinência de fezes

Fonte: a pesquisadora

Ainda em relação à IU e IA, foi calculada a incidência nas etapas 1, 2 e 3 da coorte e em toda a gestação. Na etapa 1, a incidência foi calculada excluindo as gestantes que referiram IU e IA prévias à gestação atual, persistente após o início da gravidez atual. Para a IU, a incidência foi de 3,8\%,21,2\% e 7,0\% nas três etapas, respectivamente. Na gestação, a incidência foi de 18,6\%. Para a IA, a incidência foi de $1,6 \%, 6,2 \%, 1,6 \%$ e 5,4\%, nas etapas 1,2 e 3 e na gestação, respectivamente (dados não constam em tabela).

Quanto à classificação da IU, esta pode ser considerada como de esforço, urgência ou mista. De acordo com o ICQ-SF, as gestantes que referiram perda de urina relataram um ou mais momentos em que esta aconteceu. Os dados da Tabela 10 descrevem as situações em que as mulheres referiram perda urinária. 
Tabela 10 - Distribuição das situações em que ocorre IU nas etapas 1, 2 e 3 conforme respostas das gestantes à questão 6 do ICIQ-SF (Quando você perde urina?), Guarulhos, SP - 2012-2014

\begin{tabular}{|c|c|c|c|c|c|c|}
\hline \multirow{2}{*}{ Situação em que ocorre IU* } & \multicolumn{2}{|c|}{ Etapa 1} & \multicolumn{2}{|c|}{ Etapa 2} & \multicolumn{2}{|c|}{ Etapa 3} \\
\hline & $\mathbf{n}$ & $\%$ & $\mathbf{n}$ & $\%$ & $\mathbf{n}$ & $\%$ \\
\hline "Perco antes de chegar ao banheiro" & 41 & 31,8 & 35 & 26,3 & 22 & 26,5 \\
\hline "Perco quando tusso ou espirro" & 50 & 38,8 & 63 & 47,4 & 36 & 43,4 \\
\hline "Perco quando estou dormindo" & 9 & 7,0 & 6 & 4,5 & 5 & 6,0 \\
\hline "Perco quando estou fazendo atividades físicas" & 7 & 5,4 & 10 & 7,5 & 1 & 1,2 \\
\hline "Perco quando terminei de urinar e estou me vestindo" & 12 & 9,3 & 10 & 7,5 & 10 & 12,0 \\
\hline "Perco sem razão óbvia" & 8 & 6,2 & 8 & 6,0 & 8 & 9,6 \\
\hline "Perco o tempo todo" & 2 & 1,6 & 1 & 0,8 & 1 & 1,2 \\
\hline Total & 129 & 100 & 133 & 100 & 83 & 100 \\
\hline
\end{tabular}

*Cada gestante respondeu uma ou mais situações

Fonte: a pesquisadora

A seguir, é apresentada a análise da FMAP conforme as variáveis sociodemográficas, obstétricas e clínicas. A idade materna, gestações, abortos, partos vaginais e cesarianas anteriores e maior peso do RN em parto anterior foram analisadas de forma contínua e categórica.

Os resultados mostram que houve associação estatisticamente significante entre a média da FMAP e o número de gestações, de partos vaginais e de cesarianas anteriores $(\mathrm{p}=0,004, \mathrm{p}=0,004$ e $\mathrm{p}=0,002$, respectivamente), independentemente da etapa do estudo. Em relação a gestações e partos vaginais, houve uma fraca correlação negativa, indicando que a FMAP se reduz com o aumento do número de gestações e partos vaginais. Em relação ao número e cesarianas anteriores, embora fraca, a correlação foi positiva (Tabela 11).

As variáveis gestações e partos vaginais anteriores, quando analisadas como categóricas, mostraram também associação estatisticamente significante ( $\mathrm{p}=0,009$ e $\mathrm{p}<0,001$, respectivamente), assim como as variáveis aborto anterior ( $\mathrm{p}=0,051)$ e trauma perineal em parto anterior $(\mathrm{p}<0,001)$. Vale destacar que entre as gestantes com antecedentes de gestação, aborto, parto vaginal e trauma perineal, a média da FMAP manteve-se abaixo de $30 \mathrm{cmH}_{2} \mathrm{O}$ em todas as etapas do estudo (Tabela 12). 
Ainda em relação à FMAP, as demais variáveis que mostraram associação estatisticamente significante foram IU prévia e atual ( $\mathrm{p}=0,037$ e $\mathrm{p}=0,005$, respectivamente), IA prévia $(\mathrm{p}<0,001)$ e exercício perineal não supervisionado (0,049); para as gestantes com IA prévia, houve também associação estatisticamente significante, considerando-se as etapas do estudo $(\mathrm{p}=0,016)$. Entre as gestantes com IU prévia e atual, a média da FMAP variou de 28,2 a 25,9 $\mathrm{cmH}_{2} \mathrm{O}$ e de 25,0 a $27,2 \mathrm{cmH}_{2} \mathrm{O}$ (Tabela 12).

Tabela 11 - Correlação de Pearson entre a FMAP e a idade materna, número de gestações, abortos, partos vaginais e cesarianas anteriores e maior peso do RN em parto anterior e valor-p, Guarulhos, SP - 2012-2014

\begin{tabular}{|c|c|c|c|c|c|c|c|c|}
\hline \multirow{3}{*}{ Variável } & \multicolumn{6}{|c|}{ FMAP $\left(\mathrm{cmH}_{2} \mathrm{O}\right)$} & \multirow{3}{*}{ Valor-p* } & \multirow{3}{*}{$\begin{array}{c}\text { Valor-p* } \\
\text { Xtapa }\end{array}$} \\
\hline & \multicolumn{2}{|c|}{ Etapa 1} & \multicolumn{2}{|c|}{ Etapa 2} & \multicolumn{2}{|c|}{ Etapa 3} & & \\
\hline & $\mathbf{n}$ & $\mathbf{r} \dagger$ & $\mathbf{n}$ & $\mathbf{r}_{\dagger}^{\dagger}$ & $\mathbf{n}$ & $\mathbf{r} \dagger$ & & \\
\hline Idade materna (anos) & 500 & $-0,004$ & 218 & $-0,031$ & 174 & $-0,086$ & 0,477 & 0,529 \\
\hline Gestação anterior & 500 & $-0,098$ & 218 & $-0,156$ & 174 & $-0,135$ & 0,004 & 0,514 \\
\hline Aborto anterior & 246 & $-0,072$ & 218 & $-0,071$ & 174 & $-0,035$ & 0,237 & 0,780 \\
\hline Parto vaginal anterior & 217 & $-0,149$ & 83 & $-0,174$ & 65 & $-0,251$ & 0,004 & 0,448 \\
\hline Cesariana anterior & 217 & 0,183 & 83 & 0,142 & 65 & 0,294 & 0,002 & 0,503 \\
\hline $\mathrm{RN}$ de maior peso $(\mathrm{g})$ & 215 & 0,038 & 81 & 0,104 & 65 & 0,062 & 0,921 & 0,557 \\
\hline
\end{tabular}

*LMM; †r > 0,70: correlação forte, $r=0,30-0,70$ : correlação moderada, $r<0,0-0,30$ correlação fraca

Fonte: a pesquisadora 
Tabela 12 - Distribuição das gestantes nas etapas 1, 2 e 3 da coorte, conforme a FMAP e a faixa etária, cor da pele, escolaridade, ocupação, situação conjugal, gestação, aborto, parto vaginal e cesariana anteriores, trauma perineal em parto anterior, IU e IA prévia e atual, estado nutricional, exercícios perineais e maior peso do RN em parto anterior e valor-p, Guarulhos, SP - 2012-2014

\begin{tabular}{|c|c|c|c|c|c|c|c|c|}
\hline \multirow{3}{*}{ Variável } & \multicolumn{6}{|c|}{ FMAP $\left(\mathrm{cmH}_{2} \mathrm{O}\right)$} & \multirow{3}{*}{$\begin{array}{c}\text { Valor- } \\
\text { p }^{*}\end{array}$} & \multirow{3}{*}{$\begin{array}{c}\text { Valor-p* } \\
\mathbf{X} \\
\text { etapa }\end{array}$} \\
\hline & \multicolumn{2}{|c|}{ Etapa 1} & \multicolumn{2}{|c|}{ Etapa 2} & \multicolumn{2}{|c|}{ Etapa 3} & & \\
\hline & $\mathbf{n}$ & Média (d.p.) & $\mathbf{n}$ & Média (d.p.) & $\mathbf{n}$ & Média (d.p.) & & \\
\hline Faixa etária (anos) & 500 & & 218 & & 174 & & & \\
\hline$<20$ & 37 & $30,1(16,0)$ & 19 & $29,8(13,0)$ & 19 & $28,3(14,2)$ & & \\
\hline $20 \vdash 25$ & 118 & $30,5(17,4)$ & 53 & $29,9(15,1)$ & 41 & $32,3(16,8)$ & & \\
\hline $25 \vdash 30$ & 152 & $30,6(17,6)$ & 68 & $28,7(14,0)$ & 47 & $26,5(15,3)$ & & \\
\hline $30 \vdash 35$ & 121 & $30,7(18,6)$ & 54 & $27,3(15,0)$ & 50 & $28,3(14,5)$ & 0,891 & 0,543 \\
\hline $35 \vdash 40$ & 54 & $30,5(15,5)$ & 19 & $36,1(17,0)$ & 13 & $30,7(18,1)$ & & \\
\hline$\geq 40$ & 18 & $29,8(14,8)$ & 5 & $21,8(19,1)$ & 4 & $18,1(9,1)$ & & \\
\hline Cor da pele & 499 & & 218 & & 174 & & & \\
\hline Parda & 250 & $29,4(16,4)$ & 110 & $28,9(14,7)$ & 96 & $28,3(14,7)$ & & \\
\hline Branca & 186 & $31,9(17,8)$ & 80 & $30,6(15,1)$ & 56 & $28,5(15,5)$ & & \\
\hline Negra & 59 & $31,2(19,2)$ & 26 & $25,9(14,8)$ & 20 & $30,8(19,8)$ & 0,435 & 0,641 \\
\hline Amarela & 4 & $28,8(18,6)$ & 2 & $32,3(21,6)$ & 2 & $33,1(7,7)$ & & \\
\hline Escolaridade & 499 & & 218 & & 174 & & & \\
\hline Ensino fundamental & 53 & $29,6(17,0)$ & 23 & $32,2(17,7)$ & 17 & $30,4(17,5)$ & & \\
\hline Ensino médio & 351 & $29,6(16,6)$ & 156 & $27,6(15,0)$ & 133 & $28,2(15,8)$ & 0,103 & 0,425 \\
\hline Ensino superior & 95 & $33,7(19,2)$ & 39 & $34,0(11,5)$ & 24 & $30,3(12,4)$ & & \\
\hline Ocupação & 500 & & 218 & & 174 & & & \\
\hline Trabalho remunerado & 389 & $31,3(17,7)$ & 163 & $29,4(14,6)$ & 132 & $29,0(15,2)$ & & \\
\hline Do lar ou estudante & 111 & $27,9(15,6)$ & 55 & $28,6(15,7)$ & 42 & $28,0(16,6)$ & 0,180 & 0,606 \\
\hline Situação conjugal & 498 & & 218 & & 174 & & & \\
\hline Vive com parceiro & 431 & $30,7(17,1)$ & 214 & $29,4(14,9)$ & 171 & $28,8(15,6)$ & & \\
\hline Não vive com parceiro & 67 & $29,5(18,8)$ & 4 & $19,2(10,6)$ & 3 & $25,4(8,5)$ & 0,684 & \\
\hline
\end{tabular}


Tabela 12

(cont.)

\begin{tabular}{|c|c|c|c|c|c|c|c|c|}
\hline \multirow{3}{*}{ Variável } & \multicolumn{6}{|c|}{ FMAP $\left(\mathrm{cmH}_{2} \mathrm{O}\right)$} & \multirow{3}{*}{$\begin{array}{c}\text { Valor- } \\
\text { p }^{*}\end{array}$} & \multirow{3}{*}{$\begin{array}{c}\text { Valor-p* } \\
\mathbf{X} \\
\text { etapa } \\
\end{array}$} \\
\hline & \multicolumn{2}{|c|}{ Etapa 1} & \multicolumn{2}{|c|}{ Etapa 2} & \multicolumn{2}{|c|}{ Etapa 3} & & \\
\hline & $\mathbf{n}$ & Média (d.p.) & $\mathbf{n}$ & Média (d.p.) & $\mathbf{n}$ & Média (d.p.) & & \\
\hline Gestação anterior & 500 & & 218 & & 174 & & & \\
\hline Sim & 246 & $28,9(16,2)$ & 48 & $27,0(15,3)$ & 40 & $26,1(14,6)$ & & \\
\hline Não & 254 & $32,0(18,1)$ & 170 & $31,0(14,4)$ & 134 & $28,6(15,0)$ & 0,009 & 0,592 \\
\hline Aborto anterior & 500 & & 218 & & 174 & & & \\
\hline Sim & 70 & $26,7(15,5)$ & 27 & $25,7(12,7)$ & 11 & $24,7(11,4)$ & & \\
\hline Não & 430 & $31,1(17,5)$ & 191 & $29,7(15,1)$ & 163 & $30,5(14,6)$ & $0,0 \supset 1$ & 0,432 \\
\hline Parto vaginal anterior & 500 & & 218 & & 174 & & & \\
\hline Sim & 124 & $26,1(14,7)$ & 44 & $24,7(16,3)$ & 35 & $23,2(11,8)$ & & \\
\hline Não & 376 & $32,0(17,9)$ & 174 & $30,4(14,3)$ & 139 & $30,1(16,0)$ & $<0,001$ & 0,513 \\
\hline Cesárea anterior & 500 & & 218 & & 174 & & & \\
\hline Sim & 109 & $31,5(17,2)$ & 43 & $28,0(15,3)$ & 32 & $29,6(17,3)$ & & \\
\hline Não & 391 & $30,3(17,3)$ & 175 & $29,5(14,8)$ & 142 & $28,5(15,1)$ & 0,681 & 0,501 \\
\hline Trauma perineal em parto anterior & 498 & & 218 & & 174 & & & \\
\hline Sim & 119 & $26,7(14,6)$ & 44 & $24,7(16,3)$ & 35 & $23,2(11,8)$ & & \\
\hline Não & 379 & $31,8(17,9)$ & 174 & $30,4(14,3)$ & 139 & $30,1(16,0)$ & $<0,001$ & 0,449 \\
\hline IU prévia & 499 & & 218 & & 174 & & & \\
\hline Sim & 195 & $28,2(17,8)$ & 82 & $25,9(14,8)$ & 69 & $27,3(15,3)$ & & \\
\hline Não & 304 & $32,0(16,8)$ & 136 & $31,2(14,7)$ & 105 & $29,6(15,6)$ & 0,037 & 0,087 \\
\hline IU atual & 500 & & 218 & & 174 & & & \\
\hline Sim & 95 & $27,2(15,8)$ & 93 & $25,1(14,9)$ & 61 & $25,0(13,7)$ & & \\
\hline Não & 405 & $31,3(17,6)$ & 125 & $32,2(14,2)$ & 113 & $30,7(16,1)$ & 0,005 & 0,374 \\
\hline IA prévia & 499 & & 218 & & 174 & & & \\
\hline Sim & 113 & $32,3(20,6)$ & 48 & $33,8(15,9)$ & 40 & $29,1(17,2)$ & & \\
\hline Não & 386 & $30,0(16,2)$ & 170 & $27,9(27,9)$ & 134 & $28,6(15,0)$ & $<0,001$ & 0,016 \\
\hline IA atual & 499 & & 218 & & 174 & & & \\
\hline Sim & 50 & $34,2(23,4)$ & 26 & $27,1(15,0)$ & 13 & $32,0(20,4)$ & & \\
\hline Não & 449 & $30,1(16,5)$ & 192 & $29,5(14,9)$ & 161 & $28,4(15,1)$ & 0,346 & 0,619 \\
\hline
\end{tabular}

(continua) 
Tabela 12

(cont.)

\begin{tabular}{|c|c|c|c|c|c|c|c|c|}
\hline \multirow{3}{*}{ Variável } & \multicolumn{6}{|c|}{ FMAP $\left(\mathrm{cmH}_{2} \mathrm{O}\right)$} & \multirow{3}{*}{$\begin{array}{c}\text { Valor- } \\
\mathbf{p}^{*}\end{array}$} & \multirow{3}{*}{$\begin{array}{c}\text { Valor-p* } \\
\mathbf{X} \\
\text { etapa } \\
\end{array}$} \\
\hline & \multicolumn{2}{|r|}{ Etapa 1} & \multicolumn{2}{|c|}{ Etapa 2} & \multicolumn{2}{|c|}{ Etapa 3} & & \\
\hline & $\mathbf{n}$ & Média (d.p.) & $\mathbf{n}$ & Média (d.p.) & $\mathbf{n}$ & Média (d.p.) & & \\
\hline Estado nutricional & 497 & & 218 & & 174 & & & \\
\hline Baixo peso & 46 & $27,0(12,6)$ & 32 & $29,5(14,8)$ & 24 & $31,4(14,2)$ & & \\
\hline Adequado & 227 & $32,4(18,7)$ & 82 & $31,1(14,3)$ & 69 & $30,4(16,9)$ & & \\
\hline Sobrepeso & 163 & $30,8(16,8)$ & 78 & $28,2(15,4)$ & 53 & $28,0(14,2)$ & 0,173 & 0,584 \\
\hline Obesidade & 61 & $25,7(15,4)$ & 26 & $26,0(15,3)$ & 28 & $23,6(14,7)$ & & \\
\hline Exercício não supervisionado & & & 218 & & 174 & & & \\
\hline Regularmente & - & - & 65 & $32,0(14,9)$ & 57 & $28,8(14,0)$ & & \\
\hline Nunca ou esporadicamente & - & - & 153 & $28,0(14,8)$ & 117 & $28,6(16,2)$ & 0,049 & 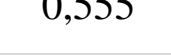 \\
\hline Exercício supervisionado & & & & & 174 & & & \\
\hline Sim & - & - & - & - & 23 & $28,6(15,2)$ & & \\
\hline Não & - & - & - & - & 151 & $29,1(16,6)$ & 0,901 & \\
\hline RN de maior peso (g) & 215 & & 81 & & 65 & & & \\
\hline$<2500$ & 24 & $27,0(15,6)$ & 8 & $28,5(16,4)$ & 6 & $23,4(19,9)$ & & \\
\hline $2500 \vdash 4000$ & 180 & $29,3(15,6)$ & 70 & $27,0(16,2)$ & 57 & $26,5(15,0)$ & 0,948 & 0,746 \\
\hline$\geq 4000$ & 11 & $25,6(12,6)$ & 3 & $30,2(6,6)$ & 2 & $25,8(5,9)$ & & \\
\hline
\end{tabular}

*LMM

Fonte: a pesquisadora

A análise da IU, conforme as variáveis sociodemográficas, obstétricas e clínicas é apresentada nos dados da Tabela 13 (variáveis contínuas) e nos dados da Tabela 14 (variáveis categóricas).

As variáveis que mostraram associação estatisticamente significante com a IU, independentemente da etapa da coorte, foram: idade materna, com média maior entre as gestantes com IU ( $p=0,044)$ (Tabela 13); situação conjugal (vivem com parceiro; $p=0,035$ ); parto vaginal anterior e trauma perineal em parto anterior (com antecedente de parto vaginal e trauma perineal; $p=0,001$, para ambas); IU prévia (sim; $\mathrm{p}<0,001)$; estado nutricional (sobrepeso e obesidade; $\mathrm{p}=0,011)$; FMAP $\left(<30 \mathrm{cmH}_{2} \mathrm{O} ; \mathrm{p}<0,001\right)$; exercício perineal não supervisionado (regularmente; $\mathrm{p}=0,021)$. Para as variáveis parto vaginal anterior, trauma perineal em parto anterior e IU prévia, houve associação 
estatisticamente significante também para a interação com o trimestre gestacional. Para as variáveis com valor em alguma das etapas, não foi possível calcular a interação, recebendo a denominação técnica de "separação perfeita" (Tabela 14).

Tabela 13 - Valores da média, desvio-padrão (d.p.), intervalo de confiança de 95\% (95\% IC), mediana, mínimo, máximo e valor-p da IU nas etapas 1,2 e 3 da coorte conforme a idade materna, número de gestações, abortos, partos vaginais e cesarianas anteriores e maior peso do RN em parto anterior, Guarulhos, SP - 2012-2014.

\begin{tabular}{|c|c|c|c|c|c|c|c|c|c|c|c|}
\hline \multirow{3}{*}{ Variável } & \multicolumn{9}{|c|}{ IU } & \multirow{3}{*}{ Valor-p* } & \multirow{3}{*}{$\begin{array}{c}\text { Valor-p* } \\
\text { etapa }\end{array}$} \\
\hline & \multicolumn{3}{|c|}{ Etapa 1} & \multicolumn{3}{|c|}{ Etapa 2} & \multicolumn{3}{|c|}{ Etapa 3} & & \\
\hline & $\mathbf{n}$ & Sim & Não & $\mathbf{n}$ & Sim & Não & $\mathbf{n}$ & Sim & Não & & \\
\hline Idade materna (anos) & 500 & & & 226 & & & 187 & & & & \\
\hline Média (d.p.) & & $29,4(6,3)$ & $27,5(5,9)$ & & $\begin{array}{l}28,1 \\
(6,2)\end{array}$ & $27,0(5,2)$ & & $27,9(5,9)$ & $27,0(5,8)$ & & \\
\hline $95 \%$ IC & & $28,1-30,7$ & $26,9-28,0$ & & $\begin{array}{c}26,8- \\
29,3\end{array}$ & $\begin{array}{c}26,1- \\
27,9\end{array}$ & & $\begin{array}{c}26,5- \\
29,4\end{array}$ & $\begin{array}{c}26,0- \\
28,0\end{array}$ & 0,044 & 0,726 \\
\hline Mediana & & 30,0 & 27,0 & & 28,0 & 26,5 & & 29,0 & 27,0 & & \\
\hline Mínimo & & 18 & 18 & & 18 & 18 & & 18 & 18 & & \\
\hline Máximo & & 46 & 45 & & 42 & 46 & & 45 & 46 & & \\
\hline Gestação anterior & 500 & & & 226 & & & 187 & & & & \\
\hline Média (d.p.) & & $1,0(1,2)$ & $0,7(0,9)$ & & $0,9(1,1)$ & $0,5(0,7)$ & & $0,6(8,0)$ & $0,5(0,7)$ & & \\
\hline $95 \%$ IC & & $0,8-1,3$ & $0,6-0,8$ & & $0,6-1,1$ & $0,4-0,6$ & & $0,4-0,8$ & $0,4-0,7$ & & \\
\hline Mediana & & 1,0 & 0,0 & & 1,0 & 0,0 & & 0,0 & 0,0 & 0,094 & 0,138 \\
\hline Mínimo & & 1 & 0 & & 0 & 0 & & 0 & 0 & & \\
\hline Máximo & & 5 & 7 & & 7 & 3 & & 4 & 3 & & \\
\hline Aborto anterior & 246 & & & & & & & & & & \\
\hline Média (d.p.) & & $0,3(0,6)$ & $0,3(0,5)$ & & $0,4(0,9)$ & $0,3(0,5)$ & & $0,3(0,5)$ & $0,1(0,4)$ & & \\
\hline $95 \%$ IC & & $0,1-0,4$ & $0,3-0,4$ & & $0,2-0,6$ & $0,1-0,4$ & & $0,1-0,5$ & $0,0-0,4$ & & \\
\hline Mediana & & 0,0 & 0,0 & & 0,0 & 0,0 & & 0,0 & 0,0 & 0,273 & 0,159 \\
\hline Mínimo & & 0 & 0 & & 0 & 0 & & 0 & 0 & & \\
\hline Máximo & & 2 & 5 & & 2 & 5 & & 2 & 1 & & \\
\hline
\end{tabular}


Tabela 13

(cont.)

\begin{tabular}{|c|c|c|c|c|c|c|c|c|c|c|c|}
\hline \multirow{3}{*}{ Variável } & \multicolumn{9}{|c|}{ IU } & \multirow{3}{*}{ Valor-p* } & \multirow{3}{*}{$\begin{array}{c}\text { Valor-p* } \\
\mathbf{X} \\
\text { etapa }\end{array}$} \\
\hline & \multicolumn{3}{|c|}{ Etapa 1} & \multicolumn{3}{|c|}{ Etapa 2} & \multicolumn{3}{|c|}{ Etapa 3} & & \\
\hline & $\mathbf{n}$ & Sim & Não & $\mathbf{n}$ & Sim & Não & $\mathbf{n}$ & Sim & Não & & \\
\hline Parto vaginal anterior & 217 & & & & & & & & & & \\
\hline Média (d.p.) & & $1,0(1,0)$ & $0,7(0,8)$ & & $0,9(0,8)$ & $0,4(0,6)$ & & $0,7(0,7)$ & $0,7(0,7)$ & & \\
\hline $95 \%$ IC & & $0,7-1,2$ & $0,6-0,8$ & & $0,6-1,1$ & $0,2-0,6$ & & $0,4-1,0$ & $0,5-0,9$ & & \\
\hline Mediana & & 1,0 & 1,0 & & 1,0 & 0,0 & & 1,0 & 1,0 & 0,108 & 0,143 \\
\hline Mínimo & & 0 & 0 & & 0 & 0 & & 0 & 0 & & \\
\hline Máximo & & 5 & 4 & & 3 & 2 & & 2 & 3 & & \\
\hline Cesariana anterior & 217 & & & & & & & & & & \\
\hline Média (d.p.) & & $0,5(0,6)$ & $0,6(0,7)$ & & $0,5(0,6)$ & $0,8(0,7)$ & & $0,5(0,5)$ & $0,5(0,6)$ & & \\
\hline $95 \%$ IC & & $0,4-0,7$ & $0,5-0,7$ & & $0,9-1,0$ & $0,3-0,6$ & & $0,3-0,7$ & $0,4-0,7$ & & \\
\hline Mediana & & 0,0 & 1,0 & & 0,0 & 1,0 & & 0,0 & 0,0 & 0,229 & 0,293 \\
\hline Mínimo & & 0 & 0 & & 0 & 0 & & 0 & 0 & & \\
\hline Máximo & & 2 & 3 & & 2 & 3 & & 1 & 1 & & \\
\hline RN de maior peso $(\mathrm{g})$ & 215 & & & 84 & & & 73 & & & & \\
\hline Média & & 3145,0 & 3128,2 & & 3167,7 & 3062,0 & & 2981,0 & 3163,6 & & \\
\hline (d.p.) & & $\begin{array}{l}(656,6) \\
29699-\end{array}$ & $\begin{array}{c}(578,4) \\
3038,8-\end{array}$ & & $\begin{array}{l}(469,4) \\
30290-\end{array}$ & $\begin{array}{l}(631,5) \\
28663-\end{array}$ & & $\begin{array}{l}(632,1) \\
2733,2-\end{array}$ & $\begin{array}{l}(470,4) \\
3030,5-\end{array}$ & & \\
\hline $95 \%$ IC & & $\begin{array}{l}2909,9- \\
3320,1\end{array}$ & 3217,5 & & 3306,4 & $\begin{array}{l}2000,5- \\
3257,7\end{array}$ & & 3228,8 & 3296,6 & 0,168 & 0,298 \\
\hline Mediana & & 3200,0 & 3200,0 & & 3200,0 & 2982,0 & & 3100,00 & 3212,5 & & \\
\hline Mínimo & & 1100,0 & 500,0 & & 1800,0 & 1470,0 & & 1490,0 & 2100,0 & & \\
\hline Máximo & & 4900,0 & 5370,0 & & 4015,0 & 5370,0 & & 38500 & 4120,0 & & \\
\hline
\end{tabular}

*GEE

Fonte: a pesquisadora 
Tabela 14 - Distribuição das gestantes nas etapas 1, 2 e 3 da coorte, conforme a IU e a faixa etária, cor da pele, escolaridade, ocupação, situação conjugal, gestação, aborto e parto vaginal e cesariana anteriores, trauma perineal em parto anterior, IU prévia, IA prévia e atual, estado nutricional, FMAP, exercícios perineais e maior peso do RN em parto anterior e valor-p, Guarulhos, SP - 2012-2014

\begin{tabular}{|c|c|c|c|c|c|c|c|c|c|c|c|}
\hline \multirow{3}{*}{ Variável } & \multicolumn{9}{|c|}{ IU } & \multirow{3}{*}{$\begin{array}{c}\text { Valor- } \\
\mathbf{p}^{*}\end{array}$} & \multirow{3}{*}{$\begin{array}{c}\text { Valor- } \\
\mathbf{p}^{*} \\
\mathbf{X} \\
\text { etapa }\end{array}$} \\
\hline & \multirow[b]{2}{*}{$\mathbf{n}$} & \multicolumn{2}{|c|}{ Etapa 1} & \multicolumn{3}{|c|}{ Etapa 2} & \multicolumn{3}{|c|}{ Etapa 3} & & \\
\hline & & $\begin{array}{c}\text { Sim } \\
\text { n (\%) }\end{array}$ & $\begin{array}{c}\text { Não } \\
\text { n (\%) }\end{array}$ & $\mathbf{n}$ & $\begin{array}{c}\text { Sim } \\
\text { n (\%) }\end{array}$ & $\begin{array}{c}\text { Não } \\
\text { n(\%) }\end{array}$ & $\mathbf{n}$ & $\begin{array}{c}\text { Sim } \\
\mathbf{n}(\%)\end{array}$ & $\begin{array}{c}\text { Não } \\
\text { n (\%) }\end{array}$ & & \\
\hline \multicolumn{12}{|l|}{ Faixa etária (anos) } \\
\hline$<20$ & 37 & $6(16,2)$ & $31(83,8)$ & 20 & $9(45,0)$ & $11(55,0)$ & 19 & $5(26,3)$ & $14(73,7)$ & \multirow{6}{*}{0,132} & \multirow{6}{*}{0,685} \\
\hline $20 \vdash 25$ & 118 & $16(13,6)$ & $102(86,4)$ & 54 & $22(40,7)$ & $32(59,3)$ & 45 & $17(37,8)$ & $28(62,2)$ & & \\
\hline $25-30$ & 152 & $22(14,5)$ & $130(85,5)$ & 70 & $26(37,1)$ & $44(62,9)$ & 52 & $16(30,8)$ & $36(69,2)$ & & \\
\hline $30-35$ & 121 & $30(24,8)$ & $91(75,2)$ & 57 & $25(43,9)$ & $32(56,1)$ & 54 & $21(38,9)$ & $33(61,1)$ & & \\
\hline $35-40$ & 54 & $20(37,0)$ & $34(63,0)$ & 20 & $10(50,0)$ & $10(50,0)$ & 13 & $6(46,2)$ & $7(53,8)$ & & \\
\hline$\geq 40$ & 18 & $1(5,6)$ & $17(94,4)$ & 5 & $4(80,0)$ & $1(20,0)$ & 4 & $1(25,0)$ & $3(75,0)$ & & \\
\hline \multicolumn{12}{|l|}{ Cor da pele } \\
\hline Parda & 250 & $53(21,2)$ & $197(78,8)$ & 112 & $50(44,6)$ & $62(55,4)$ & 101 & $37(36,6)$ & $64(63,4)$ & \multirow{4}{*}{$0,570 \dagger$} & \\
\hline Branca & 186 & $30(16,1)$ & $156(83,9)$ & 86 & $36(41,9)$ & $50(58,1)$ & 62 & $22(35,5)$ & $40(64,5)$ & & \\
\hline Negra & 59 & $12(20,3)$ & $51(79,7)$ & 26 & $10(38,5)$ & $16(61,5)$ & 22 & $5(22,7)$ & $17(77,3)$ & & \\
\hline Amarela & 4 & - & $4(100,0)$ & 2 & - & $2(100,0)$ & 2 & $2(100)$ & - & & \\
\hline \multicolumn{12}{|l|}{ Escolaridade } \\
\hline Ensino fundamental & 53 & $12(22,6)$ & $41(77,4)$ & 23 & $7(30,4)$ & $16(69,6)$ & 19 & $2(10,5)$ & $17(89,5)$ & \multirow{3}{*}{0,185} & \multirow{3}{*}{0,092} \\
\hline Ensino médio & 351 & $66(18,8)$ & $285(81,2)$ & 161 & $73(45,3)$ & $88(54,7)$ & 141 & $51(36,2)$ & $90(63,8)$ & & \\
\hline Ensino superior & 95 & $17(17,9)$ & $78(82,1)$ & 42 & $16(38,1)$ & $26(61,9)$ & 27 & $13(48,1)$ & $14(51,9)$ & & \\
\hline \multicolumn{12}{|l|}{ Ocupação } \\
\hline $\begin{array}{l}\text { Trabalho } \\
\text { remunerado }\end{array}$ & 389 & $79(20,3)$ & $310(79,7)$ & 170 & $69(40,6)$ & $101(59,4)$ & 142 & $51(35,9)$ & $91(64,1)$ & \multirow[b]{2}{*}{0,675} & \multirow[b]{2}{*}{0,226} \\
\hline $\begin{array}{l}\text { Do lar ou } \\
\text { estudante }\end{array}$ & 111 & $16(14,4)$ & $95(85,6)$ & 56 & $27(48,2)$ & $29(51,8)$ & 45 & $15(33,3)$ & $30(66,7)$ & & \\
\hline \multicolumn{12}{|l|}{ Situação conjugal } \\
\hline Vive com parceiro & 431 & $87(20,2)$ & $344(79,8)$ & 222 & $95(42,8)$ & $127(57,8)$ & 3 & $66(35,9)$ & $118(64,1)$ & \multirow{2}{*}{$0,035 \dagger$} & \\
\hline Não vive & 67 & $8(11,9)$ & $59(88,1)$ & 4 & $1(25,0)$ & $3(75,0)$ & 184 & - & $3(100,0)$ & & \\
\hline
\end{tabular}


Tabela 14

(cont.)

\begin{tabular}{|c|c|c|c|c|c|c|c|c|c|c|c|}
\hline \multirow{4}{*}{ Variável } & \multicolumn{9}{|c|}{ IU } & \multirow{4}{*}{$\begin{array}{c}\text { Valor- } \\
\mathbf{p}^{*}\end{array}$} & \multirow{4}{*}{$\begin{array}{c}\text { Valor- } \\
\mathbf{p}^{*} \\
\mathbf{X} \\
\text { etapa }\end{array}$} \\
\hline & \multirow[b]{3}{*}{$\mathbf{n}$} & \multicolumn{2}{|c|}{ Etapa 1} & \multicolumn{3}{|c|}{ Etapa 2} & \multicolumn{3}{|c|}{ Etapa 3} & & \\
\hline & & Sim & Não & & Sim & Não & & Sim & Não & & \\
\hline & & n (\%) & n (\%) & $\mathbf{n}$ & n (\%) & n (\%) & n & n (\%) & n (\%) & & \\
\hline \multicolumn{12}{|c|}{ Gestação anterior } \\
\hline Sim & 246 & $58(23,6)$ & $188(76,4)$ & 101 & $53(52,5)$ & $48(47,5)$ & 79 & $29(36,7)$ & $50(63,3)$ & \multirow{2}{*}{0,005} & \multirow{2}{*}{0,209} \\
\hline Não & 254 & $37(14,6)$ & $217(85,4)$ & 125 & $43(34,4)$ & $82(65,6)$ & 108 & $37(34,3)$ & $71(65,7)$ & & \\
\hline \multicolumn{12}{|c|}{ Aborto anterior } \\
\hline Sim & 70 & $14(20,0)$ & $56(80,0)$ & 27 & $15(55,6)$ & $12(44,4)$ & 14 & $7(50,0)$ & $7(50,0)$ & \multirow[b]{2}{*}{0,107} & \multirow[b]{2}{*}{0,346} \\
\hline Não & 430 & $81(18,8)$ & $349(81,2)$ & 199 & $81(40,7)$ & $118(59,3)$ & 173 & $59(34,1)$ & $114(65,9)$ & & \\
\hline \multicolumn{12}{|c|}{ Parto vaginal anterior } \\
\hline Sim & 124 & $36(29,0)$ & $88(71,0)$ & 45 & $30(66,7)$ & $15(33,3)$ & 40 & $14(35,0)$ & $26(65,0)$ & \multirow{2}{*}{$\mathbf{0 , 0 0 1}$} & \multirow{2}{*}{$\mathbf{0 , 0 2 4}$} \\
\hline Não & 376 & $59(15,7)$ & $317(84,3)$ & 181 & $66(36,5)$ & $115(63,5)$ & 147 & $52(35,4)$ & $95(64,6)$ & & \\
\hline \multicolumn{12}{|c|}{ Trauma perineal em parto anterior } \\
\hline Sim & 119 & $35(29,4)$ & $84(70,6)$ & 45 & $30(66,7)$ & $15(33,3)$ & 40 & $14(35,0)$ & $26(65,0)$ & \multirow{2}{*}{$\mathbf{0 , 0 0 1}$} & \multirow{2}{*}{$\mathbf{0 , 0 2 4}$} \\
\hline Não & 379 & $60(15,8)$ & $319(84,2)$ & 181 & $66(36,5)$ & $115(63,5)$ & 147 & $52(35,4)$ & $95(64,6)$ & & \\
\hline \multicolumn{12}{|c|}{ Cesariana anterior } \\
\hline Sim & 391 & $25(22,9)$ & $84(77,1)$ & 45 & $19(42,2)$ & $26(57,8)$ & 35 & $12(34,3)$ & $23(65,7)$ & \multirow{2}{*}{0,734} & \multirow{2}{*}{0,627} \\
\hline Não & 109 & $70(17,9)$ & $321(82,1)$ & 181 & $77(42,5)$ & $104(57,5)$ & 152 & $54(35,5)$ & $98(64,5)$ & & \\
\hline \multicolumn{12}{|l|}{ IU prévia } \\
\hline Sim & 196 & $81(41,3)$ & $115(58,7)$ & 84 & $52(61,9)$ & $32(38,1)$ & 71 & $32(45,1)$ & $39(54,9)$ & \multirow{2}{*}{$<0,001$} & \multirow{2}{*}{$<0,001$} \\
\hline Não & 304 & $14(4,6)$ & $290(95,4)$ & 142 & $44(31,0)$ & $98(69,0)$ & 116 & $34(29,3)$ & $82(70,7)$ & & \\
\hline \multicolumn{12}{|l|}{ IA prévia } \\
\hline Sim & 111 & $19(17,1)$ & $92(82,9)$ & 50 & $21(42,0)$ & $29(58,0)$ & 44 & $17(38,6)$ & $27(61,4)$ & \multirow{2}{*}{0,780} & \multirow{2}{*}{0,592} \\
\hline Não & 388 & $76(19,6)$ & $312(80,4)$ & 176 & $75(42,6)$ & $101(57,4)$ & 143 & $49(34,3)$ & $94(65,7)$ & & \\
\hline IA atual & & & & & & & & & & & \\
\hline Sim & 50 & $9(18,0)$ & $41(82,0)$ & 26 & $11(42,3)$ & $15(57,7)$ & 14 & $6(42,9)$ & $8(57,1)$ & & \\
\hline Não & 449 & $86(19,2)$ & $363(80,8)$ & 200 & $85(42,5)$ & $115(57,5)$ & 173 & $60(34,7)$ & $113(65,3)$ & 0,489 & 0,710 \\
\hline
\end{tabular}




\begin{tabular}{|c|c|c|c|c|c|c|c|c|c|c|c|}
\hline \multirow{3}{*}{ Variável } & \multicolumn{9}{|c|}{ IU } & \multirow{3}{*}{$\begin{array}{c}\text { Valor- } \\
\mathbf{p}^{*}\end{array}$} & \multirow{3}{*}{$\begin{array}{c}\text { Valor- } \\
\text { p }^{*} \\
\text { X } \\
\text { etapa }\end{array}$} \\
\hline & \multirow[b]{2}{*}{$\mathbf{n}$} & \multicolumn{2}{|c|}{ Etapa 1} & \multicolumn{3}{|c|}{ Etapa 2} & \multicolumn{3}{|c|}{ Etapa 3} & & \\
\hline & & $\begin{array}{c}\text { Sim } \\
\text { n }(\%)\end{array}$ & $\begin{array}{c}\text { Não } \\
\text { n (\%) }\end{array}$ & $\mathbf{n}$ & $\begin{array}{c}\text { Sim } \\
\text { n }(\%)\end{array}$ & $\begin{array}{c}\text { Não } \\
\text { n (\%) }\end{array}$ & $\mathbf{n}$ & $\begin{array}{c}\text { Sim } \\
\text { n }(\%)\end{array}$ & $\begin{array}{c}\text { Não } \\
\text { n (\%) }\end{array}$ & & \\
\hline \multicolumn{12}{|c|}{ Estado nutricional } \\
\hline Baixo peso & 46 & $3(6,5)$ & $43(93,5)$ & 33 & $11(33,3)$ & $22(66,7)$ & 24 & $8(33,3)$ & $16(66,7)$ & \multirow{4}{*}{$\mathbf{0 , 0 1 1}$} & \multirow{4}{*}{0,207} \\
\hline Adequado & 227 & $39(17,2)$ & $188(82,8)$ & 86 & $28(32,6)$ & $58(67,4)$ & 226 & $23(31,5)$ & $50(68,5)$ & & \\
\hline Sobrepeso & 163 & $35(21,5)$ & $128(78,5)$ & 81 & $45(55,6)$ & $36(44,4)$ & 73 & $23(40,4)$ & $34(59,6)$ & & \\
\hline Obesidade & 61 & $18(29,5)$ & $43(70,5)$ & 26 & $12(46,2)$ & $14(53,2)$ & 57 & $12(36,4)$ & $21(63,6)$ & & \\
\hline \multicolumn{12}{|l|}{ FMAP (cmH2O) } \\
\hline$<30$ & 277 & $62(65,3)$ & $215(53,1)$ & 114 & $61(53,5)$ & $53(46,5)$ & 101 & $41(40,6)$ & $60(59,4)$ & \multirow{2}{*}{$<0,001$} & \multirow{2}{*}{0,492} \\
\hline$\geq 30$ & 223 & $33(34,7)$ & $190(46,9)$ & 108 & $32(30,8)$ & $72(69,2)$ & 73 & $20(24,4)$ & $53(72,6)$ & & \\
\hline \multicolumn{12}{|c|}{ Exercício não supervisionado } \\
\hline Regularmente & & & & 67 & $27(40,3)$ & $40(59,7)$ & 60 & $16(26,7)$ & $50(39,4)$ & \multirow[b]{2}{*}{$\mathbf{0 , 0 2 1}$} & \multirow[b]{2}{*}{0,105} \\
\hline $\begin{array}{l}\text { Nunca ou } \\
\text { esporadicamente }\end{array}$ & & & & 159 & $69(43,4)$ & $90(56,6)$ & 127 & $44(73,3)$ & $77(60,6)$ & & \\
\hline \multicolumn{12}{|c|}{ Exercício supervisionado } \\
\hline Sim & & & & & & & 24 & $7(29,2)$ & $17(70,8)$ & \multirow{2}{*}{0,334} & \\
\hline Não & & & & & & & 163 & $59(36,2)$ & $104(63,8)$ & & \\
\hline \multicolumn{12}{|l|}{ Peso do RN (g) } \\
\hline$<2500$ & 24 & $8(33,3)$ & $16(66,7)$ & 9 & $4(44,4)$ & $5(55,6)$ & 8 & $4(50 \%)$ & $4(50 \%)$ & \multirow{3}{*}{$0,643 \dagger$} & \\
\hline $2500 \vdash 4000$ & 180 & $42(23,3)$ & $138(76,7)$ & 72 & $33(45,8)$ & $39(54,2)$ & 63 & $21(33,3)$ & $42(66,7)$ & & \\
\hline$\geq 4000$ & 11 & $4(36,4)$ & $7(63,6)$ & 3 & $1(33,3)$ & $2(66,7)$ & 2 & - & $2(100)$ & & \\
\hline
\end{tabular}

*GEE; †Separação perfeita

Fonte: a pesquisadora 
Nos dados das Tabelas 15 e 16, é apresentada a análise da IA, conforme as mesmas variáveis consideradas na análise da IU. Aquelas que mostraram associação estatisticamente significante, independentemente da etapa da coorte, foram: número de gestações anteriores $(\mathrm{p}=0,039)$ e IA prévia (sim; $\mathrm{p}<0,001)$. Igualmente, para as variáveis com valor em alguma das etapas, não foi possível calcular a interação, recebendo a denominação técnica de "separação perfeita".

Tabela 15 - Valores da média, desvio-padrão (d.p.), intervalo de confiança de 95\% (95\% IC), mediana, mínimo, máximo e valor-p da IA nas etapas 1, 2 e 3 da coorte, conforme a idade materna, número de gestações, aborto, partos vaginais e cesarianas anteriores e maior peso do RN em parto anterior, Guarulhos, SP - 2012-2014.

\begin{tabular}{|c|c|c|c|c|c|c|c|c|c|c|c|}
\hline \multirow{3}{*}{ Variável } & \multicolumn{9}{|c|}{ IA } & \multirow{3}{*}{ Valor-p* } & \multirow{3}{*}{$\begin{array}{c}\text { Valor-p* } \\
\mathbf{X} \\
\text { etapa }\end{array}$} \\
\hline & \multicolumn{3}{|c|}{ Etapa 1} & \multicolumn{3}{|c|}{ Etapa 2} & \multicolumn{3}{|c|}{ Etapa 3} & & \\
\hline & $\mathbf{n}$ & Sim & Não & $\mathbf{n}$ & Sim & Não & $\mathbf{n}$ & Sim & Não & & \\
\hline Idade materna (anos) & 500 & & & 22 & & & 187 & & & & \\
\hline Média (d.p.) & & $27,0(5,1)$ & $28,0(6,1)$ & & $17,6(4,9)$ & $27,6(4,9)$ & & $27,0(7,4)$ & $27,4(5,7)$ & & \\
\hline $95 \%$ IC & & $25,6-28,4$ & $27,4-28,5$ & & $25,7-29,5$ & $26,6-28,2$ & & $23,1-30,9$ & $26,5-28,2$ & & \\
\hline Mediana & & 26,5 & 28,0 & & 28,0 & 27,0 & & 26,5 & 28,0 & 0,852 & 0,571 \\
\hline Mínimo & & 18 & 18 & & 20 & 18 & & 18 & 18 & & \\
\hline Máximo & & 39 & 46 & & 36 & 46 & & 45 & 46 & & \\
\hline Gestação anterior & 500 & & & 22 & & & 187 & & & & \\
\hline Média (d.p.) & & $0,7(0,8)$ & $0,7(1,0)$ & & $0,6(0,8)$ & $0,6(0,9)$ & & $0,2(0,4)$ & $0,6(0,8)$ & & \\
\hline $95 \%$ IC & & $0,5-0,9$ & $0,7-0,9$ & & $0,3-0,9$ & $0,5-0,8$ & & $0-0,4$ & $0,5-0,7$ & & \\
\hline Mediana & & 0,0 & 0,0 & & 0,0 & 0,0 & & 0,0 & 0,0 & & \\
\hline Mínimo & & 0 & 0 & & 0 & 0 & & 0 & 0 & 0,039 & 0,182 \\
\hline Máximo & & 3 & 7 & & 3 & 7 & & 1 & 4 & & \\
\hline Aborto anterior & 240 & & & 10 & & & 79 & & & & \\
\hline Média (d.p.) & & $0,4(0,6)$ & $0,31(0,6)$ & & $0,4(0,5)$ & $0,3(0,7)$ & & $0,3(0,6)$ & $0,2(0,4)$ & & \\
\hline $95 \%$ IC & & $0,2-0,7$ & $0,2-0,4$ & & $0,1-0,7$ & $0,2-0,5$ & & $-0,3-1,0$ & $0,1-0,3$ & & \\
\hline Mediana & & 0,0 & 0,0 & & 0,0 & 0,0 & & 0,0 & 0,0 & 0,498 & 0,786 \\
\hline Mínimo & & 0 & 0 & & 0 & 0 & & 0 & 0 & & \\
\hline Máximo & & 2 & 5 & & 1 & 5 & & 1 & 2 & & \\
\hline
\end{tabular}




\begin{tabular}{|c|c|c|c|c|c|c|c|c|c|c|c|}
\hline \multirow{3}{*}{ Variável } & \multicolumn{9}{|c|}{ IA } & \multirow{3}{*}{ Valor-p* } & \multirow{3}{*}{$\begin{array}{c}\text { Valor-p* } \\
\text { X } \\
\text { etapa }\end{array}$} \\
\hline & & Etapa & & & & & & & & & \\
\hline & $\mathbf{n}$ & & & $\mathbf{n}$ & Sim & Não & $\mathbf{n}$ & Sim & Não & & \\
\hline Parto vaginal anterior & 217 & & & 86 & & & 73 & & & & \\
\hline Média (d.p.) & & $0,8(0,6)$ & $0,8(0,9)$ & & $0,8(0,9)$ & $0,7(0,7)$ & & $1,0(0,0)$ & $0,7(0,7)$ & & \\
\hline $95 \% \mathrm{IC}$ & & $0,5-1,0$ & $0,7-0,9$ & & $0,1-1,4$ & $0,5-0,8$ & & $1,0-1,0$ & $0,5-, 9$ & & \\
\hline Mediana & & 1,0 & 1,0 & & 0,5 & 1,0 & & 1,0 & 1,0 & 0,180 & 0,262 \\
\hline Mínimo & & 0 & 0 & & 0 & 0 & & 1 & 0 & & \\
\hline Máximo & & 2 & 5 & & 2 & 3 & & 1 & 3 & & \\
\hline Cesariana anterior & 217 & & & 86 & & & 73 & & & & \\
\hline Média (d.p.) & & $0,5(0,6)$ & $0,6(0,7)$ & & $0,6(0,5)$ & $0,6(0,7)$ & & 0,0 & $0,5(0,5)$ & & \\
\hline $95 \%$ IC & & $0,2-0,7$ & $0,5-0,7$ & & $0,3-1,0$ & $0,4-0,7$ & & $0,0-0,0$ & $0,4-0,7$ & & \\
\hline Mediana & & 0,0 & 1,0 & & 1,0 & 1,0 & & 0,0 & 0,0 & $0,306 \dagger$ & \\
\hline Mínimo & & 0 & 0 & & 0 & 0 & & 0 & 0 & & \\
\hline Máximo & & 2 & 3 & & 1 & 3 & & 0 & 2 & & \\
\hline RN de maior peso $(\mathrm{g})$ & 215 & & & 84 & & & 73 & & & & \\
\hline Média & & 2831,8 & 3163,1 & & 3280,0 & 3100,0 & & 3265,0 & 3096,4 & & \\
\hline (d.p.) & & $(720,4)$ & $(576,8)$ & & $(409,3)$ & $(564,0)$ & & $(473,7)$ & $(537,9)$ & & \\
\hline $95 \% \mathrm{IC}$ & & $2517,0-$ & $3082,2-$ & & $2996,3-$ & $2973,4-$ & & $2608,4-$ & 2971,3- & & \\
\hline Mediana & & $\begin{array}{l}3148,5 \\
2070 \Omega 0\end{array}$ & 3244,1 & & 3563,7 & 3227,0 & & 3921,6 & 3221,5 & 0,456 & 0,115 \\
\hline viecuana & & 2970,00 & 3200,00 & & 3212,50 & 3200,00 & & 3265,00 & 3200,00 & & \\
\hline Mínimo & & 1100,0 & 500,0 & & 2800,0 & 1490,0 & & 2930,0 & 1490,0 & & \\
\hline Máximo & & 3730,0 & 5370,0 & & 4015,0 & 5370,0 & & 3600,0 & 4120,0 & & \\
\hline
\end{tabular}

*GEE; †Separação perfeita

Fonte: a pesquisadora 
Tabela 16 - Distribuição das gestantes nas etapas 1, 2 e 3 da coorte, conforme a IA e a faixa etária, cor da pele, escolaridade, ocupação, situação conjugal, gestação, aborto, parto vaginal e cesariana anteriores, trauma perineal em parto anterior, IU atual e prévia, IA prévia, estado nutricional, FMAP, exercícios perineais e maior peso do RN em parto anterior e valor-p, Guarulhos, SP - 2012-2014

\begin{tabular}{|c|c|c|c|c|c|c|c|c|c|c|c|}
\hline \multirow{4}{*}{ Variável } & \multicolumn{9}{|c|}{ IA } & \multirow{4}{*}{$\begin{array}{c}\text { Valor- } \\
\mathbf{p}^{*}\end{array}$} & \multirow{4}{*}{$\begin{array}{c}\text { Valor- } \\
\mathbf{p}^{*} \\
\mathbf{X} \\
\text { etapa }\end{array}$} \\
\hline & \multirow{3}{*}{$\mathbf{n}$} & \multicolumn{2}{|c|}{ Etapa 1} & \multicolumn{3}{|c|}{ Etapa 2} & \multicolumn{3}{|c|}{ Etapa 3} & & \\
\hline & & Sim & Não & & Sim & Não & & Sim & Não & & \\
\hline & & n (\%) & n (\%) & n & n (\%) & n (\%) & n & n (\%) & n(\%) & & \\
\hline \multicolumn{12}{|l|}{ Faixa etária (anos) } \\
\hline$<20$ & 37 & $3(8,1)$ & $34(91,9)$ & 20 & - & $20(100)$ & 19 & $3(15,8)$ & $16(84,2)$ & \multirow{6}{*}{$0,683 \dagger$} & \\
\hline $20 \vdash 25$ & 117 & $15(12,8)$ & $102(87,2)$ & 54 & $8(14,8)$ & $46(85,2)$ & 45 & $1(2,2)$ & $44(97,8)$ & & \\
\hline $25-30$ & 152 & $16(10,5)$ & $136(89,5)$ & 70 & $9(12,9)$ & $61(87,1)$ & 52 & $6(11,5)$ & $46(88,5)$ & & \\
\hline $30-35$ & 121 & $12(9,9)$ & $109(90,1)$ & 57 & $5(8,8)$ & $52(91,2)$ & 54 & $3(5,6)$ & $51(94,4)$ & & \\
\hline $35-40$ & 54 & $4(7,4)$ & $50(92,6)$ & 20 & $4(20,0)$ & $16(80,0)$ & 13 & - & $13(100)$ & & \\
\hline$\geq 40$ & 18 & - & $18(100)$ & 5 & - & $5(100)$ & 4 & $1(25,0)$ & $3(75,0)$ & & \\
\hline \multicolumn{12}{|l|}{ Cor da pele } \\
\hline Parda & 250 & $22(8,8)$ & $228(91,2)$ & 112 & $15(13,4)$ & $97(86,6)$ & 101 & $7(6,9)$ & $94(93,1)$ & \multirow{4}{*}{$0,380 \dagger$} & \\
\hline Branca & 188 & $17(9,1)$ & $169(90,9)$ & 86 & $6(7,0)$ & $80(93,0)$ & 62 & $5(8,1)$ & $57(91,9)$ & & \\
\hline Negra & 59 & $10(16,9)$ & $49(83,1)$ & 26 & $4(15,4)$ & $22(84,6)$ & 22 & $2(9,1)$ & $20(90,9)$ & & \\
\hline Amarela & 4 & $1(25,0)$ & $3(75,0)$ & 2 & $1(50,0)$ & $1(50,0)$ & 2 & - & $2(100)$ & & \\
\hline \multicolumn{12}{|l|}{ Escolaridade } \\
\hline Ensino fundamental & 53 & $4(7,5)$ & $49(92,5)$ & 23 & $2(8,7)$ & $21(91,3)$ & 19 & $2(10,5)$ & $17(89,5)$ & \multirow{3}{*}{0,946} & \multirow{3}{*}{0,855} \\
\hline Ensino médio & 350 & $35(10,0)$ & $315(90,0)$ & 161 & $20(12,4)$ & $141(87,6)$ & 141 & $9(6,4)$ & $132(93,6)$ & & \\
\hline Ensino superior & 95 & $11(11,6)$ & $84(88,4)$ & 42 & $4(9,5)$ & $38(90,5)$ & 27 & $3(11,1)$ & $24(86,9)$ & & \\
\hline \multicolumn{12}{|l|}{ Ocupação } \\
\hline $\begin{array}{l}\text { Trabalho } \\
\text { remunerado }\end{array}$ & 388 & $41(10,6)$ & $347(89,4)$ & 170 & $16(9,4)$ & $154(90,6)$ & 142 & $9(6,3)$ & $133(93,7)$ & \multirow{2}{*}{0,245} & \multirow[b]{2}{*}{0,086} \\
\hline $\begin{array}{l}\text { Do lar ou } \\
\text { estudante }\end{array}$ & 111 & $9(8,1)$ & $102(91,9)$ & 56 & $10(17,9)$ & $46(82,1)$ & 45 & $5(11,1)$ & $40(88,9)$ & & \\
\hline \multicolumn{12}{|l|}{ Situação conjugal } \\
\hline Vive com parceiro & 431 & $42(9,7)$ & $389(90,3)$ & 222 & $25(11,3)$ & $197(88,7)$ & 184 & $13(7,1)$ & $171(92,9)$ & \multirow{2}{*}{0,319} & \multirow{2}{*}{$\begin{array}{c}0,324 \\
\text { (continuc }\end{array}$} \\
\hline Não vive & 67 & $8(11,9)$ & $59(88,1)$ & 4 & $1(25,0)$ & $3(75,0)$ & 3 & $1(33,3)$ & $2(66,7)$ & & \\
\hline
\end{tabular}




\begin{tabular}{|c|c|c|c|c|c|c|c|c|c|c|c|}
\hline \multirow{3}{*}{ Variável } & \multicolumn{9}{|c|}{ IA } & \multirow{3}{*}{$\begin{array}{c}\text { Valor- } \\
\mathbf{p}^{*}\end{array}$} & \multirow{3}{*}{$\begin{array}{c}\text { Valor- } \\
\mathbf{p}^{*} \\
\mathbf{X} \\
\text { etapa }\end{array}$} \\
\hline & \multicolumn{3}{|c|}{ Etapa 1} & \multicolumn{3}{|c|}{ Etapa 2} & \multicolumn{3}{|c|}{ Etapa 3} & & \\
\hline & $\mathbf{n}$ & $\frac{\text { Sim }}{\mathrm{n}(\%)}$ & $\begin{array}{c}\text { Não } \\
\text { n }(\%)\end{array}$ & $\mathbf{n}$ & $\frac{\text { Sim }}{\text { n }(\%)}$ & $\begin{array}{c}\text { Não } \\
\text { n (\%) }\end{array}$ & $\mathbf{n}$ & $\frac{\text { Sim }}{\text { n }(\%)}$ & $\begin{array}{c}\text { Não } \\
\text { n (\%) }\end{array}$ & & \\
\hline \multicolumn{12}{|c|}{ Gestação anterior } \\
\hline Sim & 246 & $24(9,8)$ & $222(90,2)$ & 101 & $90(89,1)$ & $11(10,9)$ & 79 & $3(3,8)$ & $76(96,2)$ & \multirow{2}{*}{0,176} & \multirow{2}{*}{0,384} \\
\hline Não & 253 & $26(10,3)$ & $227(89,7)$ & 125 & $110(88,0)$ & $15(12,0)$ & 108 & $11(10,2)$ & $97(89,9)$ & & \\
\hline \multicolumn{12}{|c|}{ Aborto anterior } \\
\hline $\operatorname{Sim}$ & 9 & $9(12,9)$ & $61(87,1)$ & \multirow{2}{*}{$\begin{array}{c}27 \\
199\end{array}$} & $4(14,8)$ & $23(85,2)$ & \multirow{2}{*}{$\begin{array}{c}14 \\
173\end{array}$} & $1(7,1)$ & $13(7,5)$ & \multirow[b]{2}{*}{0,609} & \multirow[b]{2}{*}{0,979} \\
\hline Não & 41 & $41(9,6)$ & $388(90,4)$ & & $22(11,1)$ & $177(88,9)$ & & $13(7,5)$ & $\begin{array}{c}160 \\
(92,5)\end{array}$ & & \\
\hline \multicolumn{12}{|c|}{ Parto vaginal anterior } \\
\hline Sim & 124 & $13(10,5)$ & $111(89,5)$ & \multirow{2}{*}{$\begin{array}{c}45 \\
181\end{array}$} & $4(8,9)$ & $41(91,1)$ & \multirow{2}{*}{$\begin{array}{c}40 \\
147\end{array}$} & $2(5,0)$ & $38(95,0)$ & \multirow[b]{2}{*}{0,415} & \multirow[b]{2}{*}{0,610} \\
\hline Não & 374 & $37(9,9)$ & $338(90,1)$ & & $22(12,2)$ & $159(87,8)$ & & $12(8,2)$ & $\begin{array}{c}135 \\
(91,8)\end{array}$ & & \\
\hline \multicolumn{12}{|c|}{ Trauma perineal em parto anterior } \\
\hline Sim & 119 & $13(10,5)$ & $106(89,1)$ & \multirow{2}{*}{$\begin{array}{c}45 \\
181\end{array}$} & $4(8,9)$ & $41(91,1)$ & \multirow{2}{*}{$\begin{array}{l}40 \\
147\end{array}$} & $2(5,0)$ & $38(95,0)$ & \multirow[b]{2}{*}{0,495} & \multirow[b]{2}{*}{0,614} \\
\hline Não & 378 & $37(9,8)$ & $341(90,2)$ & & $22(12,2)$ & $159(87,8)$ & & $12(8,2)$ & $\begin{array}{c}135 \\
(91,8)\end{array}$ & & \\
\hline Cesariana & & & & & & & & & & & \\
\hline Sim & 109 & $8(7,3)$ & $101(92,7)$ & 45 & $5(11,1)$ & $40(88,9)$ & 35 & - & $35(100)$ & & \\
\hline Não & 390 & $42(10,8)$ & $348(89,2)$ & 181 & $21(11,6)$ & $160(88,4)$ & 152 & $14(9,2)$ & $\begin{array}{c}138 \\
(90,8)\end{array}$ & $0,154 \dagger$ & \\
\hline IU prévia & & & & & & & & & & & \\
\hline Sim & 195 & $19(9,7)$ & $176(90,3)$ & 84 & $8(9,5)$ & $76(90,5)$ & 71 & $5(7,0)$ & $66(93,0)$ & 0642 & 0723 \\
\hline Não & 304 & $31(10,2)$ & $273(89,8)$ & 142 & $18(12,7)$ & $124(87,3)$ & 116 & $9(7,8)$ & $107(92,2)$ & $0,0+2$ & $0, i<J$ \\
\hline IA prévia & & & & & & & & & & & \\
\hline Sim & 111 & $43(38,7)$ & $68(61,3)$ & 50 & $12(24,0)$ & $38(76,0)$ & 44 & $7(15,9)$ & $37(84,1)$ & $<0001+$ & \\
\hline Não & 388 & $7(1,8)$ & $381(98,2)$ & 176 & $14(8,0)$ & $162(92,0)$ & 143 & $7(4,9)$ & $136(95,1)$ & $|0,001|$ & \\
\hline IU atual & & & & & & & & & & & \\
\hline Sim & 50 & $9(18,0)$ & $41(82,0)$ & 26 & $11(42,3)$ & $15(57,7)$ & 173 & $6(42,9)$ & $8(57,1)$ & 0,489 & 0,710 \\
\hline Não & 449 & $86(19,2)$ & $363(80,8)$ & 200 & $85(42,5)$ & $115(57,5)$ & 14 & $60(34,7)$ & $113(65,3)$ & $0,+07$ & 0,110 \\
\hline
\end{tabular}


Tabela 16

(cont.)

\begin{tabular}{|c|c|c|c|c|c|c|c|c|c|c|c|}
\hline \multirow{3}{*}{ Variável } & \multicolumn{9}{|c|}{ IA } & \multirow{3}{*}{$\begin{array}{c}\text { Valor- } \\
\mathbf{p}^{*}\end{array}$} & \multirow{3}{*}{$\begin{array}{c}\text { Valor- } \\
\mathbf{p}^{*} \\
\mathbf{X} \\
\text { etapa }\end{array}$} \\
\hline & \multicolumn{3}{|c|}{ Etapa 1} & \multicolumn{3}{|c|}{ Etapa 2} & \multicolumn{3}{|c|}{ Etapa 3} & & \\
\hline & $\mathbf{n}$ & $\begin{array}{c}\text { Sim } \\
\text { n }(\%)\end{array}$ & $\begin{array}{c}\text { Não } \\
\text { n(\%) }\end{array}$ & $\mathbf{n}$ & $\begin{array}{c}\text { Sim } \\
\text { n }(\%)\end{array}$ & $\begin{array}{c}\text { Não } \\
\text { n(\%) }\end{array}$ & $\mathbf{n}$ & $\begin{array}{c}\text { Sim } \\
\text { n }(\%)\end{array}$ & $\begin{array}{c}\text { Não } \\
\text { n (\%) }\end{array}$ & & \\
\hline \multicolumn{12}{|c|}{ Estado nutricional } \\
\hline Baixo peso & 49 & $3(6,5)$ & $43(93,5)$ & 33 & $2(6,1)$ & $31(93,9)$ & 24 & $1(4,2)$ & $23(95,8)$ & \multirow{4}{*}{$0,257 \dagger$} & \\
\hline Adequado & 227 & $23(10,1)$ & $204(89,9)$ & 86 & $11(12,8)$ & $75(87,2)$ & 73 & $11(15,1)$ & $62(84,9)$ & & \\
\hline Sobrepeso & 163 & $18(11,0)$ & $145(90,2)$ & 81 & $10(12,3)$ & $71(87,7)$ & 57 & $2(3,5)$ & $55(96,5)$ & & \\
\hline Obesidade & 61 & $6(9,8)$ & $55(90,2)$ & 26 & $3(11,5)$ & $23(88,5)$ & 33 & - & $33(100)$ & & \\
\hline \multicolumn{12}{|l|}{ FMAP $(\mathrm{cmH} 2 \mathrm{O})$} \\
\hline$<30$ & 276 & $28(10,1)$ & $248(89,9)$ & 114 & $15(13,2)$ & $99(86,8)$ & 101 & $8(7,9)$ & $93(92,1)$ & \multirow{2}{*}{0,737} & \multirow{2}{*}{0,977} \\
\hline$\geq 30$ & 223 & $22(9,9)$ & $201(90,1)$ & 104 & $11(10,6)$ & $93(89,4)$ & 73 & $5(6,8)$ & $68(93,2)$ & & \\
\hline \multicolumn{12}{|c|}{ Exercício não supervisionado } \\
\hline Regularmente & & & & 67 & $9(13,4)$ & $58(86,6)$ & 60 & $4(6,7)$ & $56(93,3)$ & \multirow[b]{2}{*}{0,590} & \multirow[b]{2}{*}{0,680} \\
\hline $\begin{array}{l}\text { Nunca ou } \\
\text { esporadicamente }\end{array}$ & & & & 159 & $17(10,7)$ & $\begin{array}{c}142 \\
(89,3)\end{array}$ & 127 & $10(7,9)$ & $117(92,1)$ & & \\
\hline \multicolumn{12}{|c|}{ Exercício supervisionado } \\
\hline $\begin{array}{l}\text { Sim } \\
\text { Não }\end{array}$ & & & & & & & & $\begin{array}{c}13(8,0) \\
1(4,2)\end{array}$ & $\begin{array}{l}150(92,0) \\
23(95,8)\end{array}$ & 0,439 & \\
\hline \multicolumn{12}{|l|}{ Peso do RN (g) } \\
\hline$<2500$ & 24 & $5(20,8)$ & $19(79,2)$ & 9 & - & $9(100)$ & 8 & - & $8(100)$ & \multirow[b]{2}{*}{$0,537 \dagger$} & \\
\hline $\begin{array}{l}2500 \vdash 4000 \\
\geq 4000\end{array}$ & $\begin{array}{c}180 \\
11\end{array}$ & $\begin{array}{c}15(8,3) \\
-\end{array}$ & $\begin{array}{c}165(91,7) \\
11(100)\end{array}$ & $\begin{array}{c}72 \\
3\end{array}$ & $\begin{array}{c}7(9,7) \\
1(33,3)\end{array}$ & $\begin{array}{c}65(90,3) \\
2(66,7)\end{array}$ & $\begin{array}{c}63 \\
1\end{array}$ & $\begin{array}{c}2(3,2) \\
-\end{array}$ & $\begin{array}{c}61(96,8) \\
2(100)\end{array}$ & & \\
\hline
\end{tabular}

*GEE; †Separação perfeita

Fonte: a pesquisadora 


\subsection{Análise multivariada da FMAP, IU e IA ao longo da gestação}

Conforme referido no Método, para a análise multivariada foi utilizado o processo backward, com todas as variáveis que apresentaram valor- $\mathrm{p} \leq 0,20$, na análise bivariada, com exceção das variáveis aborto, parto vaginal e cesariana anteriores e trauma perineal em parto anterior, que foram representadas pela variável número de gestações anteriores, dada a alta correlação entre todas elas. Além disso, optou-se pela inclusão das variáveis parto vaginal anterior e exercício perineal não supervisionado, no modelo inicial para a IA.

Os dados das Tabela 17 e Figura 3 apresentam a análise multivariada da FMAP. No modelo inicial foram incluídas as seguintes variáveis, iniciando por aquelas com valor-p menor: idade gestacional (por semana); IA prévia; gestação anterior (por número de gestação); IU atual; IU prévia; exercício perineal não supervisionado; escolaridade; estado nutricional; ocupação. Permaneceram no modelo final as variáveis: idade gestacional, gestação anterior, IU prévia e exercício perineal não supervisionado, com os seguintes resultados:

- Cada semana na idade gestacional reduz 0,09 $\mathrm{cmH}_{2} \mathrm{O}$ na FMAP, durante a gestação;

- Cada gestação anterior reduz $1,73 \mathrm{cmH}_{2} \mathrm{O}$ na FMAP, durante a gestação subsequente;

- Ter IU prévia reduz 3,03 $\mathrm{cmH}_{2} \mathrm{O}$ na FMAP, durante a gestação;

- Realizar exercícios perineais regularmente (pelo menos, duas vezes por semana), aumenta 2,37 $\mathrm{cmH}_{2} \mathrm{O}$ na FMAP, durante a gestação. 
Tabela 17 - Modelos inicial e final da análise multivariada da FMAP, Guarulhos, SP 2012-2014

\begin{tabular}{|c|c|c|c|c|}
\hline \multirow[b]{2}{*}{ Variável } & \multirow{2}{*}{$\begin{array}{c}\text { Modelo inicial* } \\
\text { Valor-p } \dagger\end{array}$} & \multicolumn{3}{|c|}{ Modelo final* } \\
\hline & & Coeficiente & $95 \%$ IC & $\begin{array}{c}\text { Valor- } \\
\text { p } \dagger\end{array}$ \\
\hline $\begin{array}{l}\text { Idade gestacional } \\
\text { (por semana) }\end{array}$ & 0,113 & $-0,09$ & $-0,16$ a $-0,02$ & 0,019 \\
\hline IA prévia & 0,147 & - & & \\
\hline $\begin{array}{l}\text { Gestação anterior } \\
\text { (por gestação) }\end{array}$ & 0,048 & $-1,73$ & $-3,20$ a $-0,25$ & 0,022 \\
\hline IU atual & 0,152 & - & & \\
\hline IU prévia & $\mathbf{0 , 0 5 2}$ & & & \\
\hline Sim & & $-3,03$ & $-5,96$ a $-0,11$ & 0,042 \\
\hline Não & & 0 & & \\
\hline $\begin{array}{l}\text { Exercício não } \\
\text { supervisionado }\end{array}$ & 0,018 & & & \\
\hline Regularmente & & 2,37 & 0,48 a 4,26 & 0,014 \\
\hline Nunca ou espora & ente & 0 & & \\
\hline Escolaridade & 0,064 & - & & \\
\hline Estado nutricional & 0,103 & - & & \\
\hline Ocupação & 0,251 & - & & \\
\hline
\end{tabular}

*LMM; †Teste de Wald

Fonte: a pesquisadora 
Figura 3 - Gráfico de floresta do modelo final da análise multivariada da FMAP, Guarulhos, SP - 2012-2014

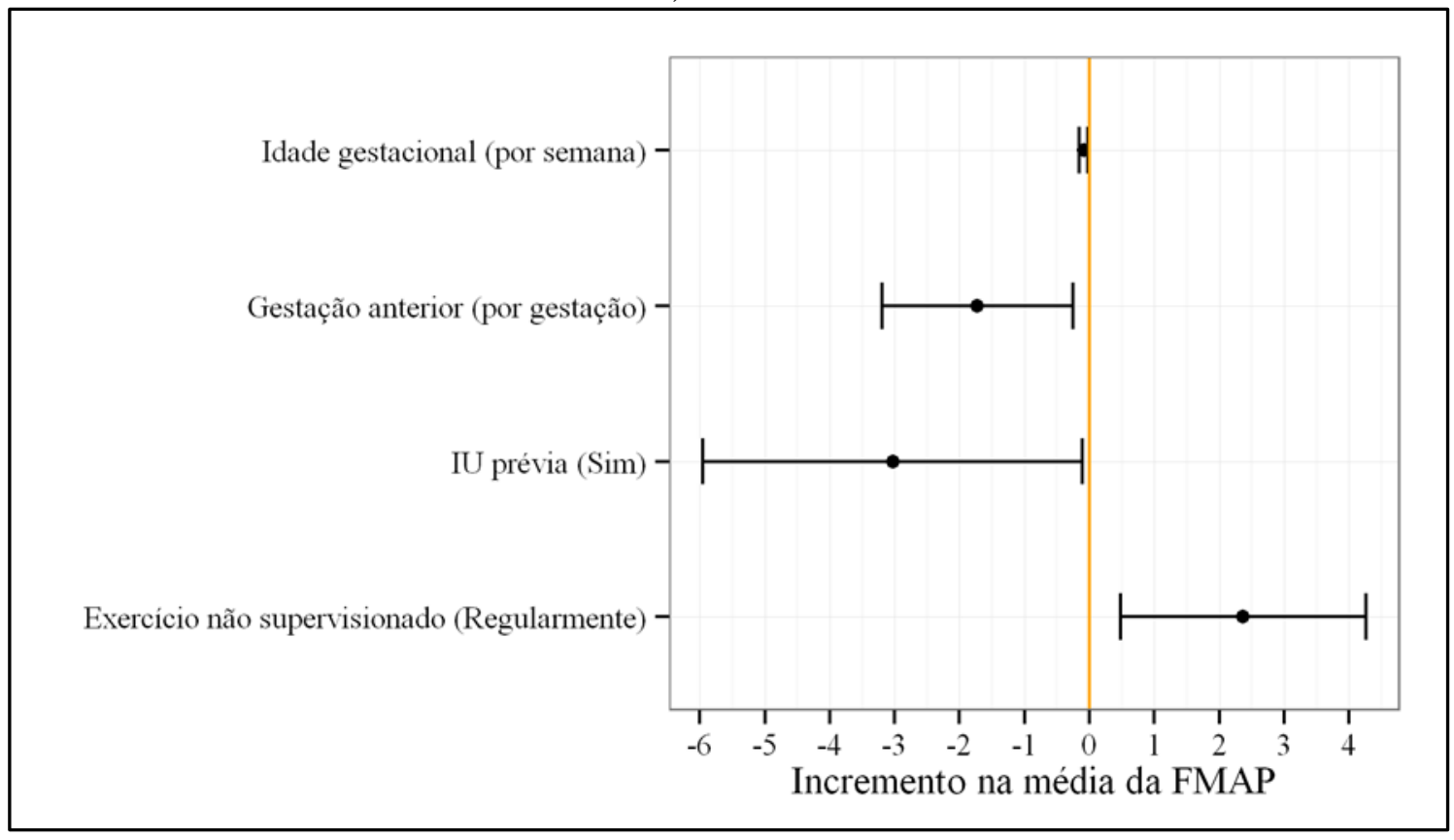

Fonte: a pesquisadora 
Nos dados das Tabela 18 e Figura 4 é apresentada a análise multivariada da IU. A opção de incluir no modelo as etapas da coorte, que correspondem aos primeiro, segundo e terceiro trimestres da gestação, ao invés da idade gestacional por semana, teve a finalidade de "não linearizar" a ocorrência do desfecho, dada maior prevalência de IU no segundo trimestre, em comparação com o início e o final da gestação.

No modelo inicial da análise, foram incluídas as seguintes variáveis, iniciando por aquelas com valor-p menor: idade gestacional (por etapa ou trimestre); IU prévia; FMAP (categorizada); estado nutricional; exercício perineal não supervisionado; situação conjugal; idade materna (por ano); gestação anterior (por gestação); maior peso do RN em parto anterior; escolaridade. Permaneceram no modelo final as variáveis: idade gestacional, IU prévia, FMAP, exercício perineal não supervisionado e idade materna, com os seguintes resultados:

- No segundo trimestre da gestação a chance de IU aumenta cinco vezes; no terceiro trimestre, esta chance aumenta três vezes;

- Ter IU prévia aumenta cinco vezes a chance de IU na gestação;

- Ter FMAP $\geq 30$ cmH2O reduz $42 \%$ as chances de IU na gestação;

- Realizar exercícios perineais regularmente (pelo menos, duas vezes por semana) reduz $47 \%$ as chances de IU na gestação;

- Cada ano na idade materna aumenta 5\% as chances de IU na gestação. 
Tabela 18 - Modelos inicial e final da análise multivariada da IU, Guarulhos, SP - 20122014

\begin{tabular}{|c|c|c|c|c|}
\hline \multirow{2}{*}{ Variável } & \multirow{2}{*}{$\begin{array}{c}\text { Modelo inicial* }{ }^{*} \\
\text { Valor-p } \dagger\end{array}$} & \multicolumn{3}{|c|}{ Modelo final* } \\
\hline & & OR & $95 \%$ IC & Valor-p $\dagger$ \\
\hline Etapa & $<0,001$ & & & \\
\hline Etapa 3 & & 3,34 & 2,09-5,31 & $<0,001$ \\
\hline Etapa 2 & & 5,26 & $3,44-8,02$ & $<0,001$ \\
\hline Etapa 1 & & 1 & & \\
\hline IU prévia & $<0,001$ & & & \\
\hline Sim & & 5,62 & 3,93-8,04 & $<0,001$ \\
\hline Não & & 1 & & \\
\hline FMAP & 0,046 & & & \\
\hline$\geq 30 \mathrm{cmH} 2 \mathrm{O}$ & & $\mathbf{0 , 5 8}$ & 0,41-0,82 & $\mathbf{0 , 0 0 2}$ \\
\hline$<30 \mathrm{cmH} 2 \mathrm{O}$ & & 1 & & \\
\hline Estado nutricional & 0,562 & - & & \\
\hline $\begin{array}{l}\text { Exercício não } \\
\text { supervisionado }\end{array}$ & 0,002 & & & \\
\hline Regularmente & & $\mathbf{0 , 5 3}$ & 0,31-0,89 & $\mathbf{0 , 0 1 6}$ \\
\hline Nunca ou esporadicamente & & 1 & & \\
\hline Situação conjugal & 0,818 & - & & \\
\hline $\begin{array}{l}\text { Idade materna } \\
\text { (por ano) }\end{array}$ & 0,146 & 1,05 & $1,02-1,08$ & 0,004 \\
\hline $\begin{array}{l}\text { Gestação anterior } \\
\text { (por gestação) }\end{array}$ & 0,086 & - & & \\
\hline Peso do RN & 0,908 & - & & \\
\hline Escolaridade & 0,197 & - & & \\
\hline
\end{tabular}

*GEE; †Teste de Wald

Fonte: a pesquisadora 
Figura 4 - Gráfico de floresta do modelo final da análise multivariada da IU, Guarulhos, SP - 2012-2014

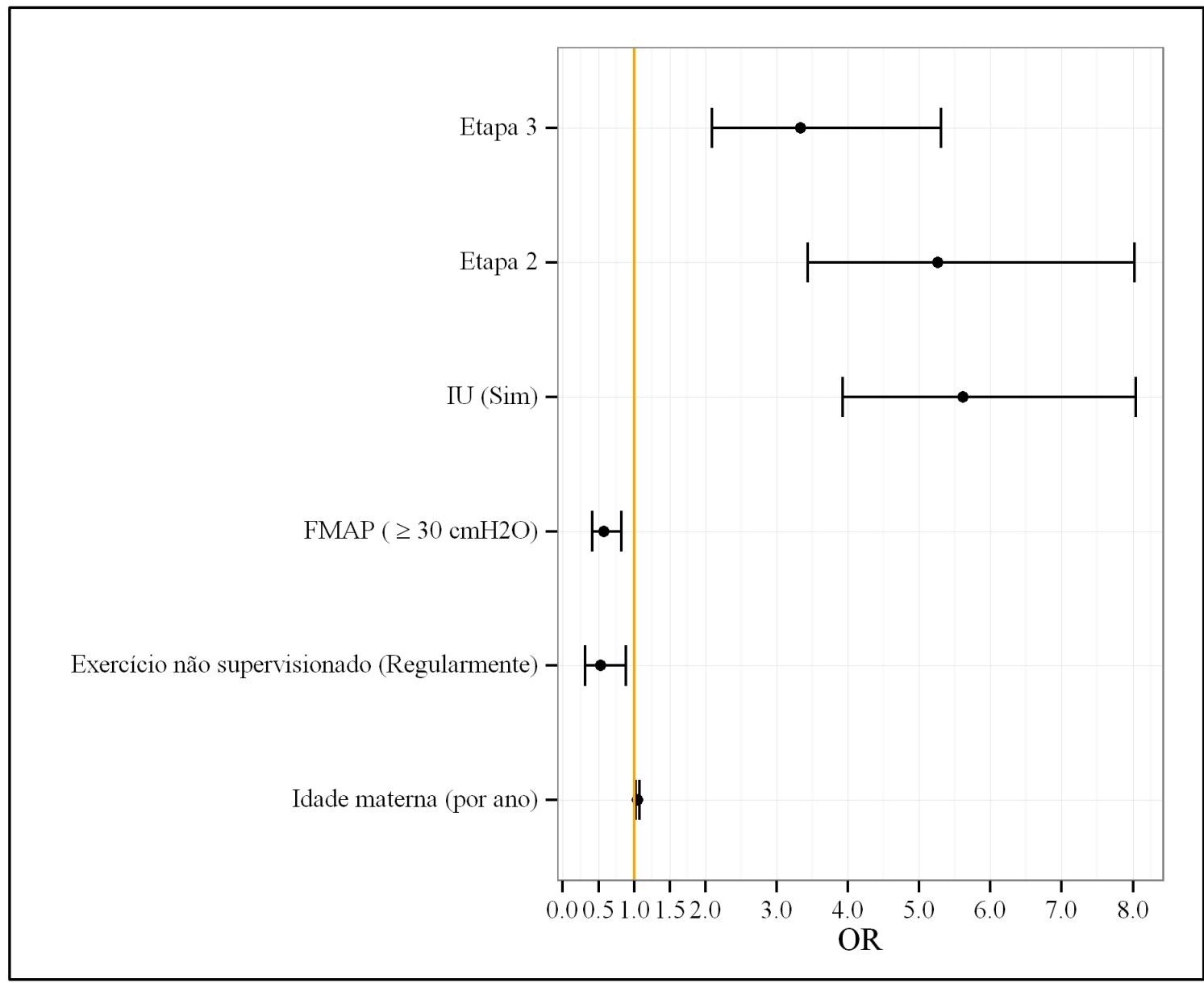

Fonte: a pesquisadora 
$\mathrm{Na}$ análise multivariada da IA, foram incluídas no modelo inicial as seguintes variáveis, iniciando por aquelas com valor-p menor: idade gestacional (por semana); IA prévia; gestação anterior (por gestação); ocupação; maior peso do RN em parto anterior; parto vaginal anterior (por parto); exercício perineal não supervisionado. Permaneceu no modelo final apenas a variável IA prévia, com o seguinte resultado (Tabela 19):

- IA prévia aumenta 11,1 vezes as chances de IA na gestação.

Tabela 19 - Modelos inicial e final da análise multivariada da IA, Guarulhos, SP - 20122014

\begin{tabular}{|c|c|c|c|c|}
\hline \multirow{2}{*}{ Variável } & \multirow{2}{*}{$\begin{array}{c}\text { Modelo inicial* }{ }^{*} \\
\text { Valor-p } \dagger\end{array}$} & & \multicolumn{2}{|c|}{ Modelo final* } \\
\hline & & OR & $95 \%$ IC & Valor-p $\dagger$ \\
\hline Idade gestacional & 0,019 & - & & \\
\hline IA prévia & $<0,001$ & & & \\
\hline Sim & & 11,13 & $6,70-18,50$ & $<0,001$ \\
\hline Não & & 1 & & \\
\hline Gestação anterior & 0,269 & - & & \\
\hline Ocupação & 0,339 & - & & \\
\hline Peso do RN & 0,320 & - & & \\
\hline Parto vaginal anterior & 0,621 & - & & \\
\hline Exercício não supervisionado & 0,358 & - & & \\
\hline
\end{tabular}

*GEE; †Teste de Wald

Fonte: a pesquisadora 


\section{DISCUSSÃO}

Preliminarmente, vale reiterar que em se tratando de um estudo longitudinal, houve um percentual elevado de perdas de seguimento no segundo $(54,8 \%)$ e terceiro trimestres $(63,2 \%)$ da gestação. No entanto, a análise destas perdas indica que foram aleatórias em relação aos desfechos estudados, reduzindo a possibilidade de viés por perdas seletivas na coorte.

\subsection{FMAP, IU e IA ao longo da gestação}

Os resultados do presente estudo mostram diminuição da média da FMAP ao longo da gestação. Avaliada por meio da perineometria, a redução de $1,8 \mathrm{cmH}_{2} \mathrm{O}$, entre o início e final da gestação foi gradativa, sem diferença estatisticamente significante (médias de 30,5, 29,2 e 28,7 $\mathrm{cmH}_{2} \mathrm{O}$, no primeiro, segundo e terceiro trimestre da gestação, respectivamente).

Caroci et al. (2010) também verificaram diminuição da FMAP ao longo da gestação, avaliada pelo perineômetro Perina 996-2®, com variação de 15,9 para 15,2 $\mathrm{mmHg}$, entre os primeiro e terceiro trimestres da gestação, sem diferença estatisticamente significante.

Embora a FMAP medida pela perineometria envolva parâmetros objetivos e quantificáveis, sua avaliação é considerada complexa e sujeita a grandes variações, conforme mostrou o desvio-padrão amplo das médias desta variável. Guaderrama et al. (2005) referem que a vagina não contém uma zona de pressão uniforme, mas, sim segmentos de pressão diferentes, que possuem três zonas de força (proximal, média e distal), o que dificulta identificar a real força dessa musculatura. Igualmente, a pressão intra-abdominal deve ser considerada na avaliação da força e não há equipamento que consiga verificar esta força na situação real da vida (Bø, Sherburn, 2005).

No presente estudo, optou-se pela perineometria sem biofeedback, mesmo considerando que este recurso poderia auxiliar a gestante no reconhecimento da força perineal realizada, fornecendo maior segurança quanto ao valor da FMAP, com atribuição de algum significado pela própria mulher Oliveira et al. (2007). Para tanto, foi feita a orientação da correta realização da contração perineal, buscando isolar sua medida pela 
observação da contração abdominal e dos glúteos durante a contração vaginal, conforme referido no Método e recomendado por Bø e Sherburn (2005), um modo de se avaliar se a musculatura ao redor da uretra, vagina e ânus está sendo contraída,

Vale destacar que foram feitas três medidas em cada avaliação, considerando-se apenas o maior valor registrado na memória do aparelho, e as gestantes que não conseguiram realizar corretamente a contração perinea, constatada pela manobra de Valsalva, foram excluídas da coorte.

Em se tratando de métodos de avaliação, existem vários equipamentos no mercado, que adotam diferentes unidades de pressão, dificultando a comparação dos resultados da FMAP. Além disso, cada aparelho tem sua especificidade, como por exemplo, a largura e a extensão da sonda (Barbosa et al, 2009; B $\emptyset$, Sherburn, 2005).

Alguns estudos indicam aumento da FMAP ao longo da gestação, embora avaliem a FMAP após o primeiro trimestre da gestação. Elenskaia et al. (2011) demonstraram, pela perineometria, que a pressão de repouso e a pressão de contração máxima aumentaram significativamente durante a gestação, tanto em nulíparas como em primíparas, considerando o valor da mediana. Oliveira et al. (2007) apresentam estudo em que também houve aumento significativo da FMAP, do segundo para o terceiro trimestre de gestação.

Elenskaia et al. (2011) supõem que o aumento da FMAP durante a gestação pode acontecer de modo fisiológico, pois assim o AP pode sustentar o aumento do peso do útero gravídico. É plausível que o maior incremento da FMAP aconteça entre o primeiro e segundo trimestres de gestação, pois, neste período, há um aumento significante no peso uterino. Posteriormente, a FMAP declinaria pelo fato da musculatura não estar fortalecida. Estudos demonstram que as gestantes que praticam exercícios perineais, regularmente, ao longo da gestação apresentam aumento da FMAP no final do terceiro trimestre (Sangsawang, Sangsawang, 2013; Hay-Smith et al., 2011; Dinc, Beji, Yalcin, 2009; Oliveira et al., 2007, Mørkoved et al., 2003).

O ponto de corte de $30 \mathrm{cmH}_{2} \mathrm{O}$ na FMAP foi definido para este estudo, com base na experiência clínica e em alguns estudos que indicam que a prevalência de IU é menos frequente entre mulheres com FMAP acima desse valor, medido pelo Peritron ${ }^{\mathrm{TM}}$. Estudos que utilizaram esse mesmo equipamento com mulheres de 20 a 34 semanas de gestação encontraram média de $\leq 30,05$ (d.p.=11,05) cmH2O na FMAP entre as incontinentes (Dinc, Beji, Yalcin, 2009; Hilde et al., 2012). Baracho et al. (2012) indicam a FMAP $<35,5 \mathrm{cmH}_{2} \mathrm{O}$ como risco para desenvolvimento de IUE em mulheres, cinco a sete 
meses após o parto. Riesco et al. (2014) propõem $30 \mathrm{cmH}_{2} \mathrm{O}$ como valor de parâmetro para novos estudos sobre o tema, sobretudo quando os exercícios perineais têm como objetivo a prevenção e tratamento da IU.

No atual estudo, observa-se que, com o ponto de corte de $30 \mathrm{cmH}_{2} \mathrm{O}$, a maioria das mulheres apresentou FMAP abaixo desse limite nos 3 trimestres da gestação $(55,4 \%$, $52,3 \%$ e 58,0\%, respectivamente), situando-as no grupo de maior potencial para desenvolver IU na gestação e no pós-parto, conforme referem Baracho et al. (2012). Visto que a prevalência de IU foi maior entre as gestantes com FMAP $<30 \mathrm{cmH} 2 \mathrm{O}$, nas etapas 1 e 2 da coorte, com diferença estatisticamente significante em relação àquelas sem IU, independente do trimestre da gestação ( $p<0,001$, para efeito da FMAP; $p=0,492$, para interação entre FMAP e etapa). De acordo com a análise multivariada, ter FMAP $\geq 30$ cmH2O reduz em $42 \%$ as chances de IU na gestação.

Vale destacar que a maioria dos estudos inclui mulheres a partir do segundo trimestre de gestação, prejudicando a análise do perfil da FMAP, desde o início da gestação, diferentemente do presente estudo, em que todas foram avaliadas, inicialmente, com idade gestacional abaixo de 13 semanas.

Conforme apresentado nos resultados, a análise bivariada indicou diminuição da média FMAP, com associação estatisticamente significante da FMAP em relação às gestações, abortos, partos vaginais e trauma perineal, independente do trimestre gestacional. No entanto, dada a alta correlação entre estas variáveis, apenas o antecedente de gestação foi incluído na análise multivariada, mostrando que cada gestação anterior reduz 1,73 cmH2O na FMAP durante a gestação subsequente.

Contraditoriamente, em relação ao número de cesarianas anteriores, houve correlação positiva, embora fraca. Nesse sentido, não é possível afirmar que a cesariana preserva a FMAP.

Elenskaia et al. (2011) e Caroci et at. (2010) demonstraram que não houve associação estatisticamente significante entre a redução da FMAP e o tipo de parto, embora a maioria das pesquisas associe o parto vaginal com o enfraquecimento dos músculos do AP (Freeman, 2013), indicando que esse impacto é menor nas mulheres que foram submetidas à cesariana (Gamero et al., 2011). Por sua vez, Hay-Smith et al. (2011) consideram que não há evidências de que o parto cause diminuição da FMAP e Baracho et al. (2012) afirmam que a FMAP é um forte preditor da IUE em primíparas que foram submetidas a parto vaginal. 
A IU prévia e IU atual foram identificadas como significantes para a diminuição da FMAP na gestação, independente da etapa da coorte. Mas, na análise multivariada, apenas a IU prévia manteve-se no modelo explicativo da variação da FMAP com as demais variáveis já referidas (idade gestacional, gestações anteriores) e com a realização de exercícios perineais regularmente, dado que ter IU prévia reduz $3,03 \mathrm{cmH}_{2} \mathrm{O}$ na FMAP durante a gestação.

Algumas variáveis aparecem em outros estudos como fatores importantes para a diminuição da FMAP na gestação, como o estado nutricional (Sangsawang, Sangsawang, 2013); porém, no presente estudo, a variável não se manteve no modelo final da análise multivariada, o que está de acordo com o estudo de Elenskaia et al. (2012).

A literatura sobre o efeito dos exercícios perineais gestação é vasta e vários estudos indicam que a realização de exercícios de forma regular e sob supervisão aumenta a FMAP e reduz a queixa de IU (Mørkved, Bø, 2014; Sangsawang, 2014; Frederice, Amaral, Ferreira, 2013; Sangsawang, Sangsawang, 2013; Baracho et al., 2012; Hilde at al., 2012; Stafne et al., 2012; Sangsawang, Serisathien, 2011; Hay-Smith et al., 2011; Dinc, Beji, Yalcin, 2009; Mørkved et al., 2004; Mørkved et al., 2003).

Os estudos são contraditórios a respeito dos exercícios perineais durante a gestação na presença de IU prévia. Wordringhet et al. (2007) referem que exercícios perineais não são eficientes para quem tem IU prévia. Lemos et al. (2008) apontam que os estudos não são conclusivos em relação aos efeitos dos exercícios perineais ao longo da gestação, embora possam reduzir a IU no pós-parto.

Mas, a maioria dos estudos demonstra que exercícios perineais realizados regularmente durante a gestação aumentam a FMAP e reduzem queixas de IU, o que está de acordo com o presente estudo, na qual as gestantes que realizaram exercícios perineais regularmente (no mínimo duas vezes por semana) apresentaram maior FMAP e menor IU na gestação, com associação estatisticamente significante. Vale destacar que este fator permaneceu para o modelo final da análise multivariada da FMAP e da IU, mostrando que a realização de exercícios perineais regularmente aumenta em 2,37 $\mathrm{cmH}_{2} \mathrm{O}$ a FMAP durante a gestação e reduzem em $47 \%$ as chances de IU na gestação.

Wesnes e Lose (2013) recomendam que um programa de treinamento perineal seja adotado durante a gestação e no pós-parto e que esta recomendação deve ser seguida, levando em conta o grau A das evidências científicas (recomendação obrigatória, deve ser sempre seguida). 
Um resultado importante que os estudos apontam é que as mulheres que são orientadas e supervisionadas para a realização dos exercícios perineais realizam o programa de exercícios com maior frequência, favorecendo o fortalecimento do AP (Stafne et al., 2012; Sangsawang, Serisathien, 2011; Ismail, 2009; Mørkved et al., 2003).

Sangsawang (2014) refere que IU na gestação pode estar associada à fraqueza dos músculos do AP, porém alguns autores são controversos a este apontamento, pois citam que o que causa a IU na gestação é inerente à fraqueza do esfíncter da uretra na gestação (Widja et al., 2001). Não é fator determinante que a mulher que teve IU na gestação apresente a queixa após o parto. Embora a IU no pós-parto esteja associada à IU na gestação, não está claro se são as mesmas mulheres que apresentam IU na gestação e no pós-parto (Huerbner, Antonic, Tunn, 2010). No início desta coorte, quando questionadas sobre o momento em que a IU prévia ocorreu, apenas 11,3\% das gestantes responderam "em gestação anterior que persiste até hoje".

Neste estudo, a IU prévia foi referida por $39,1 \%$ das gestantes que iniciaram a coorte. Embora representem menos da metade da amostra, pode-se considerar que uma grande quantidade de mulheres já apresentou IU em algum momento da vida. Especialmente, tratando-se de mulheres jovens, em idade reprodutiva. No segundo trimestre da gestação atual, 61,9\% das gestantes com IU prévia eram incontinentes ( $\mathrm{p}<0,001$, tanto para efeito da variável como da etapa da coorte). Igualmente, na análise multivariada, o antecedente de IU foi o principal preditor de IU na gestação $(\mathrm{OR}=5,62$; 95\% IC 3,93-8,04), corroborando os estudos de Sangsawang (2014), Baracho et al. (2012) e Torrisi et al. (2012).

A incidência de IU, que no primeiro trimestre de gestação foi de 3,8\%, apresentou um pico de 21,6\% no segundo trimestre. O mesmo comportamento foi observado na prevalência de IU, que sofreu aumento abrupto de 19,0\% no início da gestação, para $42,5 \%$ no segundo trimestre. Embora tenha permanecido em níveis elevados no terceiro trimestre, a análise multivariada confirmou que a chance de IU aumenta na segunda metade da gestação, especialmente, no segundo trimestre ( $\mathrm{OR}=5,26 ; 95 \% \mathrm{IC} 3,44-8,02)$.

Os resultados do estudo de Franco et al. (2014) corroboram os achados do presente estudo. Os autores concluíram que a prevalência de IU é elevada no final da gestação, com taxas de $18,96 \%$ e $39,76 \%$, no primeiro e no terceiro trimestre de gestação, respectivamente.

Sangsawang e Sangsawang (2013) referem que o aumento da pressão no AP pelo aumento do útero e o peso do feto associados às alterações hormonais da gestação, pode 
diminuir a FMAP, a sustentação do AP e a competência do esfíncter uretral, favorecendo assim o aparecimento da IU na gestação, porém não enfatizam o trimestre de maior aparecimento da IU.

A literatura mostra que a variação na incidência e prevalência de IU na gestação é ampla, com valores abaixo de $20 \%$ e acima de $70 \%$ na dependência da paridade, idade gestacional e tipo de IU (Sangsawang, 2014; Cerruto et al., 2013; Oliveira et al., 2013; Sangsawang, Sanwsawang, 2013; Bø et al., 2012; Fritel et al., 2012; Hansen et al., 2012; Stafne et al., 2012; Wesnes, Hunkkaar, Rortveit, 2012; Valeton, Amaral, 2011; Huerbner, Antolic, Tunn, 2010; Solans-Domènech, Sanchez, Espuna-Pons, 2010; Klovning et al., 2009). No entanto, a maioria dos estudos sobre IU na gestação apresenta taxas globais ou relativas aos segundo e terceiro trimestres da gestação, sem informação sobre a IU no início da gravidez.

Estudos epidemiológicos associam a IU na gestação a fatores como idade materna, etnia, hábitos de vida, doenças crônicas, aumento IMC antes e durante a gestação, número de gestações anteriores, tipo de parto e assistência recebida no parto, entre outros. Alguns destes fatores são considerados ocasionais ou reversíveis, e outros são contínuos ou cumulativos (Sangsawang, 2014; Cerruto et al., 2013; Wesnes, Lose, 2013; Bø et al., 2012; Fritel et al. 2012; Solans-Domènech, Sanchez, Espuna-Pons, 2010; Scarpa et al., 2006).

Em relação às características sociodemográficas das participantes deste estudo, a cor da pele e a escolaridade não apresentaram significância estatística para ocorrência de IU na gestação, corroborando os achados de Scarpa et al. (2006), mas em contraposição aos resultados de Oliveira et al. (2013), em que a IU na gestação foi mais frequente entre gestantes negras e com menos de 8 anos de estudo.

No presente estudo, a idade materna apresentou significância estatística para IU na gestação, aumentando em $5 \%$ as chances de sua ocorrência a cada ano. A idade da gestante também foi fator associado com a IU nos estudos de Sangsawag, (2014), Cerruto et al. (2013) e Solans-Domènech, Sanchez e Espuna-Pons (2010), na gestação e fora do período gestacional (Higa, Lopes, Reis, 2008).

Outra variável sociodemográfica considerada na coorte foi a situação conjugal. Conforme apresentado no capítulo de resultados (Tabela 7), o percentual de gestantes que vivia com o companheiro passou de $86,5 \%$ a $98,4 \%$, no primeiro e terceiro trimestres, respectivamente. Embora a análise bivariada tenha indicado p-valor=0,035, independente da etapa do estudo, esta variável não se manteve no modelo final da análise multivariada. 
Sua relação de causalidade com a ocorrência de IU não pode ser estabelecida e, também, a literatura não aborda este fator.

Os antecedentes obstétricos - gestações e partos anteriores, tipo de parto, peso do feto - vêm sendo exaustivamente estudadas, visando a ampliar a compreensão da relação causal e da fisiopatologia, que expliquem seu papel na IU feminina.

Para Sangsawag e Sangsawag (2013), na gestação, a fraqueza dos músculos do AP causa mobilidade do colo da bexiga e da uretra, levando à incompetência do esfíncter uretral.

Na comparação entre mulheres nulíparas e primíparas, Hansen et al. (2012) concluíram que a gestação aumentou em 3,3 vezes as chances de IU; um ano após o parto, a chance de IU ainda era de 2,5 vezes mais entre as primíparas.

Oliveira et al. (2013) referem que o aumento de paridade está associado com maior prevalência de IU. Igualmente, Cerruto et al. (2013) citam que a paridade é um dos principais fatores de risco para a IU na gestação e Torrisi et al. (2012) afirmam que gestação e parto vaginal anteriores podem ser considerados fatores de risco da IU na gestação.

Para Scarpa et al. (2008) e Scarpa et al. (2006), a paridade é um fator mais relevante que parto vaginal para o desenvolvimento de IUE, corroborando os achados de Sangsawag (2014), Huerbner, Antonic e Tunn (2010) e Ekstron et al. (2007).

Em relação ao parto, existe uma incerteza se o parto vaginal deve ser considerado como fator confundidor, intermediário ou de risco independente da IU no pós-parto (Wesnes e Lose, 2013). Higa, Lopes e Reis (2008) afirmam que o parto vaginal não pode ser considerado, isoladamente, como preditor de IU; porém, quando analisado com traumas perineais, pode aumentar sua propensão. Por sua vez, Wesnes e Lose (2013) referem que o trauma perineal em parto vaginal não parece estar associado com a IU no pós-parto, mas as evidências são fracas. Ainda assim, a episiotomia deve ser restrita e não pode ser indicada para prevenir IU no pós-parto.

Ainda quanto ao tipo de parto, mesmo aqueles autores que apontam o parto vaginal como preditor da IU, consideram não ser possível afirmar que a cesariana tenha efeito protetor (Baracho et al., 2012; Ekstron et al., 2008).

Revisão sistemática realizada por Lemos et al. (2008) indica que não há diferença para IU, conforme o tipo de parto. Wesnes e Lose (2013) consideram que não existem evidências científicas disponíveis para recomendar ou evitar a cesariana a fim de prevenir a IU. Além disso, Cerruto et al. (2013) citam que embora as mulheres submetidas à 
cesariana apresentem menos queixas de IU após pós-parto que aquelas com parto vaginal, esta vantagem desaparece com o tempo e depois da segunda cesariana (OR 0,47; 95\% IC 0,04-5,69).

Em contraposição, Lukcz et al. (2006) referem que o parto vaginal está associado à DAP e não há diferença estatisticamente significante ao comparar DAP entre as mulheres que foram submetidas à cesariana e nulíparas.

Fritel et al. (2012) apoiaram-se na revisão de literatura para fundamentar a teoria do trauma obstétrico e formular hipóteses que auxiliem a explicar a IU em mulheres. Os autores destacam os diferentes fatores de risco no curso da vida da mulher e as características específicas da gestação (alterações hormonais e metabólicas) que podem afetar diferentes partes do complexo do esfíncter uretral com o mecanismo da IUE. Destacam que a prevalência máxima de IUE é na gestação, não após o parto. Isto significa que há outros os mecanismos envolvidos na gênese IUE, que precedem o trauma obstétrico atribuído ao parto. Consideram que faltam estudos, sobretudo coortes, para explicar porque a IUE ocorre transitoriamente na gestação e constitui fator de risco para o aparecimento tardio da IUE na vida da mulher. Com estas observações, os autores sugerem uma tendência deletéria, porém reversível dos efeitos da gestação sobre a continência urinária.

Na presente coorte, vale reiterar que, embora os antecedentes obstétricos tenham mostrado significância estatística com a IU na gestação, estas variáveis não permaneceram no modelo final.

$\mathrm{Na}$ literatura, o estado nutricional antes e durante a gestação é apontado como fator de risco para IU na gestação (Sangsawang, 2014; Oliveira et al., 2013; Sangsawang, Sangsawang, 2013; Wesnes, Lose, 2013; Cerruto et al., 2012; Fritel et al. 2012.

Sangsawang e Sangsawang (2013) referem que o aumento do peso durante a gestação aumenta a pressão sobre os músculos do AP e a bexiga, favorecendo a mobilidade uretral. Cerruto et al. (2013) mostram associação entre obesidade e IU, indicando que mulheres com IMC >35 na gestação apresentaram pela primeira vez IU. Embora o estudo de Scarpa et al. (2006) não mostre relação entre IMC e IU, Wesnes e Lose (2013) recomendam que as mulheres deveriam manter o peso adequado antes da gestação, levando em conta o grau B das evidências científicas (recomendadas, devem ser usualmente seguidas).

$\mathrm{Na}$ população deste estudo, 45,1\% das gestantes foram classificadas com sobrepeso ou obesidade no primeiro trimestre de gestação, $47,6 \%$ no segundo e $48,4 \%$ no 
terceiro trimestre, com associação estatisticamente significante com IU, independentemente da etapa do estudo. Mas, o estado nutricional não permaneceu como variável associada após a análise multivariada.

Em relação à interferência da IU na vida da gestante, avaliada pelo ICIQ-SF, a média do escore ao longo da gestação foi compatível com interferência moderada, com base na classificação de Klovning et al. (2009). Esses autores sugerem que o escore do instrumento, com pontuação de 0 a 21, seja dividido em quatro categorias: 1-5 (leve), 612 (moderada), 13-18 (severa) e 19-21 (muito severa).

Com variação média de 8,2, 8,3 e 7,8, no primeiro, segundo e terceiro trimestres da gestação, estes resultados são similares àqueles obtidos por Bø et al. (2012). Franco et al. (2014) apresentam escore de 6,59 para o ICIQ-SF sem significância estatística para os resultados do primeiro e no terceiro trimestre. Em estudo transversal realizado por Oliveira et al. (2013), o grupo de mulheres incontinentes apresentaram escore médio de ICIQ-SF de 12,1, que os autores consideraram como de impacto severo na qualidade de vida da gestante.

Embora tenha sido utilizada em outras pesquisas sobre IU na gestação (Hansen et al., 2012; Hilde et al., 2012; Bø; Haaskstad, 2011; Solans-Domènech, Sanchez, EspunaPons, 2010), a comparação dos escores entre os estudos mostra divergências na análise dos dados, comprometendo a comparação dos resultados

Além de dimensionar a interferência da IU na vida da mulher, a pergunta do ICIQSF sobre as situações em que a perda urinária ocorre, permitiu avaliar que as situações relacionadas à IUE foram muito frequentes, conforme esperado na gestação, dadas as alterações hormonais, o aumento do peso do útero sobre a bexiga e o aumento da pressão abdominal (Sangsawang, 2014; Sangsawang, Sangsawang, 2013; Frederice, Amaral, Ferreira, 2013; Fritel et al. 2012; Sangsawang, Serisathien, 2011).

No entanto, as situações relacionadas com a IUU também foram citadas com frequência. É possível que o questionário autorrespondido não seja adequadamente compreendido por parte das mulheres. Como exemplo, a opção "Perco quando estou dormindo", pode ser entendida como noctúria.

A literatura relacionada à IA é mais escassa que aquela sobre IU. A prevalência de IA é também mais difícil de estimar, pelo uso de definições não padronizadas. Outrossim, mesmo com o desconforto físico e emocional que os sintomas produzem as mulheres relatam pouco esta queixa, em razão do constrangimento (Hay-Smith et al., 2008). 
Os estudos mostram que a IA está diretamente ligada ao trauma muscular do levantador do ânus, e isso pode acontecer em parto via vaginal, sobretudo, instrumental (com o uso de fórceps e vácuo extrator) (Chantarasorn, Shek, Dietz, 2011; SolansDomènech, Sanchez, Espuña-Pons, 2010; Hay-Smith et al., 2009; DeLancey et al., 2003).

Em revisão sistemática realizada por Hay-Smith et al. (2008), a prevalência de IA em mulheres primíparas foi de $2 \%$ a $6 \%$. Quando a IA incluiu a perda de flatos, essa prevalência variou de $13 \%$ a $27 \%$. Os autores chamam a atenção que quando ocorre trauma perineal severo no parto (lacerações de terceiro e quarto graus), principal fator de risco para IA, as taxas podem variar de $17 \%$ e $62 \%$.

Chantarasorn, Shek e Dietz (2011) realizaram estudo com 397 mulheres de uma clínica uroginecológica e encontram a 16,4\% mulheres que referiram incontinência de fezes e 22,9\% incontinência de flatos. Solans-Domènech, Sanchez e Espuña-Pons (2010) mostraram incidência acumulada de IA de 10,3\% em gestantes nulíparas. Entre estas mulheres, os fatores de risco foram idade acima de 35 anos $(\mathrm{HR}+1,7)$ e ganho excessivo de peso durante a gestação $(H R=1,5)$.

Neste estudo, 22,6\% das mulheres referiram IA prévia à gestação (a quase totalidade por incontinência de flatos), das quais, $22,1 \%$ tiveram sintomas em gestação anterior. Na análise multivariada, justamente a IA prévia foi a única variável associada, aumentando 11 vezes as chances na gestação subsequente.

Embora alguns estudos incluídos na revisão de Hay-Smith et al. (2009) apontem que realizar exercícios perineais durante a gestação pode prevenir IA antes e após o parto, a metanálise realizada e os resultados da presente coorte não confirmaram esse achado. Ainda, em relação à FMAP, conforme Chantarasorn, Shek e Dietz (2011), quando há alteração detectável na perineometria, esta deve ser associada com IA severa.

Vale ainda considerar que a avaliação da musculatura retal é de acesso difícil. Embora, atualmente, a ultrassonografia venha sendo aprimorada como um método capaz de avaliar o grau de lesão e a força muscular, mais estudos devem ser desenvolvidos (DeLancey et al., 2003).

\subsection{Limitações do estudo}

Nesta pesquisa, pode-se considerar que as possíveis limitações foram minimizadas, mediante o controle dos principais vieses - seleção, informação e confundimento -, conforme descrito a seguir (Medronho et al., 2009): 
- A análise das perdas de seguimento, indicando que estas foram aleatórias, não foram seletivas para os desfechos estudados;

- Os critérios de inclusão e exclusão, foram definidos previamente à inclusão das participantes na coorte;

- O delineamento prospectivo do estudo;

- O uso de instrumentos validados para pesquisa - ICIQ-SF e perineômetro digital, de alta precisão;

- Treinamento de toda a equipe participante da coleta de dados, com padronização dos procedimentos utilizados; e

- Tratamento estatístico com análise multivariada.

\subsection{Implicações para a pesquisa e a prática}

Os resultados desta pesquisa trazem contribuições para o conhecimento sobre o cuidado perineal de mulheres na gestação e para futuros estudos sobre o perfil da FMAP na gestação.

$\mathrm{Na}$ prática assistencial, pode subsidiar o cuidado pré-natal prestado por enfermeiras obstétricas, obstetrizes, médicos e fisioterapeutas. Em especial, dada a importância de oferecer informações sobre a ocorrência da IU e IA, para sua prevenção ou redução, ao longo da gestação e no pós-parto, com encaminhamento pela equipe de saúde.

A orientação sobre a realização de exercícios perineais regularmente durante a gestação deve ser incorporada à assistência pré-natal, desde o primeiro trimestre até o puerpério. 


\section{CONCLUSÃO}

Os resultados desta pesquisa permitem concluir que o avanço semanal da gestação, as gestações anteriores e a IU prévia contribuem para a redução da FMAP em mulheres grávidas.

Em relação à IU ao longo da gravidez, mulheres com mais idade e com IU prévia têm maior chance de desenvolver IU a partir da $20^{\text {a }}$ semana de gestação, em especial, no segundo trimestre. As mulheres consideram que a IU na gestação tem impacto moderado em sua vida diária.

Por sua vez, a realização de exercícios perineais na gestação, pelo menos duas vezes por semana, aumenta a FMAP e reduz a ocorrência de IU.

O único preditor de IA durante a gestação é a IA prévia. 


\section{REFERÊNCIAS}

Abrams P, Andersson KE, Brubaker L, Cardozo L, Cottenden A, Davila W, et al. Fourth international consultation on incontinence recommendations of the international scientific committee: evaluation and treatment of urinary incontinence, pelvic organ prolapse, and fecal incontinence. Neurourology and Urodynamics 2010;29:213-40.

Atalah ES, Castillo LC, Castro SR, Aldea P. Propuesta de un nuevo estandar de evaluación nutricional en embarazadas. Rev Med Chil. 1997;125(12):1429-36.

Avery K, Donovan J, Peters TJ, et al. ICIQ: A brief and robust measure for evaluating symptoms and impact of urinary incontinence. Neurourol Urodyn. 2004;23:322-30.

Baracho SM, Silva LB, Baracho E, Silva Filho AL, Sampaio RF, Figueiredo EM. Pelvic floor muscle strength predicts stress urinary incontinence in primiparous women after vaginal delivery. Int Urogynecol J. 2012;23(7):899-906.

Barbosa AMP, Dias A, Marini G, Calderon IM, Witkin S, Rudge MV. Urinary incontinence and vaginal squeeze pressure two years post-cesarean delivery in primiparous women with previous gestational diabetes mellitus. Clinics (São Paulo). 2011;66(8):1341-5.

Barbosa AMP, Franco MM, Souza FO, Antonio FI, Montemazuma T, Ferreira CHJ. Comparison between measurementes obtained with three different perineometers. Clinics 2009;64(6):527-33.

Barrett G, Prendy E, Peacock J, Victor C, Thakar R, Manyonda I.. Women's sexuality after childbirth: a pilot study. Arch Sex Behav 1999;28(2):179-91.

Bharucha AE, Zinsmeister AR, Locke GR, Seide BM, McKeon K, Schleck CD, et al. Risk factors for fecal incontinence: a population-based study in women. Am J Gastroenterol 2006;101:1305-12

$\mathrm{B} \emptyset \mathrm{K}$, Haakstad LAH. Is pelvic floor muscle training effective when taught in a general fitness class in pregnancy? A randomised controlled trial. Physiotherapy. 2011;97:1905 .

$\mathrm{B} \emptyset \mathrm{K}, \emptyset \mathrm{glund}$ GP, Sletner L, Mørkrid K, Jenum AK. The prevalence of urinary incontinence in pregnancy among a multi-ethnic population resident in Norway. BJOG. 2012;119(11):1354-60.

$\mathrm{B} \emptyset \mathrm{K}$, Pelvic floor muscle training is effective in treatment of female stress urinary incontinence, but how does it work? Int Urogynecol J 2004;15:76-84.

$\mathrm{B} \emptyset \mathrm{K}$, Sherburn M. Evaluation of Female Pelvic-Floor Muscle Function and Strength. Phys Ther. 2005;85:269-82. 
Brummen HJ, Bruinse HW, Van de Pol G, Heintz AP, Van der Vaart CH What is the effect of overactive bladder symptoms on woman's quality of life during and after first pregnancy? BJU Int 2006;97(2):296-300

Bruschini H. Etiopatogenia e classificaçãi da incontinência urinária feminina. In: Amaro JL, Haddad JM, Trindade JCS, Ribeiro RM. Reabilitação do assoalho pélvico nas disfunções urinária e anorretais. São Paulo: Segmento; 2005. cap. 1 p.19-24

Caroci AS, Riesco MLG, Sousa WS, Cotrim AC, Sena EM, Rocha NL, et al. Analysis of pelvic floor musculature function during pregnancy and postpartum: a cohort study. J Clin Nurs. 2010;19(17-18):2424-33.

Cerruto MA, D'Elia C, Aloisi A, Fabrello M, Artibani W. Prevalence, incidence and obstetric factors impact on female urinary incontinence in Europe: a systematic review. Urol Int. 2013;90(1):1-9.

Chantarasorn V, Shek KL, Dietz HP Sonographic detection of puborectalis muscle avulsion is not associated with anal incontinence. Aust N Z J Obstet Gynaecol. 2011;51(2):130-35

Chiarelli P, Murphy B, Cockburn J. Fecal incontinence after high-risk delivery. Obstet Gynaecol. 2003;102(6):1299-305.

Chiverton PA, Wells TJ, Brink CA, Mayer R. Psychological factors associated with urinary incontinence. Clinical Nurse Specialist September. 1996;10(5),229-33.

Ciofu C, Haab F. Profilaxia da incontinência urinária. In: Amaro JL, Haddad JM, Trindade JCS, Ribeiro RM. Reabilitação do assoalho pélvico nas disfunções urinária e anorretais. São Paulo: Segmento; 2005.cap.2 p.25-31.

DeLancey JO, Kearney R, Chou Q, Speights S, Binno S. The appearance of levator ani muscle abnormalities in magnetic resonance images after vaginal delivery. Obstet Gynecol. 2003;101(1):46-53.

Dinc A, Beji NK, Yalcin O. Effect of pelvic floor muscle exercises in the treatment of urinary incontinence during pregnancy and the postpartum period. Int Urogynecol J. 2009;20(10):1223-31.

Donovan JL, Peters TJ, Abrams P, Brookes ST, Rosette JJ, Schäfer W. Scoring the Short Form ICS male SF questionnaire. J Urol 2000;164:1948-55.

Ekstron A, Altman D, Wiklund I, Larsson C, Andolf E. Planned cesarian section versus vaginal delivery comparison of lower urinary tract symptoms. Int Urogynecol J Pelvic Floor Dysfunct 2008;19(4):459-65.

Elenskaia K, Thakar R, Sultan AH, Scheer I, Beggs A. The effect of pregnancy and childbirth on pelvic floor muscle function. Int Urogynecol J. 2011;22(11):1421-7.

Ferreira CHJ, Barbosa PB, Souza FO, Antonio FI, Franco MM, Bø K. Inter-rater reliability study of the modified Oxford Grading Scale and the peritron manometer. Physiotherapy. 2011;97(2):132-8. 
Franco EM, Parés D, Colomé NL, Paredes JRM, Tardiu LA. Urinary incontinence during pregnancy. Is there a difference between first and third trimester? Eur J Gynecol Report Biol. 2014;182(Epub sep 2):86-90.

Frederice CP, Amaral E, Ferreira NO. Sintomas urinários e função muscular do assoalho pélvico após o parto. Rev Bras Ginecol Obstet. 2011;33(4):188-95.

Freeman R. Can we prevent childbirth-related pelvic floor dysfunction?. BJOG 2013; 120:137-140

Fritel X, Ringa V, Quiboeuf E, Fauconnier A. A. Female urinary incontinence, from pregnancy to menopause: a review of epidemiological and pathophysiological findings. Acta Obstet Gynecol Scand. 2012;91(8):901-10.

Gameiro MO, Moreira ECH, Amaro JL. Exercícios perineais. In: Amaro JL, Haddad JM, Trindade JCS, Ribeiro RM. Reabilitação do assoalho pélvico nas disfunções urinária e anorretais. São Paulo: Segmento; 2005. Cap.13 p.119-22.

Gameiro MO, Sousa VO, Gameiro LF, Muchailh RC, Padovani CR, Amaro JL. Comparison of pelvic floor muscle strength evaluations in nulliparous and primiparous women: a prospective study. Clinics (São Paulo). 2011;66(8):1389-93.

Guaderrama NM, Nager CW, Lui J, Pretorius DH, Mittal RK. The vaginal pressure profile. Neurourol Urodyn. 2005;24:243-47.

Hansen BB, Svare J, Viktrup L, Jørgensen T, Lose G. Urinary incontinence during pregnancy and 1 year after delivery in primiparous women compared with a control group of nulliparous women. Neurourol Urodyn. 2012;31(4):475-80.

Hantoushzadeh S, Javadian P, Shariat M, Salmanian B, Ghazizadeh S, Aghssa M. Stress urinary incontinence: pre-pregnancy history and effects of mode of delivery on its postpartum persistency. Int Urogynecol J. 2011;22(6):651-5.

Hay-Smith J, Mørkved S, Fairbrother KA, Herbison GP. Pelvic floor muscle training for prevention and treatment of urinary and faecal incontinence in antenatal and postnatal women. Cochrane Database Syst Rev. 2011;(4):CD007471.

Higa R, Lopes MHBM, Reis MJ. Risk factors for urinary incontinence in women. Rev Esc Enferm USP. 2008;42(1):187-92.

Hilde G, Stær-Jensen J, Ellström Engh M, Brækken IH, B $\emptyset$ K. Continence and pelvic floor status in nulliparous women at midterm pregnancy. Int Urogynecol J. 2012;23(9):1257-63.

Huebner M, Antolic A, Tunn R. The impacto f pregnancy and vaginal delivery on urinary incontinence. Int J Gynecol Obstet 2010;110:249-251.

Ismael SIM. An audit of NICE guidelines on antenatal pelvic floor exercises. Int Urogynecol J. 2009;20:1417-22.

Kegel N (1948) Progressive resistance exercise in the functional retroration of the perineal muscle. Am J Obstet Gynaecol. 56:238-248. 
Klovning A, Avery K, Sandvik H, Hunskaar S. Comparison of two questionnaires for assessing the severity of urinary incontinence: the ICIQ-UI SF versus the Incontinence Severity Index. Neurourol Urodyn. 2009;28(5):411-5.

Ko PC, Liang CC, Chang SD, Lee JT, Chao AS e Cheng PJ. A randomized controlled trial of antenatal pelvic floor exercises to prevent and treat urinary incontinence. Int Urogynecol J 2011;22:17-22.

Lavy Y, Sand PK, Kaniel CI, Hochner-Celnikier D. Can pelvic floor secondary to delivery be prevented? Int Urogynecol J. 2012;23(2):165-73.

Lemos A, Souza I, Ferreira JN, Cabral-Filho E. Do perineal excercises during pregnancy prevent the development of urinary incontinence: a systematic review. Int Journal Urol 2008;15(10):875-80.

Leroy LS, Lopes MHBM. Urinary incontinence in the puerperium and its impact on the health-related quality of life. Rev Latino Am Enfermagem. 2012;20( 2):346-53.

Liang CC, Tseng LH, Horng SG, Lin IW, Chang SD. Correlation of pelvic organ prolapse quantification system scores with obstetric parameters and lower urinary tract symptoms in primiparae postpartum. Int Urogynecol J Pelvic Floor Dysfunct 2007; 18(5):537-41.

Lopes DB, Praça NS. Self-reported urinary incontinence in the postpartum period: clinical characteristics. Rev Esc Enferm USP. 2012;46(3):559-64.

Lukacz ES, Lawrencw JM, Contreras R, Nager CW, Luber KM. Parity, mode of delivery, and pelvic floor disorders. Obstet Gynecol 2006;107(6):1253-60.

Luthander C, Emilsson T, Ljunggren G, Hammarström M. A questionnaire on pelvic floor dysfunction postpartum. Int Urogynecol J. 2011;22(1):105-13.

Medronho RA, Bloch KV, Luiz RR, Werneck GL, editores. Epidemiologia. $2^{\mathrm{a}}$ ed. São Paulo: Atheneu; 2009.

Morkved S, Bo K, Schei B, Salvesen KA. Pelvic floor muscle training during pregnancy to prevent urinary incontinence: a single-blind randomized controlled trial. Obstet Gynecol. 2003;101(2):313-19

Morkved S, Bo K. Effect of pelvic floor muscle training during pregnancy and after childbirth on prevention and treatment of urinary incontinence. Br J Sports Med. 2014;48(4):299-310.

Mørkved S, Salvesen KA, Bø K, Eik-Nes S. Pelvic floor muscle strength and thickness in continent and incontinent nulliparous pregnant women. Int Urogynecol J Pelvic Floor Dysfunct 2004;15:384-90

Oliveira C, Lopes MAB, Pereira LCL, Zugaib M. Effects of pelvic floor muscle training during pregnancy. Clinics (São Paulo) 2007;62(4):439-46. 
Oliveira C, Seleme M, Cansi PF, Consentino RF, Kumakura FY, Moreira GA, et al. Urinary incontinence in pregnant women and its relation with socio-demographic variables and quality of life. Rev Assoc Med Bras. 2013;59(5):460-6.

Piassarolli VP, Hardy E, Andrade NF, Ferreira NO, Osis MJD. Treinamento dos músculos do assoalho pélvico nas disfunções sexuais femininas. Rev Bras Ginecol Obstet. 2010;32(5):234-40.

Riesco MLG, Fernandes-Trevisan K, Leister N, Cruz CS, Caroci AS, Zanetti MRD. Incontinência urinária relacionada à força muscular perineal no primeiro trimestre da gestação: estudo transversal. Rev Esc Enferm USP 2014;48(Esp):3.

Sangsawang B, Sangsawang N. Stress urinary incontinence in pregnant women: a review of prevalence, pathophysiology, and treatment. Int Urogynecol J.

2013;24(6):901-12.

Sangsawang B, Serisathien Y. Effect of pelvic floor muscle exercise programme on stress urinary incontinence among pregnant women. J Adv Nurs. 2011;68(9):1997-2007

Sangsawang B. Risk factors for the development of stress urinary incontinence during oregnancy in primigravidae: a review of the literature. Eur J Obstet Gynecol Reprod Biol. 2014;178:27-34.

Santoro GA, Which method is best for imaging of anal sphincter defects? Dis Colon Rectum 2012;55:625-27.

Scarpa KP, Herrmann V, Palma PCR, Ricetto CLZ, Morais S. Prevalence and correlates of stress urinary incontinence during pregnancy: a survey at UNICAMP Medical School, São Paulo, Brazil. Int Urogynecol J 2006;17:219-23.

Scarpa KP, Herrmann V, Palma PCR, Ricetto CLZ, Morais S. Sintomas do trato urinário inferior três anos após o parto: estudo prospectivo Rev Bras Ginecol Obstet. 2008; 30(7):355-9

Solans-Domenech M, Sanchez E, Espuna-Pons M. Urinary and anal incontinence during pregnancy and postpartum: incidence, severity, and risk factors. Obstet Gynecol. 2010;115(3):618-28.

Stafne S, Salvesen K, Romundstad P, Torjusen I, Mørkved S. Does regular exercise including pelvic floor muscle training prevent urinary and anal incontinence during pregnancy? A randomised controlled trial. Br J Obstet Gynaecol 2012;119(10):1270-80

Steen M. Promoting continence in women following childbirth. CPD continence. 2013;28(1 sept 4):49-57.

Sung VW, Hampton BS. Epidemiology of pelvic floor dysfunction. Obstet Gynecol Clin North Am. 2009;36(3):421-43.

Tamanini JTN, Dambros M, D’Ancora CAL, Palma PC, Rodrigues Netto Jr. N. Validação para o português do "International Consultation on Incontinence Questionnaire-Short Form” (ICIQ-SF). Rev Saúde Pública. 2004;38(3):438-44. 
Torrisi G, Minini G, Bernasconi F, Perrone A, Trezza G, Guardabasso V, et al. A prospective study of pelvic floor dysfunctions related to delivery. Eur J Obstet Gynecol Reprod Biol. 2012;160(1):110-5.

Valeton CT, do Amaral VF. Evaluation of urinary incontinence in pregnancy and postpartum in Curitiba. Int Urogynecol J. 2011 Jul;22(7):813-8. Epub 2011 Feb 24.

Wesnes SL, Hunskaar S, Rortveit G. Epidemiology of urinary incontinence in pregnancy and postpartum. In: Alhasso A, editor. Urinary incontinence [Internet]. Rijeka: InTech; 2012. p.21-40. [cited 2014 Mar 1]. Available from: http://www.intechopen.com/download/get/type/pdfs/id/34718

Wesnes SL, Lose G. Preventig urinary incontience during pregnancy and postpartum: a review. Int Urogynecol J. 2013;24(6):889-99

Wijma J, Weis Potters AE, de Wolf BTHM, Tinga DJ, Aarnoudse JG Anatomical and functional changes in the lower urinary tract during pregnancy. Br J Obstet Gynaecol 2011;08:726-732

Woldringh C, Wijngaart MVD, Albers-Heitner P, Nijeholt AABL, Lagro-Janssen T. Pelvic floor muscle training is not effective in women with UI in pregnancy: a randomized controlled trial. Int Urogynecol J 2007;18:383-90.

Zeger SL, Liang KY, Albert PS. Models for longitudinal data: a generalized estimating approach. Biometric 1998;44(4):1049-60. 


\section{APÊNDICE A}

\section{TERMO DE CONSENTIMENTO LIVRE E ESCLARECIDO}

Eu, Maria Luiza Gonzalez Riesco, enfermeira obstétrica, professora da Escola de Enfermagem da Universidade de São Paulo, venho convidá-la a participar da pesquisa "Cuidado perineal na gestação e após o parto: prevenção e morbidade relacionadas à força muscular perineal, função sexual e continência urinária”.

O motivo que nos leva a realizar este estudo é porque a gravidez e o parto podem influenciar na função sexual das mulheres e na força dos músculos localizados em volta da vagina (assoalho pélvico), que ajudam a sustentar a pelve e segurar a urina. Assim, os objetivos desta pesquisa são: 1) Estudar a força dos músculos do assoalho pélvico, a perda de urina e a função sexual de mulheres durante a gestação e nos seis primeiros meses após o parto; 2) Analisar se as mulheres realizam os exercícios para o assoalho pélvico durante a gestação e nos seis primeiros meses após o parto. Para medir a força dos músculos do assoalho pélvico será utilizado um aparelho eletrônico que mede a contração da vagina, através de uma sonda introduzida na vagina. Esse procedimento é indolor e não traz nenhum risco para a gravidez ou para o bebê. Os dados também serão coletados por meio de questionários autorrespondidos. O tempo gasto para responder os questionários é de 20 a 30 minutos. Os dados deste estudo serão guardados pela pesquisadora, a sua identidade será mantida em sigilo e os resultados da pesquisa serão divulgados em eventos e publicações científicas.

Você será esclarecida sobre a pesquisa em qualquer aspecto que desejar. Você é livre para recusar-se a participar, retirar seu consentimento ou interromper a participação a qualquer momento. A sua participação é voluntária e a recusa em participar não irá acarretar qualquer penalidade ou perda de benefícios. Uma cópia deste termo de consentimento será arquivada pela pesquisadora e outra será fornecida a você. A participação no estudo não terá custos para você e não será oferecida nenhuma compensação financeira. Você receberá bilhete de transporte para os encontros com a pesquisadora nas datas que não coincidirem com o seu dia de atendimento na SEISA.

$\mathrm{Eu}$,

fui informada dos objetivos da pesquisa acima de maneira clara e detalhada e esclareci minhas dúvidas. Sei que em qualquer momento poderei solicitar novas informações e modificar minha decisão, se assim o desejar. Em caso de dúvidas poderei chamar a pesquisadora Maria Luiza Gonzalez Riesco por telefone (11-9248-0041) ou e-mail (riesco@usp.br) ou o Comitê de Ética em Pesquisa da Escola de Enfermagem da Universidade de São Paulo, sito à Av. Dr. Enéas de Carvalho Aguiar, 419, São Paulo, SP. Telefone: 11-3061-7548; e-mail: edipesq@usp.br

Declaro que concordo em participar desse estudo. Recebi uma cópia deste Termo de Consentimento Livre e Esclarecido e me foi dada oportunidade de lê-lo e de esclarecer as minhas dúvidas.

Participante:

Pesquisadora: Maria Luiza Gonzalez Riesco
Assinatura

Assinatura
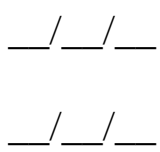


\section{APÊNDICE B}

\section{FORMULÁRIO}

Data de inclusão no estudo

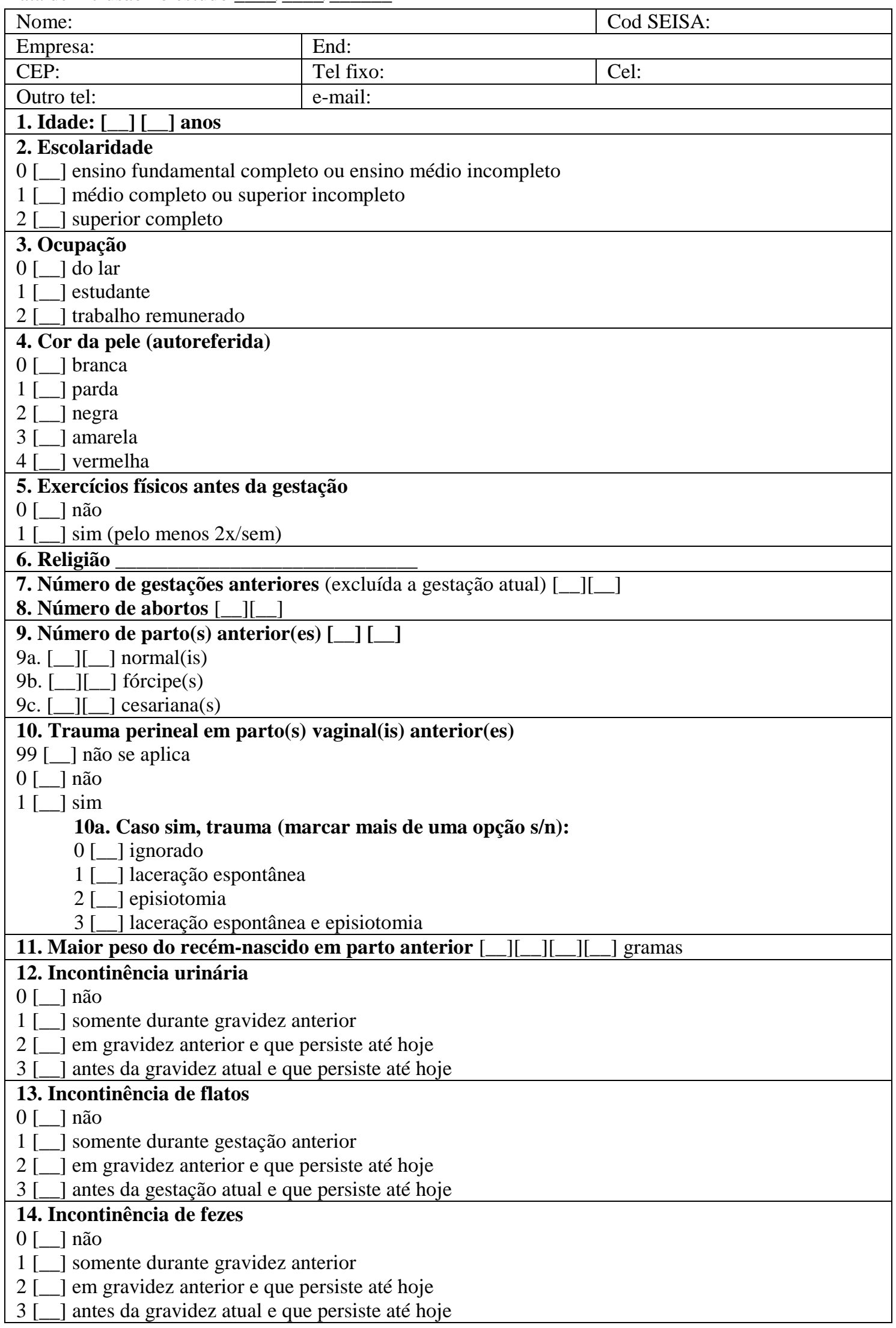




\section{ETAPAS CUMPRIDAS}

15. Etapa 1

1 [_] $\operatorname{sim}$

0 [_] não

15a. Se não, motivo

\section{Etapa 2}

1 [_] sim

0 [_] não

16a. Se não, motivo

\section{Etapa 3}

1 [_] sim

0 [_] não

17a. Se não, motivo

\section{Etapa 4}

1 [_] sim

0 [_] não

18a. Se não, motivo

\section{Etapa 5}

1 [_] sim

0 [__] não

19a. Se não, motivo

\section{Etapa 6}

1 [_] sim

0 [_] não

20a. Se não, motivo

\section{OBSERVAÇÕES}

\section{ETAPA 1}

22. Idade gestacional [__] [_] semanas [__] dias

22a. Método de cálculo

0 [_] DUM

1 [_] USG

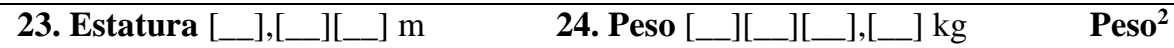

[_] ],[_] [__][_][_]

25. IMC [_] [_], [__]

26. Estado nutricional

0 [_] baixo peso

1 [_] adequado

2 [_] sobrepeso

3 [__] obesidade

\section{Situação conjugal}

0 [__] não tem parceiro (NÃO aplicar IFSF)

1 [_] não vive com parceiro

2 [_] vive com parceiro

27a. Tempo de co-habitação

0 [_] menos de um ano

1 [_] um a cinco anos

2 [_] mais de cinco anos

27b. Idade do parceiro atual [_] $][$ ] $]$ anos

\section{Atividade sexual nas últimas quatro semanas}

0 [__] não

1 [_] $\operatorname{sim}$ (aplicar IFSF) 


\section{8a. Caso sim, uso de condom \\ 1 [_] $]$ sim \\ 0 [__ ] não \\ 28b. Caso não, motivo}

\section{Incontinência urinária nas últimas quatro semanas}

0 [_] não $\quad 1$ [__] sim (aplicar ICIQ-SF)

30. Incontinência de flatos atual

0 [_] não $\quad 1$ [_] $\operatorname{sim}$

31. Incontinência de fezes atual

0 [_] não $\quad 1$ [_]

Perineometria

32. Primeira medida [__][_] $]\left[\_\right],\left[\_\right]$

33. Segunda medida [_] $]\left[\_\right]\left[\_\right],\left[\_\right]$

34. Terceira medida [_] $][\ldots]\left[[],\left[\_\right]\right.$

35. Valor maior [_] [_] ] _ ], [_]

CONTATOS TELEFÔNICOS (entre as etapas $1 \mathrm{e}$ 2)

Data I I I

36. Frequência de realização dos exercícios perineais

0 [__ ] não respondeu ao contato

1 [_] nunca (não realiza ou menos de $1 \mathrm{x} / \mathrm{sem}$ )

2 [_] esporadicamente (pelo menos $1 \mathrm{x} / \mathrm{sem}$ )

3 [_] regularmente (pelo menos $2 \mathrm{x} / \mathrm{semana}$ )

Data_L_L_

37. Frequência de realização dos exercícios perineais

0 [__ ] não respondeu ao contato

1 [_] nunca (não realiza ou menos de 1x/sem)

2 [_] esporadicamente (pelo menos $1 \mathrm{x} / \mathrm{sem}$ )

3 [_] regularmente (pelo menos $2 \mathrm{x} / \mathrm{semana})$

Data

38. Frequência de realização dos exercícios perineais

0 [__ ] não respondeu ao contato

1 [_] nunca (não realiza ou menos de $1 \mathrm{x} / \mathrm{sem}$ )

2 [_] esporadicamente (pelo menos $1 \mathrm{x} / \mathrm{sem}$ )

3 [_] regularmente (pelo menos $2 \mathrm{x} /$ semana)

4 [_] não foi preciso realizar o contato

\section{ETAPA 2}

39. Idade gestacional [__][_] semanas [__ dias

39a. Método de cálculo

0 [_] DUM

1 [_] USG

\begin{tabular}{|c|c|}
\hline $\begin{array}{l}\text { 40. Peso [__][_][__], [_ } \\
{\left[\_\right]\left[\_\right],\left[\_\right]}\end{array}$ & \\
\hline $\begin{array}{l}\text { 42. Estado nutricional } \\
0 \text { [__ baixo peso }\end{array}$ & 1 [__] adequado \\
\hline 2 [_] sobrepeso & 3 [_] obesidade \\
\hline
\end{tabular}

43. Situação conjugal, mesmo parceiro

1 [_] $\operatorname{sim}$

0 [_] não

43a. Caso não, idade do parceiro atual [__ [__ ] anos

2 [__ ] sem parceiro

\section{Atividade sexual nas últimas quatro semanas}

0 [__] não

1 [_] sim (aplicar IFSF, se tiver parceiro)

44a. Caso sim, uso de condom

1 [_] sim

0 [__] não

44b.

Caso

não,

motivo 


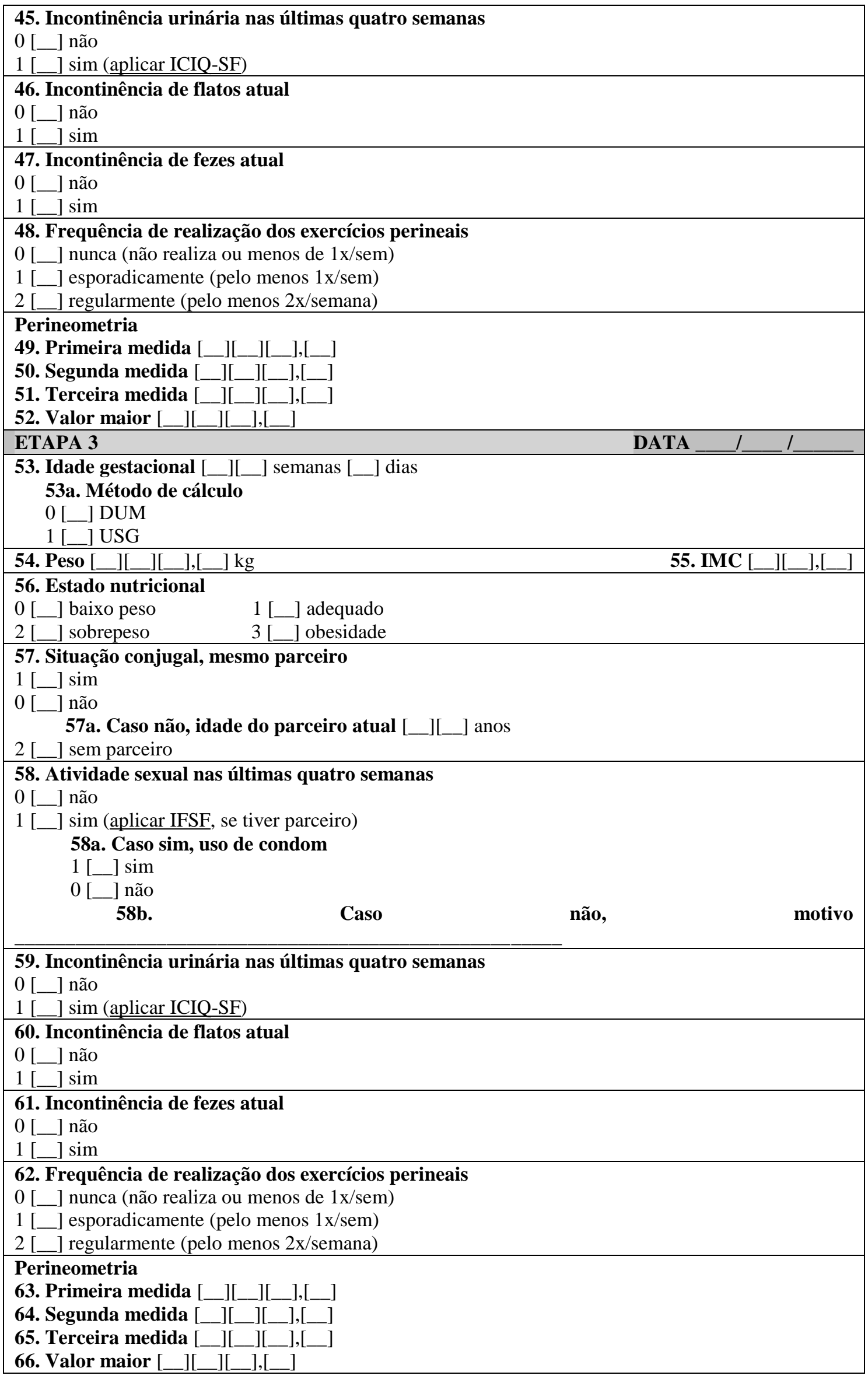



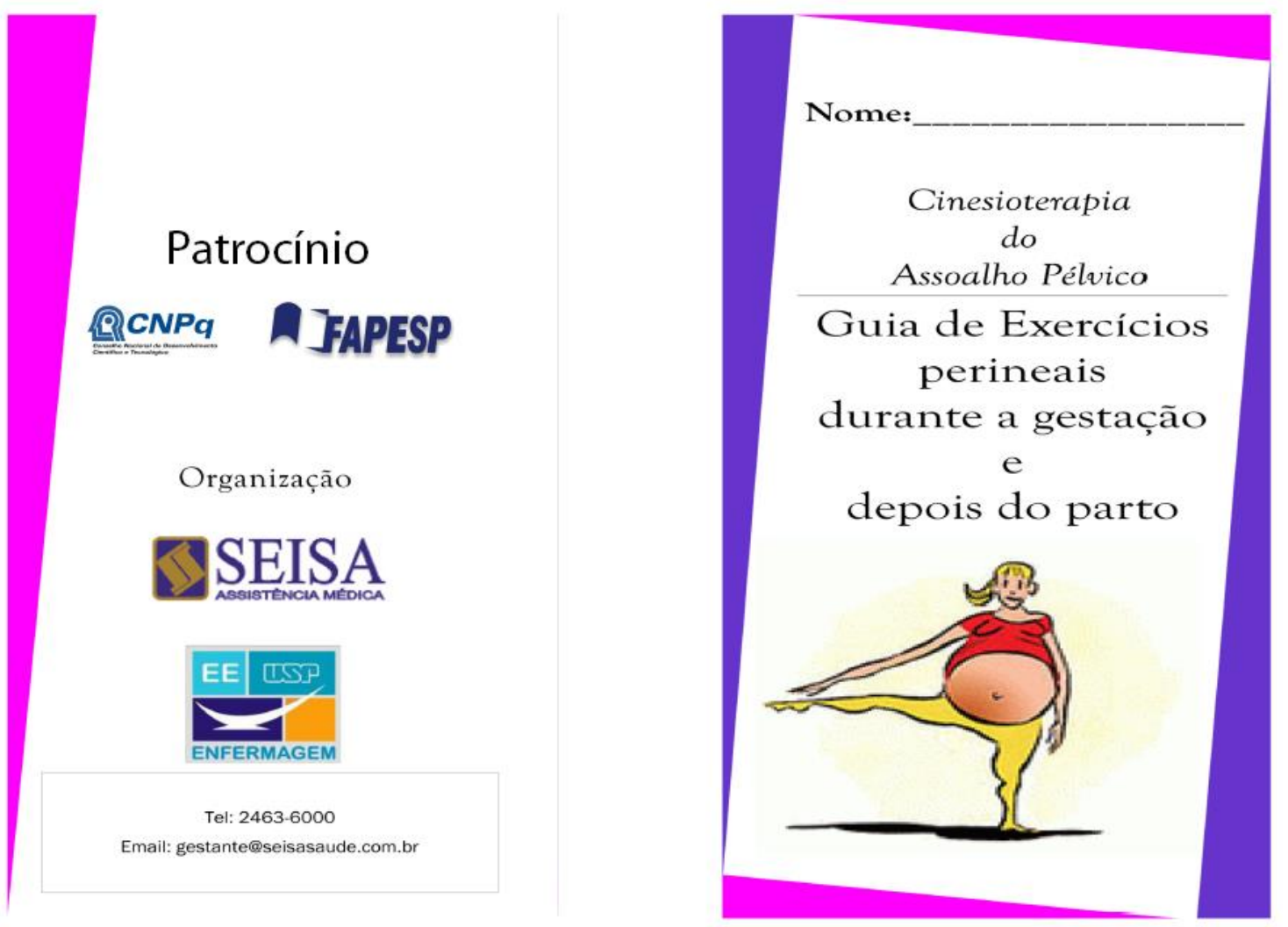

Exercício 2 Deitada na cama 10. Deitada na cama, dobre as pernas levemente separadas e deixe os pés apoiados $2^{\circ}$ - Respire profundamente e solte 0 ar $3^{\circ}$ - Contraia e relaxe rapidamente 0 assoalho pélvico por 20 vezes

40 - Descanse 8 segundos (no final da gravidez, descanse deitada do lado esquerdo) Repita os passos $2^{\circ}, 3^{\circ}, 4 \circ$ mais duas vezes $5 \circ$ - Contraia 0 assoalho pélvico, conte lentamente até 8 ( 8 segundos) e relaxe $6 \circ$ - Descanse 8 segundos Repita os passos $5^{\circ}$ e $6^{\circ}$ mais nove vezes

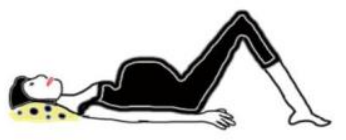

Exercício 3

Sentada na cadeira

10. Sente na cadeira com as costas apoiadas e os pés no chão

$2^{\circ}$ - Respire profundamente e solte 0 ar

$3 \circ$ - Contraia e relaxe rapidamente 0 assoalho pélvico por 20 vezes

40 - Descanse 8 segundos

Repita os passos $2^{\circ}, 3^{\circ} \mathrm{e} 44^{\circ}$ mais duas vezes

$5^{\circ}$ - Contraia 0 assoalho pélvico, conte lentamente até 8 ( 8 segundos) e relaxe

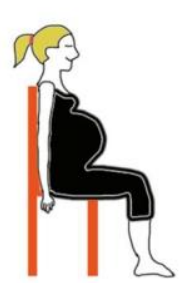

$6 \circ$ - Descanse

8 segundos

Repita os passos $5^{\circ} \mathrm{e}$

$6 \circ$ mais nove vezes
Exercício 4

Em pé

10. Fique em pé com os braços ao longo do corpo e pés paralelos e levemente afastados

$2^{\circ}$ - Respire profundamente e solte 0 ar

$3^{\circ}$ - Contraia e relaxe rapidamente 0 assoalho pélvico por 20 vezes

40 - Descanse 8 segundos

Repita os passos $2^{\circ}, 3^{\circ} \mathrm{e} 4^{\circ}$ mais duas vezes

$5^{\circ}$ - Contraia 0 assoalho pélvico, conte

lentamente até 8

( 8 segundos) e relaxe

$6 \circ$ - Descanse

8 segundos

Repita os passos $5^{\circ} \mathrm{e} 6^{\circ}$ mais nove vezes

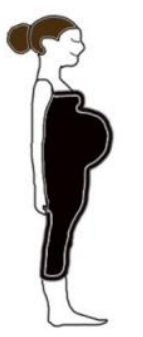




\section{APÊNDICE D}

\section{TERMO DE AUTORIZAÇÃO PARA A REALIZAÇÃO DA PESQUISA CIENTÍFICA}

São Paulo, 18 de julho de 2012.

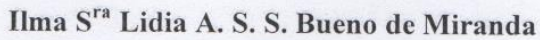
Gerente Geral da SEISA Assistência Médica

Eu, Maria Luiza Gonzalez Riesco, enfermeira obstetra, docente da Escola de Enfermagem da Universidade de São Paulo, sou responsável pela pesquisa "Cuidado perineal na gestação e após o parto: Prevenção e Morbidade Relacionadas à Força Muscular Perineal, Função Sexual e Continência Urinária”, que tem como pesquisadoras assistentes a Enfermeira Obstetra Karina Fernandes Trevisan e a Obstetriz Nathalie Leister.

A pesquisa, cujo protocolo enviamos em anexo, será realizada com mulheres durante a gestação e por seis meses após o parto. Tem como objetivos: 1) analisar a força muscular perineal (FMP), a função sexual e a continência urinária de mulheres durante a gestação e nos seis primeiros meses após o parto; 2) avaliar o efeito da cinesioterapia (CT) supervisionada e não supervisionada do assoalho pélvico (AP) na continência urinária, na função sexual e na FMP em mulheres incontinentes durante a gestação e nos seis primeiros meses após o parto; 3) verificar a adesão das mulheres à CT do AP durante a gestação e nos seis primeiros meses após o parto.

Informamos que o projeto foi aprovado pelo Comitê de Ética em Pesquisa da Escola de Enfermagem da Universidade de São Paulo e que a participação das mulheres será inteiramente voluntária, após receberem informações e depois da leitura e assinatura do Termo de Consentimento Livre e Esclarecido.

Assim, solicitamos sua autorização para a realização da pesquisa no Centro Clínico de Obstetrícia e Pré-Natal (CCOPN), da SEISA Assistência Médica, e nos colocamos à disposição permanente para quaisquer esclarecimentos ou solicitações relativos à presente pesquisa.

Informamos que no protocolo acima referido constam os nomes dos membros da equipe de pesquisa, o cronograma e o orçamento de execução projeto, sob nossa resposabilidade.

Sem mais, agradecemos imensamente a colaboração.

Atenciosamente,

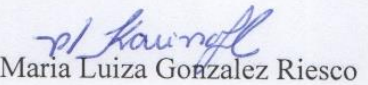

Professora Associada do Departamento de Enfermagem Materno-Infantil e Psiquiátrica da Escola de Enfermagem da Universidade de São Paulo

Responsável pela pesquisa

De acordo, 30107112

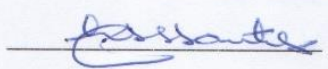

Lidia A. S. S. Buenade Mirandd Diretora Executiva 


\section{ANEXO 1 \\ PROTOCOLO - PRÉ-NATAL - SEISA}

\section{INTRODUÇÃO}

O Programa de pré-natal do Centro Clínico de Obstetrícia e Pré-Natal (CCOPN) visa o atendimento à saúde da gestante com qualidade. Significa ter disponibilidade para o atendimento da gestante desde o início do primeiro trimestre de gestação, garantir todos os exames laboratoriais e de imagem necessários e o atendimento a todas as necessidades de saúde dela.

\section{OBJETIVO}

Este documento tem como objetivo ser um facilitador no momento da assistência prestada à gestante e família, durante a consulta médica e de enfermagem.

A consulta de enfermagem está respaldada pela Lei do Exercício Profissional (LEP) n. 7.498/86 e resoluções COFEN 195/97 e 271/2002.

\section{CAMPO DE APLICAÇÃO}

Gestantes atendidas no Centro Clínico de Obstetrícia e Pré-Natal, em Guarulhos, Unidade São Miguel e Unidade Arujá.

\section{REFERÊNCIAS NORMATIVAS}

Lei do Exercício Profissional de Enfermagem (LEP) n. 7.498/86;

Resoluções do COFEN 195/97 e 271/2002;

Manual Técnico e Assistência Pré-Natal do Ministério da Saúde - 2005.

\section{DIRETRIZES}

Toda equipe deverá seguir o descrito neste Protocolo de Padronização da Assistência.

\section{Atendimento à Gestante}

A enfermeira/obstetriz poderá acompanhar qualquer outra consulta do ciclo gravídico puerperal. As mesmas possuem respaldo deste protocolo para solicitação de exames e prescrição de medicações que aqui descrito estiverem.

A enfermeira/obstetriz e o(a) médico(a) do CCOPN formam a equipe de pré-natal e devem atender as consultas de maneira contínua e complementar.

\section{Consulta específica para enfermeira/obstetriz}

$1^{\text {a }}$ consulta de pré-natal;

Consulta entre 20 - 24 sem (além da rotina - orientações específicas do Aleitamento Materno);

Consulta entre 30 - 34 sem (além da rotina - orientações sobre trabalho de parto e parto).

- $\mathrm{O}$ (a) médico(a) obstetra prenatalista deverá acompanhar todas as outras consultas do pré-natal.

Consultas subsequentes:

- mensais até 29 semanas de gestação;

- quinzenais 30 a 36 semanas de gestação;

- semanais de 37 a 40 semanas de gestação; 
- a cada 3 dias após $40^{\mathrm{a}}$ semanas de gestação. Após a $37^{a}$ semana:

- Realizar toque via vaginal e amnioscopia, se dilatação do colo uterino;

- Solicitar cardiotocografia basal para avaliação da vitalidade fetal a cada consulta e pelo menos um USG para avaliação do líquido amniótico.

\section{Observação:}

Em caso de Cesárea Eletiva: encaminhar para Hospital Carlos Chagas com 37 semanas, às terças-feiras pela manhã (PSGO), para uma avaliação e programação do parto. A paciente não receberá alta do pré-natal - deverá ser avaliada pelo prenatalista até a data do parto.

Em casos de urgência: fazer contato via telefone com plantonista do Hospital Carlos Chagas e encaminhar a paciente de ambulância, carro próprio ou taxi, de acordo com as condições da mesma.

São considerados urgências: DHEG, diabetes descompensado, oligoâmnio, restrição de crescimento intrauterino (RCIU), trabalho de parto, entre outros.

\section{Primeira Consulta}

História clínica detalhada da paciente com preenchimento completo da Ficha Clínica; Exame Físico Clínico Geral - inspeção, palpação e ausculta;

Exame Físico Obstétrico - avaliação das mamas, inspeção abdominal (se gestante com mais de 12 semanas, realizar mensuração da altura uterina e ausculta fetal, exames especular e toque via vaginal.

Solicitação dos seguintes exames:

Hemograma complete;

$>$ Tipagem sanguínea ABO e Rh (Se paciente Rh negativo, solicitar tipagem do pai do bebê);

$>$ Glicemia de jejum;

$>$ Urina I e Urocultura com antibiograma; se necessário;

> Sorologias para HIV, hepatite B e C, rubéola, toxoplasmose, sífilis;

$>$ Proctoparasitológico de fezes (PPF);

$>$ Coleta de citologia oncótica para as pacientes que há mais de um ano não realizaram este exame;

$>$ US obstétrico (solicitar US obstétrico com TN (translucência nucal) para gestantes entre 11 e 13 semanas e 6 dias);

OBS:

Pacientes com resultado de sorologias anteriores:

- Se IgG for positiva para toxoplasmose/rubéola não será necessário repeti-las;

- Se IgG negativa para toxoplasmose/ rubéola, solicitar IgG e IgM para ambas;

- Toxoplasmose: se IgG negativa, repetir sorologia a cada 2 meses

\section{Orientações Gerais:}

- Alimentação fracionada (alimentos saudáveis);

- Sono e repouso/uso de roupas confortáveis;

- Estimular ingesta de líquidos;

- Orientar importância de não segurar a urina, se vontade de urinar;

- Estimular relação sexual (exceto em casos específicos);

- Prevenção de estrias (uso de creme hidratante ou óleo corporal); 
- Preparo das mamas (não utilizar creme em mamilos, passar toalha de banho nos mamilos diariamente. Em caso de mamilo invertido, utilizar exercícios de seringa de $20 \mathrm{ml}$ invertida);

- Estimular o uso de protetor solar no rosto;

- Durante o trabalho, se permanecer muito tempo sentada, orientar importância de realizar caminhadas periódicas e utilizar apoio para os pés quando sentada; se permanecer muito tempo, orientar a importância de pausas periódicas para sentar e elevar os pés, principalmente, do meio para o final da gestação;

- Se gestante tabagista, etilista ou usuária de drogas, estimular parar o vício e oferecer apoio da saúde emocional, se necessário;

- Estimular realização de caminhadas leves e alongamento para diminuir dores musculares e tensões;

- Orientar não fazer uso de medicações sem orientação médica;

- Estimular participar do curso de gestante.

Encaminhar para consulta médica em 30 dias, se gestação sem complicações.

- Encaminhar para consulta médica (gestação de alto risco) se:

- Hipertensão arterial crônica com pressão arterial;

- Doença Hipertensiva Específica da Gravidez (DHEG/Pré-eclâmpsia);

- Cardiopatias;

- Nefropatia;

- Doenças do colágeno (Lupus Eritematoso Sistêmico, Artrite Reumatóide etc);

- Diabetes Melitus (prévia ou gestacional);

- Doenças tireoidianas (hiper ou hipotireoidismo);

- Pneumopatias;

- Anemias graves (ou hemoglobinopatias);

- Epilepsia não controlada;

- Trabalho de parto prematuro/aborto habitual;

- Mioma.

\section{Consultas subsequentes}

- Avaliação da ficha clínica;

- Cálculo da Idade Gestacional,

- Avaliação dos exames;

- Avaliação das queixas;

- Exame físico obstétrico: mensuração a altura uterina e ausculta dos batimentos cardíacos fetais;

- Anotação de todos os dados na ficha clínica;

- Orientações específicas para cada fase da gestação.

$\underline{\text { Relação de exames necessários }}$

\section{0 semanas}

- US morfológico de $2^{\circ}$ trimestre;

- US transvaginal para medição de colo uterino;

- Encaminhar para primeira dose da vacina antitetânica e hepatite B para quem não for imune. 
$\mathbf{2 4}^{\mathrm{a}}$ a $\mathbf{2 8}^{\mathrm{a}}$ semanas - teste simplificado de tolerância à glicose de 24 a 28 semanas ,com 50 gramas de dextrosol (teste de 1 hora); se resultado >130, solicitar GTT de 3 horas, com 100 gramas de dextrosol.

- Urina I com assepsia.

$\mathbf{2 8}^{\mathrm{a}}$ semanas - (se paciente Rh negativo e marido Rh positivo, solicitar Coombs indireto mensal e prescrever imunoglobulina anti-Rh-Rhogan®, nos casos não sensibilizados).

$32^{\mathrm{a}}$ semanas

- Sorologias para HIV e sífilis;

- Hemograma complete;

- Urina I com assepsia.

$35^{\mathrm{a}}$ a $37^{\mathrm{a}}$ semanas

- Solicitar pesquisa de estreptococos beta hemolítico do grupo B anal e vaginal, entre 35 e 37 semanas, para todas as pacientes;

- US obstétrico.

Rastreamento para Diabetes Gestacional:

1) Pacientes baixo risco para Diabetes Gestacional:

Solicitar teste de triagem com 2 semanas

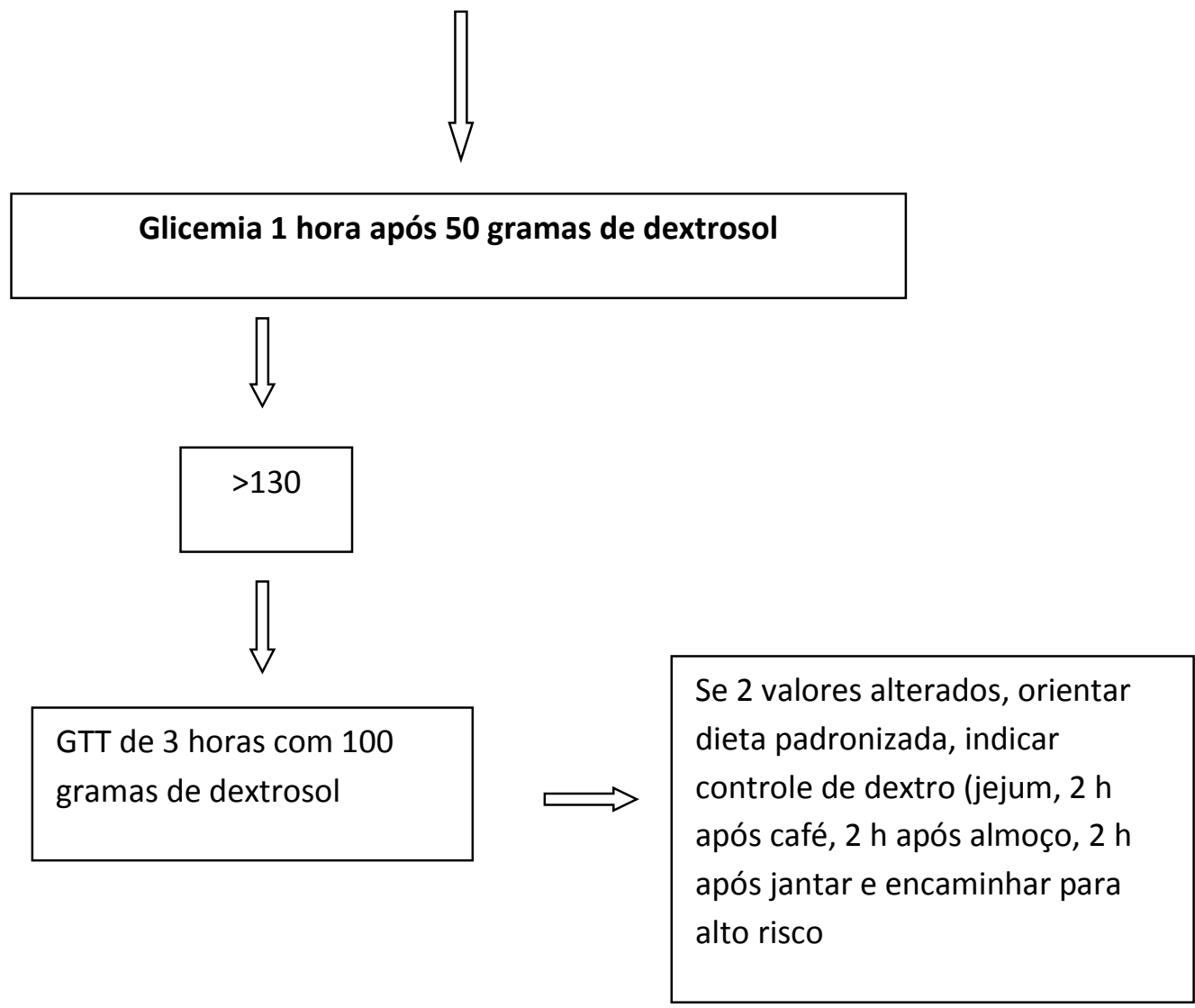


2) Paciente de alto risco para diabetes gestacional, solicitar GTT de 3 horas, com 28 semanas.

\section{Protocolo de Medicações}

Infecções genitais

Candidíase vaginal

- Gynax $\mathrm{N} 囚(60 \mathrm{~g})$ : aplicação via vaginal, de 7 a 10 noites;

- Nistatina ${ }^{\circledR}$ creme vaginal (micostatin): aplicação vaginal, por 14 noites;

- Na recidiva Colpistatin® (benzoilmetronidazol $250 \mathrm{mg}$ nistatina.100.000 UI cloreto de benzalcônio $5 \mathrm{mg}$ ): aplicação vaginal, por 10 dias (após o 12 semanas);

Tricomoniase/gardnerella

- Flagyl ginecologico® (metronidazol): aplicação por 10 noites via vaginal, após 12 semanas de gravidez;

- Na recidiva Colpistatin® aplicação vaginal por 10 dias, após 12 semanas

Corrimentos mistos

- Flagyl nistatina ${ }^{\circledR}$ (metronidazol/micostatin): aplicação por 10 noites, após 12 semanas;

- Na recidiva, Colpistatin®: aplicação vaginal por 10 dias, após 12 semanas

\section{Infecções intestinais}

Helmintíases, amebíase, giardíase, isosporíase, balantidiase, blastocistose

- Annita ${ }^{\circledR}$ (nitazoxanida) $500 \mathrm{mg} 2$ vezes por dia, por 3 dias consecutivos, com alimentos.

Obs: O uso de Annita com anticoagulantes do tipo cumarínicos como a varfarina e com o anticonvulsivante fenitoína deve ser avaliado com cautela.

Prevenção de defeito aberto de tubo neural

- Acido fólico $5 \mathrm{mg}$ por dia ate 12 semanas.

Observação: pacientes epiléticas e usuárias de anticonvulsivantes - deverá ser mantido durante toda gravidez.

Prevenção de anemia ferropriva

- Combiron fólico® (ferrocarbonila $120 \mathrm{mg}$ nitrato de tiamina $4 \mathrm{mg}$ riboflavina $1 \mathrm{mg}$ cloridrato de piridoxina $1 \mathrm{mg}$ cianocobalamina $25 \mathrm{mcg}$ nicotinamida $10 \mathrm{mg}$ ácido fólico $2 \mathrm{mg}$ pantotenato de cálcio $2 \mathrm{mg}$ ): administrar $1 \mathrm{cp} \mathrm{VO} \mathrm{com} \mathrm{ou} \mathrm{sem}$ alimento, a partir de 20 semanas de gravidez;

- Em situações de dificuldade social da paciente, poderá ser prescrito sulfato ferroso 1 cp por dia;

- Em caso de intolerância aos anteriormente indicados, outras opções de polivitaminicos (Natele ${ }^{\circledR}$, Damater ${ }^{\circledR}$, Vitergan pré-natal ${ }^{\circledR}$, Myravit-gest ${ }^{\circledR}$, entre outros).

Nauseas e vomitos

- Dramin ${ }^{\circledR}$ (dimenidrinato) - $1 \mathrm{cp} \mathrm{VO} \mathrm{de} \mathrm{6/6} \mathrm{horas;}$

- Meclin® (meclizina): 25 mg VO de 8/8 horas.

\section{Queimação e refluxo}

- Hidróxido de alumínio - suspensão - 1 colher de sopa de 4/4 horas. 


\section{Constipação}

- Benestare®: 1 cp VO a cada 12 horas, junto das refeições;

- Tamarine®: $1 \mathrm{cp}$ VO à noite.

\section{Cefaleia}

- Paracetamol@ 500/750 mg - 1 cp VO de 6/6 horas, se cefaléia.

\section{Cólica}

- Buscopan Plus® - 1 cp VO de 8/8 horas.

\section{Desconforto abdominal por flatus}

- Dimeticona ${ }^{\circledR}$.

\section{Descolamento de vesícula vitelina}

- Ultragestan ${ }^{\circledR}-200 \mathrm{mg}-1 \mathrm{cp}$ via vaginal, $2 \mathrm{x}$ ao dia, de $12 / 12$ horas.

\section{Infecção urinária}

Medicação de primeira escolha e na ausência do antibiograma.

- Cefalexina ${ }^{\circledR}(500 \mathrm{mg})-1 \mathrm{cp}$ VO de $6 / 6$ horas por 10 dias

- Ampiilina ${ }^{\circledR}(500 \mathrm{mg})-1 \mathrm{cp}$ VO de $6 / 6$ horas por 10 dias

Na presença do antibiograma, seguir a medicação apontada pelo exame, desde que permitido para gestante.

\section{Hipertensão}

Para quem faz uso de alguma medicação antihipertensiva, substituir por:

- 1 Aldomet ${ }^{\circledR}-250 \mathrm{mg}-1 \mathrm{cp}$ de $8 / 8$ horas.

Controle de PA 2 vezes ao dia, sempre no mesmo horário e retorno em 20 dias.

Para quem não é hipertensa:

- Visken® - $5 \mathrm{mg}$ de 12/12 horas.

Controle de PA 2 vezes ao dia, sempre no mesmo horário e retorno em 20 dias 


\section{ANEXO 2 \\ INTERNATIONAL CONSULTATION ON INCONTINENCE QUESTIONNAIRE-SHORT FORM (ICIQ-SF) \\ ICIQ -SF}

Nome do Paciente:

Data de Hoje:

Muitas pessoas perdem urina alguma vez. Estamos tentando descobrir quantas pessoas perdem urina e o quanto isso as aborrece. Ficaríamos agradecidos se você pudesse nos responder às seguintes perguntas, pensando em como você tem passado, em média nas ÚLTIMAS QUATRO SEMANAS.

1. Data de Nascimento:

2. Sexo: Feminino

Masculino ( Dia / Mês / Ano )

3. Com que freqüêria voce perde urina? (assinale uma resposta)

\begin{tabular}{|c|c|}
\hline Nunca & \begin{tabular}{|l} 
\\
\end{tabular} \\
\hline Uma vez por semana ou menos & \\
\hline Duas ou três vezes por semana & \\
\hline Uma vez ao dia & \\
\hline Diversas vezes ao dia & 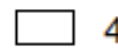 \\
\hline O tempo todo & \\
\hline
\end{tabular}

4. Gostaríamos de saber a quantidade de urina que você pensa que perde (assinale uma resposta)

Nenhuma $\square 0$

Uma pequena quantidade $\square 2$

Uma moderada quantidade $\square 4$

Uma grande quantidade $\square 6$

5. Em geral quanto que perder urina interfere em sua vida diária? Por favor, circule um número entre 0 (năo interfere) e 10 (interfere muito)

$$
\begin{array}{lllllllllr}
0 & 1 & 2 & 3 & 4 & 5 & 6 & 7 & 8 & 9 \\
\text { Não interfere } & & & & & & & & \text { Interfere muito }
\end{array}
$$

ICIQ Escore: soma dos resultados $3+4+5=$

6. Quando você perde urina?

(Por favor assinale todas as alternativas que se aplicam a você)

Nunca

Perco antes de chegar ao banheiro

Perco quando tusso ou espiro

Perco quando estou dormindo

Perco quando estou fazendo atividades físicas

Perco quando terminei de urinar e estou me vestindo

Perco sem razăo óbvia

Perco o tempo todo 


\section{ANEXO 3 \\ PARECER DO COMITÊ DE ÉTICA EM PESQUISA}

Plataforma Brasil - Ministério da Saúde

Escola de Enfermagem da Universidade de São Paulo - EEUSP

PROJETO DE PESQUISA

Título: CUIDADO PERINEAL NA GESTAÇÃO E APÓS O PARTO: Prevenção e Morbidade

Relacionadas à Força Muscular Perineal, Função Sexual e Continência Urinária

Área Temática:

Pesquisador: Maria Luiza Gonzalez Riesco

Versão: 1

Instituição: Escola de Enfermagem da Universidade de São CAAE:05096412.7.0000.5392

Paulo - EEUSP

PARECER CONSUBSTANCIADO DO CEP

Número do Parecer: 74373

Data da Relatoria: 14/08/2012

\section{Apresentação do Projeto:}

O projeto propõe estudo sobre a influência da gestação e do parto sobre a musculatura do assoalho pélvico que possam trazer morbidades do trato genito-urinário e da musculatura perineal. Também está previsto realizar um ensaio clínico aleatorizado propondo-se uma intervenÇão: a cinesioterapia do assoalho pélvico. A força muscular perineal, a função sexual e a continência urinária podem sofrer alterações durante a gestação e nos seis primeiros meses após o parto.

A cinesioterapia supervisionada é baseada em movimentos voluntários e repetidos para gerar força muscular, previne a rigidez muscular, mantém ou recupera a força. A cinesioterapia do assoalho pélvico durante a gestação aumenta a força muscular perineal e pode promover maior facilidade ao parto vaginal.

Os pesquisadores propõem estudar uma coorte de mulheres que iniciarem o pré-natal no primeiro trimestre, entre outubro de 2012 e março de 2013, em um serviço de saúde do setor suplementar, em Guarulhos (SP) com estimativa de inclusão de 500 sujeitos. As mulheres serão acompanhadas até seis meses após o parto. Será realizado também um ensaio clínico aleatorizado com 100 gestantes com incontinência urinária na gestação, distribuídas nos grupos experimental e controle (com realização de sessões quinzenais de cinesioterapia supervisionada do assoalho pélvico, durante 12 semanas, e cinesioterapia não supervisionada do assoalho pélvico, respectivamente). Os desfechos e os instrumentos de avaliação são: força muscular perineal avaliada pela perineometria; função sexual, avaliada pelo Índice da Função Sexual Feminina-IFSF; incontinência urinária, avaliada pelo International Consultation on Incontinence Questionnaire-Short Form-ICIQ$\mathrm{SF}$. Todas as mulheres serão avaliadas no primeiro, segundo e terceiro trimestre da gestação e em torno de 45,90 e 180 dias após o parto. Será realizada análise descritiva e inferencial dos dados. O projeto recebeu será financiado pela FAPESP.

\section{Objetivo da Pesquisa:}

Os objetivos são analisar a força muscular perineal de mulheres durante a gestação e nos seis primeiros meses após o parto; analisar a função sexual de mulheres durante a gestação e nos seis primeiros meses após o parto; analisar a continência urinária de mulheres durante a gestação e nos seis primeiros meses após o parto; avaliar o efeito da cinesioterapia (CT) supervisionada e não supervisionada do assoalho pélvico (AP) na continência urinária, na função sexual e na força muscular perineal em mulheres incontinentes durante a gestação e nos seis primeiros meses após o parto; verificar a adesão das mulheres à CT do AP durante a gestação e nos seis primeiros meses após o parto.

\section{Avaliação dos Riscos e Benefícios:}

A cinesioterapia do assoalho pélvica não traz riscos diretos à gestação, no entanto, algumas mulheres podem se sentir desconfortáveis com a realização dos exercícios.

Os benefícios referem-se à possibilidade de promover incremento na força muscular perineal das mulheres, e, no grupo observacional, poder detectar anormalidades e melhor conhecimento do assoalho pélvico. 
Comentários e Considerações sobre a Pesquisa:

O projeto tem grande relevância pois promoverá maior conhecimento sobre medidas que possam auxiliar no fortalecimento do assoalho pélvico das mulheres no período da gestação, favorecendo ao parto e possibilitando desenvolver intervenções que possam trazer benefícios à saúde.

Considerações sobre os Termos de apresentação obrigatória:

Os termos de consentimento propostos estão adequados e atendem à resolução 196 .

\section{Recomendações:}

Pela aprovação do projeto

Conclusões ou Pendências e Lista de Inadequações:

Projeto aprovado

\section{Situação do Parecer:}

Aprovado

Necessita Apreciação da CONEP:

Não

Considerações Finais a critério do CEP:

A aprovação do Comitê de Ética em Pesquisa da EEUSP não substitui a autorização da instituição coparticipante para o início da pesquisa.

14 de Agosto de 2012

Assinado por

Celia Maria Sivalli Campos 